NBSIR 86-3498

\title{
Summaries of Center for Fire Research Grants and In-House Programs - 1986
}

Sunva M. Cherry, Ecitor

LS. DEPARTMENT OF CDMMERCE

ivationa! Qureau of Staroarcs

Vationai Engineering Laboratcry

Centiar or Fire Fesearch

Gathersturg, WD 20899

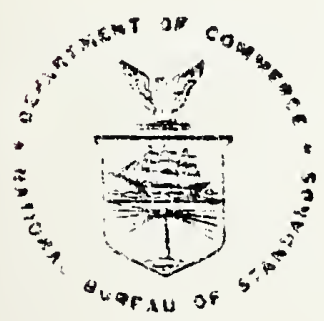

\footnotetext{
OQC-O-TMENT OF GOMRERCE

100 EAU OF STANDARUS

.456

\#86-3498

1986
} 


\section{-}


NBSIR $86 \cdot 3498$

SUMMARIES OF CENTER FOR FIRE

RESEARCH GRANTS AND IN-HOUSE

PROGRAMS - 1986

Sonya M. Cherry, Editor

U.S. DEPARTMENT OF COMMERCE

National Bureau of Standards

National Engineering Laboratory

Center for Fire Research

Gaithersburg, MD 20899

December 1986

U.S. DEPARTMENT OF COMMERCE, Malcolm Baidrige, Secretary NATIONAL BUREAU OF STANDARDS. ERnest Ambler, Director 



\section{CENTER FOR FIRE RESEARCH PROGRAMS}

Ad Hoc Working Group on Mathematical Fire Modeling . . . . . . . . . 2

Compartment Fire Modeling Research . . . . . . . . . . . . . 3

Fire Growth and Extinction . . . . . . . . . . . . . . . 8

Fire Performance and Validation. . . . . . . . . . . . . . . 14

Fire Research Information Services . . . . . . . . . . . . . . 17

Fire Simulation. . . . . . . . . . . . . . . . . . . 18

Flammability and Toxicity Measurement. ................ 21

Hazard Analysis. . . . . . . . . . . . . . . . . . . 27

Polymer Combustion Research. . . . . . . . . . . . . . . 31

Smoke Dynamics Research Group. . . . . . . . . . . . . . . . 36

\section{GRANTS}

Argonne National Laboratory

Feasibility of Field Detection and Analysis of the Toxic

Products of Combustion. . . . . . . . . . . . . . . . .

Brown University

A Study of the Effects of Oxygen Transport and Temperature

History on the Chemistry of PMMA and Cellulose Pyrolysis. . . .

Brown University

Burning of Charring Materials . . . . . . . . . . . . . 48

Brown University

Soot Dynamics in Flames . . . . . . . . . . . . . . 51

California Institute of Technology

Experimental Study of Environment and Heat Transfer in a

Room Fire... . . . . . . . . . . . . . . . . . . .

Case Western Reserve University

Experimental and Analytical Study of Fire Sprinkler

Scaling Laws. 
Clemson University

Graphical Presentation and Numerical Analysis of Fire

Data for Model Validation. . . . . . . . . . . . . . .

Clemson University

Ternary Reactions Among Polymer Substrate-0rganohalogen-Antimony Oxides in the Condensed Phase Under Pyrolytic, Oxidative and

Flaming Conditions . . . . . . . . . . . . . . . . . .

Factory Mutual Research Corporation

Development of a Model to Provide Comprehensive Fire Property

Data . . . . . . . . . . . .

Factory Mutual Research Corporation

Prediction of Fire Dynamics. . . . . . . . . . . . . . . . . .

The George Washington University

Chemical Pathways to Soot Formation in Diffusion Flames. . . .

Marquette University

Thermal Stabilization of Polymers by Cross-Iink Formation. . . .

Michigan State University

Effect of Water on Ignition of Cellulosic Materials. . . . . .

The Pennsylvania State University

Vertical Wall Fire in a Two-Layer Stratified Atmosphere. . . .

Rutgers, The State University of New Jersey

Negatively Buoyant and Penetrative Flows Generated in

Enclosure Fires. . . . . . . . . . . . . . . . . .

Southwest Research Institute

Analysis of Hazards to Life Safety in Fires: A Comprehensive

Multi-Dimensional Research Program - Second Year. . . . . . . .

University of California, Berkeley

Fire Modeling. . . . . . . . . . . . . . . . . . . .

University of California, Berkeley

Fire Propagation in Concurrent Flows . . . . . . . . . . .

University of California, Berkeley

Flame Radiation. . . . . . . . . . . . . . . . .

University of Dayton Research Institute

Mathematical Modeling of Furniture Fires . . . . . . . . . . .

University of Maryland

Interaction of Radiation and Conduction in Polymeric Materials. 
University of Maryland

Transient Cooling of a Hot Surface by Droplets Evaporation. . . 128

University of Maryland

Transient Heat Transfer in Ceiling Jers . . . . . 。 . . . 132

The University of Michigan

Radiation from Turbulent Luminous Flames. . . . . . . . . . . 136

University of Montana

Kinetics of Oxygen Chemisorption and Desorption of Combustion

Products in the Smoldering Combustion of Cellulosic Material. . .

University of Pittsburgh

Toxicity of Plastic Combustion Products . . . . . . . . . . 142

Texas A\&M University

Computer Verification, Validation and Use of Selected State-

of-the-Art Fire Safety Model for One-Story Multi-Compartment

Buildings . . . . . . . . . . . . . . . . . . 144 
Summaries of Center for Fire Research Grants and In-House Programs - 1986

\begin{abstract}
This report was prepared for distribution at the Annual Conference on Fire Research, November 3-7, 1986. It contains extended abstracts of grants for fire research sponsored by the Center for Fire Research, National Bureau of Standards, as well as descriptions of the internal programs of the Center for Fire Research.

Key words: Cellulose; charring; combustion; Fire models; flame spread; ignition; polymers; smoke; soot; toxicity.
\end{abstract}




\section{AD HOC WORKING GROUP ON MATHEMATICAL FIRE MODELING CENTER FOR FIRE RESEARCH \\ FY 86}

\section{Professional Personnel}

Robert S. Levine, Chairman of Steering Committee John A. Rockett, Chairman of Computer Committee James G. Quintiere, Chairman of Models Subcomittee

NOTE: The Modeling Committee is chaired by Professor Howard Emmons, formerly of Harvard University, the Subprogram Committee by John de Ris of Factory Mutual, and the User's Needs Committee by Irwin Benjamin of Benjamin-Clarke.

A number of CFR personnel are members of the technical comittees.

\section{Program Objectives}

The objectives of this committee are to facilitate the development and use of mathematical models of fire and to coordinate and facilitate research needed to improve the models. The Steering Committee includes members from other government agencies who have influence on their agencies' research and development in this field. The coordination, of course, is voluntary.

\section{Project Areas}

Each applicable area is included in another program abstract. The major portion of the CFR effort is in the Fire Modeling Program.

\section{Associated Grants}

Several grants are listed elsewhere.

\section{Activity}

During FY 86, the Working Group held a workshop on "Experimental Aspects of Measuring and Controlling Burning Rate by Radiation to the Fuel Surface" and a workshop on "CO Formation in Fires". 


\section{COMPARTMENT FIRE MODELING RESEARCH \\ FIRE SAFETY TECHNOLOGY DIVISION \\ FY 86}

\section{Professional Personnel}

Leonard $Y$. Cooper, Head

Henri E. Mitler, Physicist

William Davis, Physicist

Glenn P. Forney, Computer Scientist

David W. Stroup, Fire Protection Engineer

John A. Rockett, Guest Worker

Masahiro Morita, Guest Worker (Tokyo Science Univ.)

Vahid Motevalii, Guest Worker (Univ. of Maryland)

\section{Program Objectives}

(1) Develop, maintain, improve and provide assistance in the use of benchmark Compartment Fire Model computer codes.

(2) Develop and maintain a catalog of submodel algorithms and subroutines for general use in compartment fire models.

(3) Formulate, develop, and establish the validity of new and improved analytic/computational compartment-fire-phenomena submodel algorithms for use in compartment fire simulations.

\section{$\underline{\text { Scope }}$}

The work focuses on the development of benchmark computer codes(s) which would be useful in simulating the phenomena which occur in compartment fire scenarios. The term "benchmark computer code" is intended to connote a well. documented computer code which: a) is based on physics and numerics of proven reliability; b) is numerically robust; and $c$ ) is user-friendly in the sense that it can be used with relative ease by researchers and professional fire safety practitioners, and that it can be transferred to and used with computer hardware readily available to the fire science/technology community.

While the benchmark computer code(s) would be up-to-date in the sense of including algorithms which describe the details of fire phenomena currently under investigation in the fire research community, they would not be responsive to forecasts of future research thrusts. In terms of the complexity of compartment configurations, the capability of the new generation of benchmark code(s) would be limited to the simulation of fire-generated environments only in those compartment spaces which affect actual fire development, e.g., in rooms of fire involvement and "freely connected" adjacent spaces. In terms of the level of "user-friendiness", the code(s) would be useful to researchers and practitioners with relatively high levels of commitment and technical skill.

\section{Proiects and Products}

\section{Compartment Fire Models}

The Benchmark Compartment Fire Model (BCFM). With a variety of objectives in mind, many different compartment fire model computer codes have been developed 
within the fire safety/research community. Yet, no one of these can be described as being a "benchmark" model in the sense that it is reliable enough to be accepted as a standard of reference for the performance of designoriented fire models. It is the major objective of the Compartment Fire Modeling Research (CFMR) Group to develop such a BCFM computer code. During the last year a program for the development of the BCFM was established and initiated.

Single-Room Fire Simulations. The Harvard single-room model has been operational at NBS for some years. It has been used both for demonstration calculations and as a test bed for new modeling concepts. The "official" Harvard 5 model has been enriched successfully. The results of this have led to two new and different versions of the model; namely, NBS/Harvard 5.2, 5.3, and subversions of these. The first stage effort in the above-mentioned BCFM development program has been to consolidate the advances of these Harvardbased codes. The product of this effort, a BCFM prototype one-room compartment fire model is complete and is in review. The new consolidated code, named FIRST (FIre Simulation Technique) is supported by a comprehensive user's manual. Both software and manual will be issued in the first quarter of FY87.

Under support of the Nuclear Regulatory Commission (NRC) the development of an algorithm to model the effect of burning in the vitiated air of the upper layer is near completion and is being tested in an advanced development version of FIRST. Also supported by the NRC was a comparison of the capabilities of several different compartment fire models.

An advanced version of the ASET (Available Safe Egress Time) computer program was developed to include simulation of the response of thermal fire detectors in two-layer compartment fire environments. This work is continuing as a joint activity with the Fire Simulation Laboratory Group of CFR.

Multi-Room Fire Simulations. The Harvard 6 code was brought to NBS in 1983. It was made operational on the CFR computer, made to conform strictly to the ANSII FORTRAN 77 standard, and a series of minor errors were corrected. Several enrichments have been added to the code. As a part of this effort, an extensive debugging capability was also added. A separate plot package, originally developed for NBS/Harvard 5.2, has been adapted. Comparisons are now being made between simulations of the resulting code and data from a series of full-scale multi-room tests which were carried out at NBS in 1980.

Under support from the Navy, an initial study was completed which identifies means of using deterministic compartment fire modeling to improve the risk analysis of the Navy's Fire Damage Simulation Model.

A Program for the Development of a Benchmark Compartment Fire Model Computer Code, L.Y. Cooper, J.A. Rockett, H.E. Mitler and D. W. Stroup, NBSIR 85-3252, to appear in Proceedings of 1986 ASTM International Symposium on Mathematical Modeling of Fires and Related Test Methods, Dec., 1986, New Orleans.

User's Guide to FIRST, A Prototype Benchmark Fire Model, Mitler, H.E. and Rockett, J.A., to appear as NBSIR. 
Simulating Fires on a Computer, Mitlex, H.E., presented at 1986 Joint Meeting of the Society of Plastics Industry and the Fire Retardant Chemicals Association, March 21, 1986.

Comparison of Several Compartment Fire Models: An Interim Report, Mitler, H.E., NBSIR 85-3233.

The NBS/Harvard Mark VI Multi-Room Fire Simulator, Rockett, J.A. and Morita, M., NBSIR 85-3281.

The Harvard Fire Model, Mitler, H.E., 1984 SFPE Symposium on Computer Applications in Fire Protection: Analysis, Modeling and Design, Fire Safety Journal, 9,7 (1985).

ASET: A Computer Program for Calculating Available Safe Egress Time, Cooper, L.Y. and Stroup, D.W., 1984 SFPE Symp. on Computer Applications in Fire Protection: Analysis, Modeling and Design, Fire Safety Journal, 9, 29 (1985).

Naval Fire Fighting Trainers - Effect of Ventilation on Fire Environment (Model Calculations for 19 F3 FFT), McCaffrey, B.J., Rockett, J.A. and Levine, R.S., NBSIR 85-3238.

Fire Growth in Combat Ships, Rockett, J.A., to appear as NBSIR.

Implementing Life Safety Through Designed Safe Egress, Cooper, I.Y. and Nelson, H.E., to appear in the Chapter on Fire in Monograph on Planning and Design of Tall Buildings, Council on Tall Buildings and Urban Habitat.

The Need and Availability of Test Methods for Measuring the Smoke Leakage Characteristics of Door Assemblies, Cooper, L.Y., Fire Safety: Science and Engineering, ASTM STP 882, Harmathy, T.Z., Ed., American Society for Testing and Materials, Philadelphia, 1985, pp. 310-329.

Comparisons of NBS/Harvard 6 Simulations and Full-Scale, Multi-room Compartment Fire Test Data, Rockett, J.A., Morita, M. and Cooper, L.Y. to appear as a NBSIR.

Thermal Response of Interior Aircraft Ceilings During Fuel Spill Fire Scenarios, Cooper, L.Y., Proceedings of lst International Symposium on Fire Safety Science, Oct. 7-11, 1985, Gaithersburg, Hemisphere Publishing.

2. Compartment Fire Model Catalog of Submodel Algorithms and Associated Computer Subroutines

This project involves a series of short-and long-term activities. These involve: a) reviewing the subroutine algorithm's and associated computer subroutines of existing compartment fire model computer codes, and identifying those which are of "benchmark" quality; b) merging these into a single, portable, algorithm/subroutine library, making improvements and developing additional entries as appropriate; and c) developing a format for a Catalog of Compartment Fire Submodel Algorithms/Subroutines, and a mechanism for publication, distribution and revision of the Catalog. The Catalog will be for general use in zone compartment fire models. The first edition of the 
Catalog is complete and is in review. Distribution in the first quarter of FY87 is anticipated.

The Establishment of a Catalog of Compartment Fire Model Algorithms and Associated Computer Subroutines, Stroup, D.W., NBSIR 85-3263.

A Catalog of Compartment Fire Model Algorithms and Associated Computer Subroutines, Stroup, D.W., to appear as NBSIR.

3. Compartment-Fire-Generated Flow Dynamics, Flame Spread/Growth and Heat Transfer: Submodel/Algorithm Development and Verification.

A theoretical study of the structure and upward spread rate of wall fires is near completion. This work was undertaken from the point of view that the results be consistent with available experimental data, and useful in an algorithm which is simple enough for use in zone compartment fire models.

Experimental programs complement continuing theoretical activities which are being carried out to formulate, develop and validate algorithms for simulating compartment-fire generated flow dynamics and heat transfer. The ability to simulate such phenomena is necessary for reliable predictions of the compartment fire environment. This is the environment which defines the impact of the compartment on fire growth development and which determines completely the extent of hazard. In one example of such an activity a reducedscale, experimental program and supporting analysis was completed where the thermal response of different ceiling constructions positioned above fires of different strengths and fire ceiling separations was measured. In another example, details of the flow characteristics of ceiling jets are being established in a manner that will allow one to simulate the response of arbitrarily deployed fire detection system components in developing compartment fires.

A study has been initiated with the objectives of mathematically modeling the smoldering of cigarettes on furniture, describing the influence of furniture on the burning of a cigarette, and predicting whether furniture will ignite for a particular cigarette configuration and furniture composition. This work is part of a larger program which includes extensive experimental work and is supported by the Consumer Product Safety Commission.

Heat Transfer in Compartment Fires Near Regions of Ceiling Jet-Wall Impingement, Cooper, L.Y., Proceedings of 1985 Fall Technical Meeting of Eastern Section of Combustion Institute, Nov. 4-6, 1985, Philadelphia.

Ceiling Jet Properties and wall Heat Transfer in Compartment Fires Near Regions of Ceiling Jet-Wall Impingement, Cooper, L.Y., NBSIR 86-3307.

A Bouyant Source in the Lower of Two Homogeneous Stably Stratified Layers, Cooper, L.Y., Proceedings of 20th Symposium (International) on Combustion, The Combustion Institute, p. 1567 (1984).

An Experimental Study of the Transient Thermal Response of Unconfined Ceilings Above Fire Plumes, Woodhouse, A., Marks, C.H. and Cooper, L.Y., Proceedings of 1985 Fall Technical Meeting of the Eastern Section of the Combustion Institute, Nov. 4-6, 1985, Philadelphia, submitted for presentation and 
publication in Proceedings of 2nd ASME-JSME Thermal Engineering Joint Conference, March, 1987.

Burning of a Blume in the Upper Layer, Mitler, H.E., to appear in Proceedings of 1986 ASTM International Symposium on Mathematical Modeling of Fires and Related Test Methods, Dec., 1986, New Orleans.

Methods to Calculate the Response Time of Heat and Smoke Detectors Installed Below Large Unobstructed Ceilings, Evans, D.D. and Stroup, D.W., Fire Technology, 22, pp. 54-66, 1986.

Evaluating Thermal Fire Detection Systems [English Units], Stroup, D.W., Evans D.D. and Martin, P., NBS Special Publication 712, April 1986.

Development of an Automated Probe Positioner for Measurements in Fire. Generated Plumes and Ceiling Jets, Stroup, D.W., NBSIR 86-3379, presented at 1986 ASME International Computers in Engineering Conference, July 23, 1986. Chicago.

Heat and Mass Transfer Research Topics in Fire and Controlled Combustion Systems, Cooper, L.Y., and Kennedy, L.A., to appear in Mechanical Engineering.

The Thermal Response of Unconfined Ceilings Above Growing Fires and the Importance of Convective Heat Transfer, Cooper, L.Y. and Stroup, D.W., to appear in Journal of Heat Transfer.

The Buoyant Plume-Driven Adiabatic Temperature Revisited, Cooper, L.Y. and Woodhouse, A., to appear in Journal of Heat Iransfer.

\section{Associated Grants and Contracts}

Negatively-Buoyant and Penetrative Flows Generated in Enclosure Fires, Jaluria, Y., Rutgers - The State University of New Jersey.

Transient Heat Transfer in Ceiling Jets, Marks, C.H., University of Maryland. 


\section{FIRE GROWTH AND EXIINCTION \\ CENTER FOR FIRE RESEARGH \\ FY 86}

\section{$\underline{\text { Staff }}$}

James Quintiere, Head

Betty Thames, Secretary

Howard Baum, NBS Fellow

Edward Budnick, Fire Protection Engineer

Dan Corley, Physicist

David Evans, Research Engineer

Margaret Harkleroad, Physicist

Randy Lawson, General Physical Scientist

Bernard McCaffrey, Mechanical Engineer

Ken Steckler, Physicist

Wenhao Meng, Guest Worker, Univ. of MD

Phil DiNenno, Research Associate, Hughes Associates

James Jackson, Research Associate, Armstrong World Industries

Larry Buffington, Fire Protection Engineering Student

James Morehart, Mechanical Engineering Student

Dan Madrzykowski, Engineering Technician

William Rinkinen, Engineering Technician

Robert Vettori, Engineering Technician

Henry Wheelock, Engineering Technician

Ji-Jen Chiou,-Guest Worker, (Taiwan)

Hideo Ohtani, Guest Worker, IHI (Japan)

\section{Program Objectives}

Through research we aim to develop predictive methods to describe the processes of growth and extinction related to natural fire phenomena and fire safety systems.

\section{Scope}

The work addresses the processes of fire growth and decay associated with fires within structures and with free burning fires. It examines the overall dynamics of fire growth and its suppression in order to identify and understand the significant underlying processes; ignition, flame spread, burning rate, extinction, and the related transport processes. It utilizes mathematical techniques, experimental studies and correlations, and similitude methods to develop accurate predictions for realistic configurations and materials. As appropriate, it formulates and demonstrates its predictive methods for specific applications.

\section{Project Areas}

\section{Suppression}

Research is being conducted to understand extinction dynamics associated with water spray suppression of a variety of fires and the performance of fire protection sprinkler systems. These included detailed studies of extinction 
of lifted gas jet diffusion flames, room fire suppression of laboratory liquid fuel spill fires, heat transfer between solid surfaces and evaporating droplets, quantification of droplet sizes and trajectories from commercial sprinkler devices, and studies of the thermal response of heat sensitive elements used in sprinkler and heat detection systems.

Large scale blowout fire suppression tests were conducted cooperatively with the Blowout Fire Prevention School at Louisiana State University. Methane jet Elames up to $1 / 2 \mathrm{GW}$ were tested.

An analysis of the stability of methane jet flames was completed. This showed, for the first time, flame blow-off characteristics at flow rates relevant to gas-well blowouts.

The performance of new technology fast response sprinkler systems and plastic pipe was evaluated in a series of tests conducted cooperatively with the General Services Administration and the National Institutes of Health.

Our shadowgraphic drop size analyzer system is being utilized to characterize the initial spray characteristics for several European and U.S. sprinkler devices. This is part of a cooperative effort on sprinkler performance with the Fire Research Station at Borehamwood, England and Polytechnic of the South Bank in London under support from Brandforsk in Stockholm, Sweden.

Measurement and analysis of droplet evaporation from hot metal surfaces have been completed. The extension of the analysis and measurements to low thermal conductivity solids is underway in this cooperative study between CFR and the Mechanical Engineering Department at the University of Maryland.

Temperature measurements were made above and below the penetration plane of a plume flowing from a cool lower layer to a heated upper layer of gas. This was done using a specially designed microcomputer controlled probe positioning device and data acquisition system to automatically record data within a cylindrical enclosure. The measurements were used to check the accuracy of models for transition conditions in two-layer plume flow calculations. The best fit to the data was achieved by assuming continuity of centerline plume temperature and integrated excess enthalpy.

An analysis of thermal response of Fire Detection Systems was completed. The results of this analysis were published in tabular form to allow fire protection engineers easy access to design calculations that yield expected response time for thermally activated sprinkler and heat detection systems at a given spacing. The two volume set (SI and English Units) can be considered companion volumes to the already in use tables published as part of NFPA $72 E$ Standard on Automatic Fire Detectors that yield results in terms of detector spacing for a given response time.

\section{Publications:}

McCaffrey, B.J. and Evans, D.D., Very Large Methane Jet Diffusion Flames, Proceedings of the 2lst International Symposium on Combustion, Munich, West Germany, August 3-8, 1986. 
Morehart, J. and Evans, D., Investigation of the Effects of a Stratified Two Layer Environment on Fire Plume Temperatures, NBSIR in preparation.

Stroup, D., Evans, D., and Martin, P., Evaluating Thermai Fire Detection Systems NBS Special Publication 712 (English Units) and 713 (S.I. Units), April 1986.

Evans, D.D., and McCaffrey, B.J., Recent Advances in Suppression of Wellhead Fires Using Water Sprays, MMS Technical Assessment and Research Program Seminar, November 1986.

Evans, D.D. and Stroup, D.W., "Methods to Calculate the Response Time of Heat and Smoke Detectors Installed Below Large Unobstructed Ceilings", Fire Technology, Vol 22, No. 1, February 1986.

Evans, D.D., Ceiling-Jets, chapter for SFPE Quantitative Methods Handbook to be published.

Di Marzo, M. and Evans, D.D., Evaporation of a Water Droplet Deposited on a Hot High Thermal Conductivity/Diffusivity Solid Surface to be published International Journal of Heat and Mass Transfer, and NBSIR 86-3384, Aug. 1986.

Gore, J.P., Faeth, G.M., Evans, D., and Pfenning, D.B., Structure and Radiation Properties of Large-Scale Natural Gas/Air Diffusion Flames to be published in Fire and Materials.

Stroup, D.W., Development of an Automated Probe Positioner for Measurements in Fire Generated Plumes and Ceiling Jets, NBSIR 86-3379 May 1986.

Di Marzo, M. and Trehan, A.K., Transient Cooling of a Hot Surface By Droplets Evaporation, NBS-GCR-86-516, July 1986.

McCaffrey, B.J., Momentum Diffusion Flame Characteristics and the Effects of Water Spray, NBSIR 86-3442, June 1986.

McCaffrey, B.J., Radiation Measurements of Large Methane Diffusion Flames and the Effects of Water Sprays, Eastern States Combustion Institute, Philadelphia, PA, November 4-6, 1985.

Trehan, A.K., Di Marzo, M. and Evans, D.D., Transient Cooling of a Hot Surface by Droplet Evaporation, Eastern States Combustion Institute, Philadelphia, PA, November 4-6, 1985 .

\section{Turbulent Burning}

This work combines the use of theoretical, computational and experimental methods to resolve phenomena associated with turbulent reacting flows.

Single, plume flow patterns generated by dynamically and kinematically consistent use of experimental plume correlations were imbedded into a computational scheme that was used to predict flows generated by urban conflagrations consisting of thousands of individual fires randomly distributed in space and size spread over tens of square kilometers. 
Diffusion and mixing of reactants of general configurations in a vortex field under isothermal conditions in two dimensions were completed. Current work is emphasizing three dimensional configurations and non-isothermal effects.

Measurements of soot yield and morphology from a variety of fuels in pool fire and crib configurations were made. Optical extinction measurements were also made. This will be supplemented by velocity and temperature measurements in continuing work.

Modeling of soot agglomeration and transport phenomena using realistic soot structures has been carried out. This will be continued and supplemented with optical extinction analyses in future work, and applied to the Nuclear Winter study.

\section{Publications and Presentations}

Baum, H.R., Corley, D.M., and Rehm, R.G., "Time-Dependent Simulation of Small Scale Turbulent Mixing and Reaction", Twenty-First Symposium (International) Combustion, Munich, W. Germany, August 3-8, 1986.

Rehn, R.G., Baum, H.R., and Lozier, D.W., "Two-Dimensional Flame in a Vortex Field", SIAM 1986 National Meeting, Boston, July 21-25, 1986.

Evans, D., Baum, H.R., McCaffrey, B., Mulholland, G., harkleroad, M., and Manders, W., Combustion of Oil on Water", Proceedings of the Ninth Arctic Marine Oilspill Program Technical Seminar, Edmonton, Alberta, June 10-12, 1986, pp. 301-336, (1986).

Baum, H.R., "Multiple Plume Flow Fields", Defense Nuclear Agency Program Technical Review, Moffett Field, CA, February 25-27, 1986.

Mulholland, G.W., "Smoke Emission and Properties", Defense Nuclear Agency Program Technical Review, Moffett Field, CA, February 25-27, 1986.

Mountain, D.R., Mulholland, G.W., and Baum, H.R., "Simulation of Aerosol Agglomeration in the Free Molecular and Continuum Flow Regimes", J. Colloid and Interface Science (in press)

Pitts, W. and McCaffrey, B.J., Response Behavior of Hot-Wires and Films in Different Gases, Journal of Fluid Mechanics, August 1986.

McCafirey, B.J., "Flame-heights", SFPE Quantitative Methods Handbook to be published.

\section{Fire Dynamics of Systems and Materials}

This area of activity represents the exploration of complex phenomena in fire and the application and development of engineering approaches for their prediction.

The analog technique of using salt and fresh water to yield the motion of smoke in complex structures is being further developed. The measurement of salt concentration to predict smoke concentration is being examined. 
The energy release rates of an extensive series of shipboard cable fires were deduced from oxygen and temperature measurements. This work was done tosupport the development of safe materials and their selection for use on combat ships.

The enclosure fire behavior caused by the burning of a discrete wall slab of PMMA showed a dramatic affect of the enclosure and its opening size on the fire conditions. Enclosure mass loss rates ranged from the free burn value of the slab to nearly seven times this value for experiments of $0.75 \mathrm{~m}$ in height. A single full-scale ( $2.4 \mathrm{~m}$ high) counterpart experiment, substantiated a significant increase in the rate of burning due to the enclosure. A crude analysis of the small-scale results shows that the mass loss rate of PMMA is linearly related to the oxygen and incident radiative heat flux proportioned over the upper and lower (layer) wall surfaces.

A device was designed and used to measure the bulk heat of gasification (I) for materials. The value is determined as a function of time by determining the net heat added (q) to the sample under radiative exposure conditions. The measured mass loss (m) under a nitrogen atmosphere is then used to complete the process, i.e. $L=q / m$. Results for PMMA show a distinct dependence of $I$ on time and incident heat flux.

A study was initiated under the sponsorship of the Minerals Management Services (DoI), to determine the combustion characteristics of crude oil burning on water.

\section{Publications}

Steckler, K., Harkleroad, M., and Braun, E., Heat Release Rates from Shipboard Cable Fires, NBS letter report to Dr. F. Williams, September, 1986.

Steckler, K.D., Baum, H.R., and Quintiere, J.G., Salt Water Modeling of Fire Induced Flows in Multicompartment Enclosures, Twenty-First International Symposium on Combustion, Munich. West Germany, August 1986, to be published by The Combustion Institute, Pittsburgh, PA, (expanded report issued as NBSIR 833327, March 1986).

Budnick, E.K., and Evans, D.D., "Hand Calculations for Enclosure Fires", NFPA Fire Protection Handbook 16th Ed. March 1986.

Evans, D., Baum, H., McCaffrey, B., Mulholland, G., Harkleroad, M., and Manders, W., Combustion of Oil on Water, NBSIR 86-3420, June 1986. Also, Proceedings of the Ninth Arctic Marine Oilspill Program Technical Seminar, Edmonton Alberta, June 10-12, 1986.

McCaffrey, B.J., Rockett, J.A. and Levine, R.S., Naval Fire Fighting Trainers - Effect of Ventilation on Fire Environment, NBSIR 85-3238, 1985.

\section{Flame Spread}

Research is continuing in order to establish procedures for developing and identifying the key material properties necessary to predict flame spread. 
The test apparatus which measures ignition and lateral flame spread on a vertical sample has been produced commercially and is receiving world wide attention. Many international laboratories now have this test apparatus.

Results from the lateral device have been shown to be applicable to predicting flame spread on horizontal surfaces as well as vertical surfaces.

Measurements related to upward spread focused on flame heights for burning solids as a function of their mass loss rates.

A large scale experiment of flame spread on a wall of BMMA in a room was performed and the analysis of these results will serve to evaluate the test method strategy needed to predict the process.

A review of flame spread was prepared as a chapter for the new SFPE handbook.

Work has been done for the USCG, FAA and industry; and we have participated in standards organizations .. ASTM, ISO and IMO.

\section{Publications}

Harkleroad, M., "Ignition and Flame Measurements of Aircraft Lining Materials", to be published by the FAA.

Atreya, A., Carpentier, C. and Harkleroad, M., "Effect of Sample Orientation in Piloted Ignition and Flame Spread". Fire Safety Science - Proceedings of the lst International Symposium, Hemisphere Publishing Corporation, 1986, P. 97.

Quintiere, J., Harkleroad, M. and Hasemi, Y., "Wall Flames and Implications to Upward Flame Spread", Combustion Science and Technology, 1986, Vol. 88, pp. 191-222.

Quintiere, J., "Surface Flame Spread", a chapter for the SFPE Handbook to be published.

Saito, K., Quintiere, J.G. and Williams, F.A., "Upward Turbulent Flame Spread", Fire Safetv Science. Proceedings of the lst International Sumposium, Hemisphere Publication Corporation, 1986, pp. 75-86. 
FIRE PERFORMANCE AND VALIDATION

FIRE MEASUREMENT AND RESEARCH DIVISION

CENTER FOR FIRE RESEARCH

FY 86

\section{Professional Personnel}

Sanford Davis, Head

Emil Braun, Physicist

$\mathrm{J}$. Newton Breese, Computer Programmer

C. Lynn Forney, Mathematician

Billy T. Lee, Fire Prevention Engineer

Richard D. Peacock, Chemical Engineer

J. Samuel Steel, Physicist

Huang Dingyi, Guest Worker (Shanghai Fire Research Institute)

\section{Objectives}

The objectives are to develop the generic methodology for assessing the accuracy and limitations of fire models and to design and conduct tests to evaluate the fire performance of components, systems, and structures.

\section{Scope}

This work includes two important efforts: first, the conduct of unique, highly instrumented experiments to establish fire behavior on a realistic scale in order to contribute to model development and, second, the evaluation and validation of fire models by providing a mathematical tool for comparing experimental data with model outputs utilizing expertise in facility fire test experimental design, instrumentation, and data processing and analysis.

\section{Projects}

1. Validation of Fire Models

The objective of this project is to develop the methodology for the evaluation and validation of fire models; it focuses on the development of mathematical and computational techniques for fulfilling this objective. With the large amount of data collected during the room/corridor tests, including multiple tests to develop statistical information on test reproducibility, the presentation of the data in a standardized graphical form is extremely important in the interpretation of the results.

Peacock, R.D., Davis, S., Lee, B.T., Jones, W.W., and Steel, J.S., Experimental Data for Model Validation, NBSIR in preparation. 
The objective of this project is to provide support for continued development of the toxic hazard model by implementation of full-scale tests, designed to measure transport of smoke and toxic gases, supporting efforts to model vertical smoke movement and to validate the horizontal transport model. Completion of the interior and installation of the instrumentation in the townhouse was delayed because of other projects raking precedence. Ultimately, three tests were carried out: PMM on one wall of the burn room, three "chairs" (sofa, love seat, and chair) in the burn room, and a fully furnished room. During the coming year, three series of experiments will be performed using a square wave output from a natural gas diffusion burner open shaft, vent only, and vent with staircase - to develop.data for the movement of smoke and other combustion products in a vertical direction.

\section{Upgrade of Large-Scale Testing Facilities}

The new computer based data acquisition system was further enhanced during the past year. Along with two additional data collection stations installed on the tast floor (bringing our total to four stations and 600 channels), a new data acquisition system was installed and interfaced to the computer based system to allow use of all our existing digital scanners (for a total capacity of 1600 channels in 100 or 200 channel blocks. Development of real-time full-color graphics capabilities to allow simultaneous presentation of test data and previously recorded test data or model calculations began which will further enhance our data collection and presentation during large scale Eire tests.

Breese, J.N., and Peacock, R.D., A User's Guide for RAPID, Reduction Algorithms for the Presentation of Incremental Fire Data, Nat. Bur. Stand., NBS Special Publication 722, August 1986.

4. Flame Spread on Walls

The objective of this project is to examine flame spread on selected wall materials burning outside of a room and inside a full-size room to provide a data base for the development and refinement of analytical models. This work complements small-scale work on flame spread ( upward, downward, and lateral) both before and after flashover. The experimental study is designed to analyze flame spread along a combustible wall surface using a controlled ignition source along the floor, either against the back wall or in one rear corner, or at the wall ceiling interface. The heat release of the specimen can be monitored to determine the combustion efficiency of the burning material as the fire develops.

Lee, B.T., and Steel, J.S., Standard Room Fire Test Research at the National Bureau of Standards, NBSIR to be published.

Lee, B. T., Quarter-Scale Room Fire Tests of Interior Finishes, Fire and Materials, Vol. 9, No. 4. 1985.

Huang, D.Y., Evaluation of Quarter-Scale Compartment Fire Modeling for Constant and Stepped Heat Inputs, submitted to Fire and Materials. 
The objective of this continuing project is to study the hazards associated with the installation, operation, and maintenance of solid fuel burning appliances used for space heating in single family dwellings and in similar small-scale applications. Fire incidents from the use of solid fuel burning equipment rose from 66,800 to 130,100 between 1978 and 1981 . This trend slowed from 1981 to 1982 to slightly less than a seven percent increase. The frequency of fire incidence stabilized between 1982 and 1983 (increasing during this time less than one percent) and actually decreased in 1984 (dropping nearly 11 percent). Bositive actions by the Center for Fire Research and others are believed responsible for improving the safety of these appliances and, thus, reversing an increasing fire incidence rate. The overall research program has included typical operating conditions of modern heating appliances, intensity and duration of chimney fires in factory-built and masonry chimneys, clearance reduction systems for protection of combustible walls and ceilings, and wall pass-through systems for connection of appliances to chimneys through combustible walls.

Efforts within the next year will focus on the safety of the use of new high efficiency combustion devices becoming available in the wood heating industry. The primary concerns are the buildup of creosote in chimneys (to be determined quantitatively with a specially built chimney) and the thermal load imposed on the surroundings by the device.

Peacock, R.D., and Dipert, R.A., STOVE: A Predictive Model for Heat Transfer from Solid Fuel Appliances, Nat. Bur. Stand., NBSIR 86-3300, August 1986.

Peacock, R.D., Chimney Fires: Intensity and Duration, published in Fire Technology, July 1986.

Peacock, R.D., Wood Heating Safety Research: An Update, submitted to Fire Technology.

6. Flammability of Composites for Naval Ship Use

The objective of this program is to assist the Navy in designing fireresistant ship components from fiber-and metal-reinforced composites by systematically assembling data on composites' flammability properties. To date, the laboratory work performed has been using the cone calorimeter; this work is being extended to more advanced composite materials. In addition, depending on the availability of suitable specimens, flame spread measurements will be made with the IMO apparatus. Fire scenarios, currently being developed by the Navy, will be translated into full-scale experiments.

Brown, J.E., Loftus, J.J., and Dipert, R.A., Fire Characteristics of Composite Materials - A Review of the Literature, Nat. Bur. Stand., NBSIR 85-3226, August 1986.

Associated Grants and Contracts

James P. Jarvis - Clemson University," Graphical Presentation and Numerical Analysis of Fire Data for Model Validation." 


\section{FIRE RESEARCH INFORMATION SERVICES \\ CENTER FOR FIRE RESEARCH \\ FY 86}

\section{Project Leader}

Nora H. Jason

\section{Program Objective}

The Fire Research Information Services (FRIS) is an on-going project within the Center for Fire Research (CFR), National Bureau of Standards. It was started in 1971 and incorporated several personal collections at the National Bureau of Standards, as well as the Federal Fire Council collection. Over the years, it has grown and now contains approximately 30,000 reports, documents and books. (On an average, 1500 items are added to the collection each year.) It reflects the programmatic needs of the Center for Fire Research, as well as developing a national and international fire research collection for use by NBS staff, researchers, fire departments, fire science students and the fire community at large.

One of the major obstacles in fire research has been accessing fire research information. Although the FRIS collection is one of the most complete, it only has been a manual system and, therefore, not readily accessible to the fire research comunity. The first step has been initiated towards filling this gap. FRIS has begun to automate its collection and the on-line bibliographic database is called FIREDOC. All ney bibliographic records are added to FIREDOC. Retrospective input is being completed by modules, e.g., all CFR reports going back to the beginning of the NBS fire programs.

An extensive document distribution program is carried on, both on a regular basis and on a demand basis. The publication and distribution of grantee reports (in the NBS Government Contract Report series) to selected subject interest groups is part of this program. AlI NBS report series are listed in the automated bibliographic data base and available through the Government Printing Office of the National Technical Information Service.

The journal collection contains approximately 100 titles. The focus is on the research activities of the CFR, as well as fire-related research needs. The titles are quite unique to FRIS.

For interested people who cannot come to the FRIS, an extensive inter-library loan program is carried out with participating Iibraries through the United States. FRIS is located at the National Bureau of Standards, Building 224, Room A-252. The telephone number is (301)921-3249. 


\section{FIRE SIMULATION \\ CENTER FOR FIRE RESEARCH \\ FY 86}

\section{Professional Personnel}

Harold E. Nelson, Head

Daniel Gross, Research Engineer

Richard L. Smith, Knowledge Engineer

W. Douglas Walton, Fire Protection Engineer

\section{Program Objectives}

To provide for the expedient transfer of scientifically based technology to the professional applications community and provide a point of interface between the computer based activity of the Center for Fire Research and others doing similar or complementary work.

\section{$\underline{\text { Scope }}$}

The work addresses development of engineering systems for design application, and the development of expert systems, the collection of the supporting data and programs, and the operation of a working and training laboratory dedicated to computer modeling and other fire safety computations.

\section{Projects}

1. Engineering Method Development. The purpose of this project is to assemble, adjust, coordinate existing data, models, physics, and other needed elements to develop engineering methods useable by fire protection engineers and others involved in building design. The object is a progressive evolution of a fire protection engineering technology based on scientific investigation and technical experiments undertaken by NBS and others in the fire research community. The overall approach is to develop validated engineering methods for appraising fire safety in buildings or design and the impact of specific fire criteria proposals. The program is designed to produce a progressively expanding set of capabilities with useful methods becoming available in the near future. The program has a three level approach. Some work is already underway in levels one and two. The levels are as follows:

Level One: Assessment of life safety within a reasonably

large space which includes the area of fire origin (eg:

auditoriums, hospital wards, offices, laboratories, machine shops, and similar spaces).

Level Two: Assessment of life safety and the mitigation of damaging fire effects in a facility involved in a series of connected rooms and spaces on a single floor (eg. hospital nursing unit, and similar divided spaces). 
Level Three: Assessment of life safety, wission continuity and property value risk covering mullistory conditions.

The initial effort was supported by funds from the Aiz Force. A system of fast responding models and formulas has been structured, a report published outlining the potential system, and a number of the input and computational subroutines organized into a consistent format. The future depends on availability of funds and resources.

2. Fire Simulation Laboratory. For more than a decade rasearchers have been ceveloping computer programs 50 predict of model the growth of fize and its effects in buildings. Although the variety of Eire scenarios inich can be adiressed with these computer programs is limited at present, thete is a growing interest in the fire protection comminity in adapting these computer programs for specific needs.

This interest, and the need for efficient transfer of recently developed technology in computerized fire simulation, has prompted the Center for Fire Research (CFR) to establish a Fire Simulation Laboratory (ESL). This laboratory is a place winere individuals frow the private sector, Federal, state and local government agencies, academic instivutions and others can utilize computer programs, state of the art graphics, video and reference paterials, and associated data bases to:

(1) further develop computer fine modeling programs and integrata them ziti data.

(2) Cemonstrate the capability of computer fire podels to address fire questions and issues.

(3) provide training in the use and applicacion of zise simulation techniques, and

(4) provide ansiers to fire problems.

During this first year the Simulation laborazory has concucted severai worksiops to introduce engineers to modeling and has served as a resource to various researchers.

3. Data Sources for Predictive Modeling. This project supports and implements projecss requiring daca for use in lize growth and swoke zuansport zodeis. This involves determining the appropriace soureas of information for basic lhermophysical property data and for measurements of the 佂e responses of jpical combustibie contents. A specific outpul is a IASI 17-compatijle data base cataiog inciuding the jollowing ypes of data: (a) thermophysicai propeztias, (b) furnizure calorimeter, (c) cone calorineter, and (d) soxic porency.

4. Expez Sustems. This project has as its ojjective to develop a computer program wich jill rake an exper estimate of the jire safety of a builcing based on CFR's detsministic physical models, technical data, and experz judgment. It will have the capability to explain any conclusions iz rakes. In addition, it should be readily useabie by CR's cilients. 
The approach being used is to write a computer program using a IISP machine and state-of-the-art expert system development software tools. The approach is to base an expert system on a methodology similar to the one used in the report "Credible Engineering Methodologies" by H. E. Nelson. The particular expert systems developed will be determined by selecting appropriate subjects for the construction of expert systems and are important to the fire community. Our initial expert is Harold E. Nelson. The initial choice of a subject for an expert system is a general purpose warehouse. A system is being developed that will first determine if the concepts or plans for a warehouse are in compliance with the United States Air Force regulations. These regulations include by reference all well known fire codes. When this phase is complete, expert engineering analysis will be added that is similar in content to the material included in Engineering Methods Development.

\section{Publications}

Smith, R.L., ASKBUDJr: A Primitive Expert System for the Evaluation of the Fire Hazard of a Room, National Bureau of Standards, NBSIR 86-3319, Gaithersburg, MD, March 1986.

Smith, R.L., ASKBUDJr: A Precursor of an Expert System for the Evaluation of Fire Hazard, Fire Technology (to be published).

Nelson, H.E., Concepts for Life Safety Analysis, The 7 th Society of Fire Protection Engineers Symposium, Quantitative Methods for Life Safety Analysis, College Park, MD, March 5-7, 1986.

Nelson, H.E., "FIREFORM", A Computerized Collection of Convenient Fire Safety Computations, NBSIR 86-3308, National Bureau of Standards, Gaithersburg, MD, 1986.

Nelson, H.E., Walton, W.D., The Basic Structure of the Fire Protection Design Assessment System, NBSIR 85-3298, National Bureau of Standards, Gaithersburg, MD, 1986. 
FLAMMABILITY AND TOXICITY MEASUREMENT

CENTER FOR FIRE RESEARCH

FY86

\section{Professional Personnel}

Vytenis Babrauskas, Head

Richard H. Harris jr., General Physical Scientist

Gerald King, Fire Prevention Engineer

John F. Rrasny, Textile Technologist

Barbara C. Levin, Toxicologist

Gregory M. Michaels, General Engineer

Marc Nyden, Research Chemist

Maya Paabo, Research Chemist

Trudi H. Hensley, Guest Worker, University of Pittsburgh

Joshua L. Gurman, Research Associate (AISI)

\section{Program Objectives}

To develop measurement methods and the underlying principles for characteri. zing the combustibility of furnishings and building materials and the impact of the combustion products on living organisms.

\section{$\underline{\text { Scope }}$}

Typical efforts of this group include:

- assessing the appropriate applications of the NBS toxicity screening test method

- determining the extent to which a limited number of gases determine the lethality of combustion products

- developing a rationale and the methodology for predicting soot and specific gas production in full-scale fires from bench-scale methods

- exploring possible alternatives to animal testing for measuring the impact of combustion products on people

- generating a valid, detailed model for the burning of upholstered furniture

- producing a data base for the burning parameters of various furnishings for use in fire hazard models

- developing an appropriate measurement methodology for the propensity of cigarettes to ignite soft furnishings

- reinforcing the relationship of combustion in the cone calorimeter to large scale burning and aiding the promulgation of the cone calorimeter for engineering and code applications

\section{Projects}

1. Heat release rate and related properties of materials

The focus in this area is measurement of materials properties in the cone calorimeter. This instrument was initially developed for heat release rate studies. More recently, the capability was added to do smoke obscuration, 
soot mass, gas species yield characterizations. In addition, data are regularly taken on ignitability, mass loss rate, and the effective heat of combustion. The cone calorimeter was recently adopted by ASTM as a tentative (grey pages) method, $\mathrm{P}-190$. As a parallel effort, in the international community, ISO TC92 SC1 WG5 (the ISO working group on heat release rate) has made a commitment to develop the cone calorimeter into an ISO standard. The commercial production of cone calorimeters has been started in the United States; the initial unit was calibrated and checked out at NBS this sumer. The list of laboratories equipped to do this work is growing--in addition to a second unit built at NBS, and the half-dozen units being built commercially, there are units in place in Japan and Belgium, and several more units are being built in Europe. In addition, a British equipment maker is to start producing units for the European market commercially. Work has been started this year on making real-time measurements of soot mass production in the cone calorimeter, and on correlating these measurements to full-scale measurements in the furniture calorimeter. Finally, some very rough rules for estimating full-scale heat release rates in the absence of a validating full-scale data base were developed for use with the fire hazard analysis computer model, and an initial database issued of previously unpublished cone calorimeter measurements on various materials.

Babrauskas, V., Comparative Rates of Heat Release from Five Different Types of Test Apparatuses, J. of Fire Sciences. 4, 148-159 (1986).

Babrauskas, V., Smoke Measurement Results from the Cone Calorimeter, pp. 420-434, Proc. of the 8th Joint Panel Meeting UJNR Panel on Fire

Research and Safety, Building Research Institute, Isukuba, Japan (1985).

\section{Upholstered furniture flamability}

The monograph on furniture flammability has finally been issued; however, a number of issues related to upholstered furniture flammability are still seen to be in need of exploration. One such study was done to determine if smallscale open flame tests, such as the BSI test (BS5852), provide additional, unique information of furniture flammability not obtainable in cone calorimeter measurements. The results showed that, while there are still a number of foam/fabric combinations whose behavior is not well understood, the ease of ignition in a BS5852 type open flame test can be correlated to the time to reach a certain critical heat release rate in the cone calorimeter. Also, several furniture calorimeter studies were made during this year on fireresistive upholstered chair constructions; data analysis is still ongoing.

Babrauskas, V., and Krasny, J.F., Prediction of Upholstered Chair Heat Release Rates from Bench-Scale Measurements, pp. 268-284 in Fire Safety Science and Engineering (ASTM STP 882), T.Z. Harmathy, ed., Amer. Soc. for Testing and Materials (1985).

Babrauskas, V., and Krasny, J.F., Fire Behavior of Upholstered Furniture (NBS Monograph 173). Nat. Bur. Stand. (1985). 
The toxicity of single and multiple fire gases is being studied to determine whether the toxic effects of the combustion products from materials can be explained by the biological interactions of the primary fire gases or if minor, more obscure gases need to be considered. IC 50 values for Fischer 344 rats have been calculated for the individual gases, $\mathrm{CO}$, $\mathrm{HCN}$, or decreased oxygen, for 30 minute exposures plus relevant post-exposure periods using the NBS Toxicity Test Method. LC 50 values have also been determined for $C O$ and HCN (as individual gases) for exposure times of 1, 2, 5, 10, 20, and 60 minutes. To date, combination experiments with $\mathrm{CO}$ and $\mathrm{HCN}$ indicate that they act in a linearly additive manner for the $5,10,20,30$, and 60 minute time periods. A comparison was also made of the concentrations of the major combustion products generated from a number of materials at their LC $_{50}$ values with the combined gas model. The results indicate that the observed toxicity in 17 out of 24 cases can already be explained by the biological interactions of the examined primary toxic fire gases. This success ratio is expected to increase when several more primary gases can be included. These results already provide information for the fire hazard analysis computer model.

Levin, B.C., Gurman, J.I., Paabo, M., Baier, L., Procell, L., and Newball, H.H., Acute inhalation toxicity of hydrogen cyanide. The Toxicologist 6.59 (1986).

Gurman, J.L., Paabo, M., and Levin, B.C., An improved gas chromatographic method for the measurement of blood cyanide. The Toxicologist 6. 138 (1986).

\section{Analytical measurements of primary gas species}

The toxicological ("N-gas") model above is predicated on the ability to analyze the necessary gas species in a combustion environment. Gas concentrations have to be available which are valid despite the presence of a large number of potential interferents and which are time resolved (since the material pyrolysis process may exhibit a strong time-dependent character). For $\mathrm{CO}, \mathrm{CO}_{2}$, and $\mathrm{O}_{2}$ such an analytical capability has long been available. For a few other gases ( $\mathrm{HC} 2, \mathrm{HCN}$ ) recent efforts have been made to validate proposed methods. For other gases, however, time-resolved techniques with a well-characterized validity have typically not been available. To obtain this capability (to be used in conjunction with the cone calorimeter) a Fourier transform infrared spectrometer was installed and a concerted effort is under way to develop robust algorithms for time-resolved multi-component quantitation.

Babrauskas, V., Levin, B.C., and Gann, R.G., A New Approach to Fire Toxicity Data for Hazard Evaluation, ASTM Standardization NewS. 14, 28 33 (Sept. 1986).

5. Toxicological synergism between carbon monoxide and carbon dioxide.

The acute inhalation toxicities of $\mathrm{CO}$ and $\mathrm{CO}_{2}$ as individual and combined gases have been examined in rats. The $30 \mathrm{~min} L_{50}$ values for $C O$ in air were 4600 
ppm for square-wave exposures. No post-exposure deaths occurred from the $C O$. Animals exposed to $\mathrm{CO}_{2}$ concentrations ranging up to $14.7 \%$ for 30 min wereneither incapacitated nor fatally injured. The addition of non-lethal concentrations of $\mathrm{CO}_{2}$ ( 1.7 to 17.38 ) to sublethal concentrations of $\mathrm{CO}$ (2500 to $4000 \mathrm{ppm}$ ) caused deaths of the exposed rats both during and following (up to 24 hours) the 30 min exposures. At the most toxic combination of these two gases $\left(2500 \mathrm{ppm} \mathrm{CO}\right.$ plus $5 \% \mathrm{CO}_{2}$ ), the rate of formation of $\mathrm{COHb}$ was 1.5 times faster than that found in rats exposed to $2500 \mathrm{ppm}$ of $\mathrm{CO}$ alone. The COHb equilibrium levels, however, were the same (788). In addition, exposure to both $\mathrm{CO}$ and $\mathrm{CO}_{2}$ produced a much greater degree of acidosis than that generated by either of the gases singly. The results fit a mathematical model indicating a synergistic interaction within the range of the experiments.

6. Reviews of the literature on the gaseous products and toxicity generated from the pyrolysis and combustion of seven plastics

Detailed reviews of the literature on the thermal decomposition products and inhalation toxicity of seven plastics commonly found in residential homes were completed during the past year. A summary of all the reviews was also published during this time. The materials that were examined were ABS (NBSIR 85-3248), nylon (NBSIR 85-3280), polyester (NBSIR 85-3139), polyethylene (NBSIR 85-3268), polystyrene (NBSIR 85-3277), PVC (NBSIR 85-3286), and rigid polyurethane foam (NBSIR 85-3224).

Levin, B.C., A summary of the NBS Literature reviews on the chemical nature and toxicity of the pyrolysis and combustion products from seven plastics: acrylonitrile-butadiene-styrenes ( $A B S$ ), nylons, polyesters, polyethylenes, polystyrenes, poly(vinyl chlorides) and rigid polyurethane foams. NBSIR 85-3267 (1986).

7. Development of an in vitro bacterial assay system to assess combustion product toxicity

Initial studies examining the potential of an in vitro system utilizing aerobic bacteria to assess the relative combustion product toxicity generated from materials were made. The effects of pure toxic gases known to be generated in fires and other fire associated factors on the growth rate of the aerobic bacteria, Bacillus subtilis, were determined. Optical density of the bacterial culture was measured to determine growth. The culture was demonstrated to be insensitive to $C O$, but was encouragingly sensitive to $\mathrm{HCN}$, with a 200 ppm concentration producing a 5 -fold decrease in growth rate.

Rutkowski, J.V. and Levin, B.C., Development of an in vitro bacterial assay system to assess combustion product toxicity. The Pharmacologist 28. 209 (1986)

8. Toxicological comparison of large-scale room burns with small-scale experiments

This study involved a comparison between the toxicity results and chemical measurements obtained from small-scale tests on upholstered furniture compo- 
nent materials with test data obtained from full-scale furniture systems. The component materials were a flexible polyurethane foam with and without a fire retardant and a cotton fabric. Both room fire tests and furniture calorimeter measurements were conducted. Small-scale testing of the individual components were conducted in the NBS toxicity test method and in the cone calorimeter. The experiments, in general, showed broad agreement between bench-scale and full-scale, but significantly more data will have to be accumulated before an engineering strategy is finalized.

\section{Cigarette ignition study}

This work is being done under the Cigarette Safety Act of 1984. So far, the relative propensity of 12 currently-sold cigarettes was evaluated on a variety of substrates simulating upholstered furniture. The substrates varied in cover fabric and padding. The cigarettes were placed on the flat surface or into the crevice, and covered with a piece of fabric or left uncovered. The study showed some statistically significant differences in the ignition propensity among the cigarettes on some of the substrates. The results have not been extrapolated to the total population of furniture and mattresses in U.S. homes. A similar evaluation of 32 experimental filter and non-filter cigarettes varying systematically in tobacco blend, circumference, tobacco packing density, length, paper porosity, and smolder accelerant content has been completed, as has an evaluation of patented cigarettes designed to have low ignition propensity. The literature pertinent to the ignition by smoldering cigarettes of upholstered furniture and mattresses was searched. It was found that the smoldering behavior of cigarettes on substrates differs from that of cigarettes burning in air: cigarette temperatures on substrates tend to be lower, and burning rate slower. This reduction seems to be larger for substrates which ignite than for those which self-extinguish after the cigarette burns out. The characteristics of soft furnishings which ensure resistance to cigarette ignition have been established, but those of cigarettes with low propensity to ignite have not.

Krasny, J.F., and Gann, R.G., Relative Propensity of Selected Commercial Cigarettes to Ignite Soft Furnishings Mockups. NBSIR 86-3421 (1986).

\section{Associated Grants}

1. Argonne National Laboratory, Joseph R. Stetter - Feasibility of Field. Detection and Analysis of the Toxic Products of Combustion.

2. Brown University, Merwin Sibulkin - Study of Effects of Material Properties on Flaming Combustion of Charring Fuels.

3. Factory Mutual, Archibald Tewarson - Development of a Model to Brovide Comprehensive Fire Property Data.

4. SRI International, Charles S. Rebert - Electrophysical Incapacitation and Persistent Behavioral Dysfunction of Rats Associated with Combined Exposure to Carbon Monoxide and Carbon Dioxide. 
5. Southwest Research Institute, Gordon Hartzell - Analysis of Hazards to life Safety in Fires.

6. University of Dayton Research Institute, Mark Dietenberger - Mathematical Modeling of Furniture Fires.

7. University of Pittsburgh, Yves Alarie - Toxicity of Plastic Combustion Products. 


\section{HAZARD ANAIYSIS \\ FIRE SAFETY TECHNOLOGY DIVISION \\ FY 86}

\section{Professional Personnel}

Richard W. Bukowski, P.E., Head

Bernard M. Levin, Research Psychologist

A. Jeffrey Shibe, Research Fire Protection Eng.

S. Wayne Stiefel, Operations Research Anal.

Walter W. Jones, General Physical Scientist

John H. Klote, Research Mechanical Eng.

Kevin Greenaugh, General Engineer

Daniel M. Alvord, Computer Specialist

Keith Wayland, IPA (Visiting Faculty)

Peter M. Dubivsky, Research Assoc. (UL)

A. Sekizawa, Guest Worker

\section{Program Objectives}

To develop predictive, analytical methods which enable the quantitative assessment of hazard and risk from fires.

\section{Scope}

The predictive methods being developed are based on numerical modeling, but also include hand calculation methods for estimating hazards, and production of design curves/tables for use by architects and engineers. To ensure use, necessary data must be readily available, and data input and presentation must be in terms readily understandable by the average professional. Thus, the projects include a strong emphasis on state-of-the-art computer graphics and computer aided design techniques.

\section{Projects}

1. Toxic Hazard Assessment Models

The objective of this project is to develop quantitative methods to predict the development of occupant hazard in building fires. The main thrust of the group (and the Center) this past year has been the completion and publication of the first version of the Hazard Assessment Method - HAZARD I. This consists of a three volume report and a set of $51 / 4$ in. disks containing the software necessary to conduct hazard analyses of products used in residential occupancies. All of the software provided will operate on any IBM PC (XI or AT) or compatible computer. The programs include a scenario development guidance utility; an interactive program for inputing data to the fire model; a data base program and files of thermophysical, thermochemical, and reference toxicity data; the FAST model for multi-compartment energy and mass transport; a graphics utility for plotting data; a detector/sprinkler activation model; an evacuation model which includes human decision/behavior; and a tenability model which evaluates the impact of the predicted exposure of the occupants in cerms of incapacitation or lethality from temperature or toxic gases or incapacitation by second degree burns from radiant flux exposure. 
Also included in the report is a set of nine representative example cases of typical residential fires as established by two panels of outside experts. These are three fire scenarios, selected by a panel composed of representatives of the major fire services organizations, in each of three single-family residences (three bedroom ranch and townhouse, and four bedroom two-story), which were felt to represent typical homes by a panel from the model building codes, NFPA, and the architectural community. In addition to serving as examples of the use of the system, these cases can be used as a baseline against which the change in hazard associated with products of interest can be measured, and as a resource of typical buildings for evaluating specific products, or fire scenarios for evaluating building designs and their fire protection features.

While the scope of this first hazard assessment method is limited to residential occupancies, the work necessary to extend it to other occupancy classes is underway. This first version is being introduced in order to begin the process of familiarization of the fire protection community with the method and its use in addressing the critical issues facing them. In addition, feedback from users, both positive and negative, is crucial to identify the improvements necessary to maximize the usefulness of the method in addressing these issues.

Bukowski, R. W., et al. HAZARD I - Vol. 1: Hazard Assessment Method, Vol. 2: Representative Example Cases, and Vol. 3: Data Base Listing, NBS Special Publication, in press.

Bukowski, R. W., Evaluation of Furniture Fire Hazard Using a Hazard Assessment Computer Model, Fire and Materials, Vol. 9, No. 4, 1985.

Bukowski, R. W., Quantitative Determination of Smoke Toxicity Hazard - A Practical Approach for Current Use, Fire Safety Science - Proceedings of the First International Symposium, Pagni, P.J. and Grant, C.E., eds., Hemisphere Publishing Corp. NY, NY, pp 1089-1100, 1986.

\section{Building Smoke Transport Model}

This work consists of development of a computer model to simulate smoke movement throughout large buildings including simulation of the effects of HVAC systems, smoke control systems, inside to outside pressure difference, wind and smoke buoyancy. This model will consist of a number of subroutines for smoke transport under specific conditions which can be used with other fire models. The zone model FAST, for example will be used to simulate smoke movement within the building compartments. Ultimately, when models of smoke flow in corridors and shafts are developed these too will be incorporated.

A model of smoke movement through HVAC systems has been written which predicts the flow of smoke and gases through the components at a HVAC system as a function of time. It is a network model of general nature such that the most simple to the most complicated HVAC system can be simulated. Documentation and numerical verification are currently underway.

In recent years, the possibility of using elevators as a means of fire escape, particularly by the handicapped, has received considerable attention from the fire protection community. Thus, a joint project was initiated between NBS 
and the National Research Council of Canada to investigate the feasibility of elevator smoke control systems.

Full scale tests are underway at the 10-story NRCC fire research tower in Ottawa to verify the results of predictions of elevator smoke control performance which used the computer program ASCOS developed at NBS. An analysis of elevator piston effect without smoke control has been completed to help answer questions about the pressures produced by elevator car motion. An analysis of piston effect during smoke control system operation is currently being conducted.

Klote, J.H. and Tamura, G.T., "Piston Effect and Smoke Problem", submitted to Fire Safety Journal for publication.

\section{Smoke Transport Modeling}

The primary objective of this project is modeling the growth of fires and the spread of smoke and toxic gases. Interest runs the gamut from the room of fire origin to compartments which are sufficiently distant to be in the "far field" of the fire. The goal is to provide a model which allows one to generate a description for a building and the insult to which it is subjected, then to model the course of the fire, and finally generate an easily understood description of the results. A secondary objective is connecting laboratory scale experiments with full scale fire performance of materials and buildings. The thrust is to be able to predict the outcome of a fire given appropriate measurements which can be conducted in a laboratory. If successful, this application of the model will allow a great economy of scale as most materials and configurations necessary for performance testing can be done in the laboratory.

Verification and validation are ongoing projects to check the accuracy of the model predictions. It is an important step in the acceptance of such a technique by the engineering and code communities. Recently, a series of experimental studies was completed using the NBS full scale test facility and the corresponding theoretical predictions. The present work is aimed at identifying the strengths and weaknesses of the current model prior to adding such features as ventilation systems, or self-consistent burning furniture.

The work has focused on two roots of the modeling tree. First is to develop fast and reliable numerical software. Second, we must be sure that the physical models to be incorporated are consistent and to the extent possible, complete. Recently, an important improvement has been made in the latter aspect.

The current suite of programs consists of an input program(MINPUT), the simulation model(MOST) and a program for displaying the output(MPLOT).

Jones, W.W. and Bodart, X., Buoyancy Driven Flow as the Forcing Function of Smoke Transport Models, NBSIR 86-3329 (1986).

Jones, W.W., A Model of Smoke Transport (MOST), submitted to Fire Safety Journal. 
Jones, W.W. and DeWitt, C., Heat Transfer through Multilayer Boundaries: Implementation and Validation, 2nd ASME-JSME Thermal Engineering Joint Conference, Honolulu.

Peacock, R., Davis, S., Lee, B., Jones, W., and Steel, S., Experimental Data for Modeling Validation, in review.

\section{Computer Graphics}

The objective of the graphics task is to support the modeling effort by providing results of the model calculations which can be readily interpreted. A secondary purpose is to provice in-situ visualization of experimental data to aid in understanding the processes which occur as a fire grows and spreads. We are working with state-of-the-art equipment and software, much of the latter being specifically developed for this work.

Jones, W.W. and Fadell, A., A Device Independent Graphics Kernal, NBSIR 86-3235 (1985). 


\section{POLYMER COMBUSTION RESEARCH \\ FIRE MEASUREMENT AND RESEARCH DIVISION \\ CENTER FOR FIRE RESEARCH}

FY 86

\section{Professional Personnel}

\section{Takashi Kashiwagi, Head}

Walter M. Shaub, Research Chemist

James E. Brown, Research Chemist

Lisha Glinsman, Research Chemist

William Manders, Research Chemist

Thomas J. Ohlemiller, General Engineer

William J. Parker, Physicist

Jeffrey Didion, Mechanical Engineer

Elizabeth Finlayson, Guest Worker

Akihiko Ito, Guest Worker

\section{Program objectives}

(1) Improve the understanding of the chemical and physical processes which underlie macroscopic fire phenomena. The research embraces broad areas covering both solid and gas phase processes, with particular attention to phenomena in the solid phase such as degradation chemistry and heat and mass transport processes in the solid phase.

(2) Devise new techniques and methods for studying these phenomena.

(3) Furnish fundamental scientific information to support the other activities within the Center for Fire Research.

\section{Scope}

Chemical and physical processes associated with ignition, flame spread and smoldering of polymeric materials are being studied. The approach of this group is basic and aims to understand the mechanisms of polymer degradation (natural and synthetic polymers), heat and mass transport processes in the solid phase and to obtain thermal properties of the material.

\section{Project}

\section{Polymer Gasification and Ignition}

The prediction of ignition, flame spread, steady burning and flashover requires a knowledge of the rate of gasification of solids. The rate of gasification is determined by the rate of energy input from an external source and/or of energy feedback from a flame to the material, by the degradation chemistry, and by the heat and mass transport processes in the material. The complex coupling between degradation chemistry and heat and mass transport processes in the material is the major reason why we cannot predict the rate of gasification of solid materials. Therefore, the objective of this project is to increase our understanding of the degradation chemistry, heat and mass 
transport processes in polymeric materials (synthetic polymers as a first step) through a carefully designed program of theoretical and experimental research.

Careful experimental studies show that the "weak links" in PMMA are head-tohead linkages and unsaturated double bonds at the ends of polymer chains. Their effects on degradation rates were demonstrated using specifically polymerized PMMA samples supplied from the University of Osaka (Professor $\mathrm{K}$. Hatada). The effects of initial molecular weight and ambient oxygen on degradation initiation from these weak linkages were studied. Results show that ambient oxygen stabilizes the degradation initiated from scission at head-to-head linkages by trapping polymer radicals created from the scission. Also, ambient oxygen slightly stabilizes end-initiated degradation but it enhances the rate of degradation greatly at high temperatures.

Two theoretical models were developed to calculate changes in weight loss and in the molecular weight distribution of a vinyl polymer without any transport processes. The degradation reaction scheme consists of end initiation, random scission initiation, depropagation, termination and transfer reactions. This model is based on the approximation of a steady state radical concentration. Effects of initial molecular weight on changes in weight loss and in the molecular weight are being studied and compared between the predicted results and the experimental data using the above PMM samples. Another theoretical model was developed to examine the validity of the commonly used approximation of a steady state radical concentration. A degradation reaction scheme consisting of random initiation, depropagation and termination reactions was used for this study. Results indicate that an unusual buildup of monomer radicals is observed without specific treatment of the monomer radicals such as enhanced rate of monomer radical transfer reaction or immediate vaporization of monomer radicals. Guidelines for the approximation to be reasonable are derived for the range of characteristic parameters such as normalized zip length and radical number per initial chain length.

A technique to measure the time-dependent temperature distribution in a transparent polymer was developed. This technique is based on holographic interferometry. The technique was applied to measure the temperature distribution in PMMA when flame spreads over the surface. Conductive flux distributions (along and perpendicular to the surface) in PMMA were derived to understand how the flame spread over the polymer surface. This technique is being applied to measure time dependent temperature distributions in PMMA which is headed by external radiation.

"A Model Describing the Steady-State Pyrolysis of Bubble-Forming Polymers in Response to an Incident Heat Flux" by Wichman, I. Combustion and Flame, 63, 217 (1986).

"Differences in PMMA Degradation Characteristics and their Effects on its Fire Properties" by Kashiwagi, T., Inaba, A., and Brown, J.E., Proceedings of First International Symposium, Hemisphere, 483 (1986).

"Effects of Weak Linkages on Thermal and Oxidative Degradation of Poly (methyl methacrylate)" by Kashiwagi, T., Inaba, A., Brown, J.E., Hatada, K., Kitayama, T., and Masuda, E., Macromolecules, (in press). 
"A Calculation of Thermal Degradation Initiated by Random Scission. 1. Steady-State Radical Concentration" by Inaba, A., and Kashiwagi, I., Macromolecules (in press).

"A Calculation of Thermal Degradation Initiated by Random Scission. 2. Unsteady Radical Concentration" by Inaba, A., and Kashiwagi, T., Macromolecules (submitted).

"A Measurement Technique for Determining the Temperature Distribution in a Transparent Solid Using Holographic Interferometry" by Ito A., and Kashiwagi, T. Applied Optics (submitted).

"Temperature Measurements in PMMA During Downward Flame Spread in Air Using Holographic Interferometry" by Ito A., and Kashiwagi, T. TwentyFirst International Symposium on Combustion (in press)

\section{Smoldering Combustion of Cellulosics}

The propensity for smoldering exhibited by cellulosic materials continues to be a subject of major concern. Smoldering combustion is driven by exothermic oxygen attack on the surface of organic materials; wood-based materials such as cellulosic insulation are particularly prone to this attack. The process is slow but self-sustaining once initiated. It poses a life threat as a copious source of toxic gases. Also, it provides a relatively easy pathway to flaming combustion that may not be precluded by flave retardants. It is this latter aspect--smoldering as an initiator of flaming--which has been examined recently for cellulosic insulation materials. Smolder to flaming tests were conducted using unretarded cellulosic insulation material and insulation with either boric acid (a smolder-retardant) or borax (a flame retardant). Both suppress flaming effectively when the smoldering insulation is isolated from other flammable material. Much of their effectiveness is lost when unretarded wood abuts the smoldering insulation since the wood itself ignites.

Smolder spread over solid wood is to be examined in a series of experiments now getting underway. Initial emphasis will be on the effective equivalence ratio and major gasification products. The details of the degradation of wood and its components are also of continuing interest. Solid-state NMR is being used to characterize the early steps of degradation of lignin and hemicelluloses.

\footnotetext{
"Forced Smolder Propagation and the Transition to Flaming in Cellulosic Insulation", by Ohlemiller, T., NBSIR 85-3212, October 1985.

"Modeling of Smoldering Combustion Propagation" by Ohlemiller, T., Progress in Energy and Combustion Science, 11, 277 (1985)
}

3. Fundamentals of Wood Gasification and Combustion

This work is aimed at clarifying and quantifying the physical and chemical processes underlying gasification of wood at fire level heat fluxes and the conditions required to oxidize the resultant gases. Major support comes from the Department of Energy. 
An extensive set of one-dimensional radiative heating tests on thermally thick wood samples has been completed; these included the effects of wood type, grain orientation, water content, thickness, flux and ambient oxygen level on gasification rate and product composition. The conditions required to fully oxidize certain of these products are currently being explored in a laminar flow reactor. Also a modeling study is underway to develop time-temperature plots which describe the combustibility of representative gasification products under oxidative and pyrolytic conditions. To construct these plots, rate constants for oxidation and pyrolytic degradation of specific organic compounds have either been extracted from the literature or estimated.

\footnotetext{
"Products of Wood Gasification" by Ohlemiller, T., Kashiwagi, T. and Werner, K., NBSIR 85-3127 (April 1985).

"Wood Gasification at Fire Level Heat Fluxes", Ohlemiller, T., Kashiwagi, T. and Werner, K., submitted to Combustion and Flame.
}

\section{Heat Release Rate of Wood}

A preliminary model has been developed for the heat release rate of wood as a function of the incident radiant flux, thickness, moisture content, rear surface boundary conditions and the thermophysical and thermochemical properties. The thermophysical properties include the density, thermal conductivity and specific heat. The thermochemical properties include the heat of combustion of the volatiles, the heat of pyrolsis and the kinetic parameters which describe the rate of mass loss. These properties are taken to be a function of the temperature and the residual mass fraction and in the case of the thermochemical properties must be determined separately for all of the major chemical components of the wood. The model has been setup on IBM computer and the major thrust of the project for the past year has been to experimentally determine the required input properties for checking out the model against heat release rate measurements in the cone calorimeter.

A combination pyrolyzer and catalytic converter (PYROCAT) was constructed and used at the Forest Products Laboratory during the summer of 1985 to obtain data on the heat of combustion of the volatiles and the kinetic parameters for the chemical components of Douglas fir heartwood. These components included cellulose, lignin, mannan and xylan. This was followed by a period of data interpretation and a rebuilding of the apparatus in order to improve upon the precision of the results. Some preliminary work has been done on the development of a method for measuring the thermal diffusivity of the char at elevated temperature.

The measurement of the required property data for every type of wood would be a tedious process. However, all woods are, to a reasonable degree of approximation, made up of some combination of a small number of chemical components in different proportions and the thermal conductivity of wood, at least near room temperature, is a well known function of the density.

Therefore, the possibility exists for predicting the required properties of the wood and their temperature and residual mass fraction dependence from a small set of more easily determined parameters such as the density and the chemical composition. Thus future research on this project will include the development of models for the properties themselves. Since wood is a very 
complex material this can only be done in an approximate way but it may be adequate for fire modelling purposes.

"Development of a Model for the Heat Release Rate of Wood - A Status Report" by Parker, W., NBSIR 85-3163, Nat. Bur. Stand. (U.S.), (May 1985).

"Prediction of the Heat Release Rate of Wood" by Barker, W., Proceedings of the First International Symposium on Fire Safety Science, Hemisphere Publishing Corporation, 1986, pp 207-216.

\section{Associated Grants and Contracts}

1. "Ternary Reactions Among Polymer Substrate-Organohalogen-Antimony Oxidez in the Condensed Phase Under Pyrolytic, Oxidative and Flaming Conditions", Michael J. Drews and Christine W. Jarvis, Clemson University

2. "A Study of the Effects of Oxygen Transport, and Temperature History on the Chemistry of Polymethyl Methacrylate and Cellulose Pyrolysis", Eric M. Suuberg, Brown University.

3. "Flame Radiation", Chang-Lin Tien, Lawrence Berkeley Laboratory.

4. "Kinetics of Oxygen Chemisorption and Desorption of Combustion Products in the Smoldering Combustion of Cellulosic Material", G. Richards, U. of Montana.

5. "Thermal Stabilization of Polymers by Cross-Link Formation", C. Wilkie, Marquette University.

6. "Interaction of Radiation and Condition in Polymeric Materials, W. Aung, University of Maryland. 


\section{Smoke Dynamics Research Group \\ Fire Measurement and Research Division \\ Center for Fire Research \\ FY 86}

\section{Professional Personnel}

George W. Mulholland, Head

Nelson P. Bryner, Chemical Engineer

W. Gary Mallard, Research Chemist

William M. Pitts, Research Chemist

Kermit C. Smyth, Research Chemist

James Gentry, Guest Worker

Victor Henzel, Guest Worker

J. Houston Miller, Faculty Research Associate

K.C. Muck, Guest Worker

Roberto Samson, Guest Worker

\section{Program Objectives}

Develop scientifically sound principles, metrology, data, and predictive methods for the formation/evolution of smoke components in flames for use in understanding and modeling general fire phenomena.

\section{Scope}

This work embraces broad areas underpinning CFR programs with focussed study in the areas of hot gas physics and chemistry. Effects are directed toward improved understanding of the chemical and physical processes which underlie macroscopic fire phenomena and include development of new techniques and methods for studying these processes.

\section{Soot Formation Chemistry and Physics}

Flame radiation from incandescent soot dominates flame spread and heat transfer in large fires. Escaping particulates hinder vision and impair breathing, as well as being a sensitive signature for fire detection. Despite this importance, there is little understanding at the molecular level of the soot formation process; i.e., how small molecules grow rapidly to become soot particles. We are now in the seventh year of a long-term study of the fundamental chemistry and physics of soot formation, carried out jointly with the NBS Thermal Processes Division in the Center for Chemical Engineering and also in collaboration with the Chemical Kinetics Division in the Center for Chemical Physics.

A series of optical and mass spectrometric profile measurements have been completed for methane/air diffusion flames on our Wolfhard-Parker burner. We have used fluorescence to monitor $\mathrm{OH}, \mathrm{C}_{2}$, and polycyclic hydrocarbons (three ways), multi-photon ionization to detect methyl radicals and small soot 
particles and Rayleigh-mie scattering to observe the emergence of large soot particles. In addition, mass spectrometric profiles of $\mathrm{CO}_{2}, \mathrm{H}_{2} \mathrm{O}$, methane, acetylene, butadiene, benzene, toluene, diacetylene, triacetylene, vinyl acetylene, methylacetylene, and allene have been taken. These results clearly delineate the region of soot nucleation: soot particles first appear on the high temperature, radical-rich side of a zone containing numerous pyrolysis products. Velocity measurements using laser Doppler velocimetry and thermocouple temperature profiles have also been obtained. The combined data provide the most detailed description of the chemical structure in a hydrocarbon diffusion flame obtained to dace.

The species profiles have been analyzed to determine production and destruction rates of intermediate hydrocarbons in our methane/air diffusion flame. These results show that acetylene plays the major role in surface growth on particles (as found in premixed flame studies). Furthermore, direct tests of proposed models of chemical growth can now be made which strongly suggests that a pathway involving vinyl radical addition to acetylene is the fastest route to form benzene.

In addition to species characterization studies, physical properties of soot are being investigated. The kinetics of cluster aggregation and structure of the resulting clusters have been studied using a "Brownian dynamics" computer simulation of conditions appropriate for soot growth. These simulations are now being extended with the new NBS Cyber 205 to increase the number of particles in an agglomerate from about 200 to 2000 and to include rotational diffusion as well as translational diffusion. The observed microstructure of soot produced by a coannular diffusion flame with acetylene was found to be in good agreement with the computer simulations. Theoretical and experimental work is in progress to study the optical and aerodynamic properties of soot.

The smoke emission coefficient and the light extinction coefficient have been measured for smoke produced by free burning propane, heptane, wood cribs, rigid polyurethane, Prudhoe Bay crude oil, and upholstered chairs. The fires range in scale from about 50 to $500 \mathrm{kw}$. The elemental carbon content and the optical properties of the smokes appear to be independent of the material burning. This study is in support of the Defense Nuclear Agency study of the global climatic effects of a major nuclear exchange.

"Soot Inception in a Methane/Air Diffusion Flame as Characterized by Detailed Species Profiles" by Smyth, K.C., Miller, J.H., Dorfman, R.C., Mallard, W.G. and Santoro, F.J., Comb. \& Flame, 62, 157 (1985).

"Detection of the Methyl Radical in a Methane/Air Diffusion Flame by Multiphoton Ionization Spectroscopy" by Smyth, K.C. and Taylor, P.H., Chemical Physics Letters, 122, 518 (1985).

"Multiphoton Ionization Spectra of trans-1, 3-Butadiene: Reassignment of a Rydberg Series" by Taylor, P.H., Mallard, W.G., and Smyth, K.C., I. Chem. Phys. 84. 1053 (1986).

"The Chemical Structure of Methane/Air Diffusion Flames: Concentrations and Production Rates of Intermediate Hydrocarbons" by Miller, J.H. and 
Smyth K.C., Symposium on Chemical Mechanisms Associated with Combustion, American Chemical Society National Meeting (April, 1986).

"Methyl Radical Concentrations and Production Rates in a Laminar Methane/Air Diffusion Flamen by Miller, J.H. and Taylor, P.H., Combustion Science and Technology (in press).

"Chemical Production Rates of Intermediate Hydrocarbons in a Methane/Air Diffusion Flame" by Miller, J., Mallard, W.G., and Smyth, K.C., TwentyFirst Symposium (International) on Combustion (in press).

"Reactions of Phenyl Radicals with Ethene, Ethyne, and Benzene" by Fahr, A., Mallard, W.G., and Stein, S.E., Twenty-First Symposium (International) on Combustion (in press).

"Soot Particle Formation in Laminar Diffusion Flames" by Santoro, R.S. and Miller, J.H., Langmuir (submitted for publication).

"Global Soot Growth Model" by Mulholland, G.W., Proceedings of the First Internation Fire Safety Science Symposium, edited by C.E. Grant and P.J. Pagni (Hemisphere Publishing Corp., Washington), 709. (1986).

"On the Applicability of Smoluchowski's Equation with a Constant Kernel to Covalescence" by Mulholland, G.W. and Mountain, R.D., J. Chem. Phys. 84,4109 (1986).

"Simulation of Aerosol Agglomeration in the Free Molecular and Continuum Flow Regimes" by Mountain, R.D., Mulholland, G.W., and Baum H., J. Colloid and Interface Science (in press).

"Smoke Production and Properties" by Mulholland, G.W., Society of Fire Protection Engineers Handbook (in press).

"Fractal Analysis of Soot Agglomerates" by Samson, R.J., Mulholland, G.W., and Gentry, J.W., Langmuir (submitted).

2. Estimation of CO Emission in Room Fires

It is known that $C O$ is a major contributor to most fire related deaths. The goal of this new project is the prediction of CO emission both pre and post flashover. Available data on room burns is now being analyzed along with results from the Cone Calorimeter.

3. Turbulent Chemically-Reacting Flow

In a large fire plume, the combustion region is turbulent and is characterized by highly variable (both spatial and temporal) distributions of temperature and species concentration. In such cases the flame properties are dominated by the substantial temperature and species concentration fluctuations. Due to the scarcity of measurements on such systems and the complexity of the phenomena, the understanding of turbulent fire plumes is poor. This project is designed to be a basic experimental study of chemically reacting flow in which the effects of density differences due to composition, temperature, and heat release on turbulent mixing are elucidated. 
The project has required the development of new experimental diagnostic techniques as well as the applications of these techniques to measurement in turbulent flow fields. Up to the present time we have been primarily concerned with the effects of density differences due to composition on the mixing behavior of an axisymetric jet flowing into a slow coflow of a second gas. The findings of these studies are being used in attempts to better understand turbulent mixing in certain types of combustion systems.

Rayleigh light scattering has been shown to be a particularly powerful technique for monitoring real-time, spatially-resolved concentration fluctuations in these flow fields. By combining the light scattering technique with hot-wire anemometry a new diagnostic for simultaneous concentration and velocity measurement has been developed. As a part of this work an extensive experimental study of the responses of hot-wire and film anemometers to flows of different gases was initiated. This study has not only improved our understanding of these velocity measurement devices, but has also yielded a much improved understanding of heat transfer from cylinders.

As part of our diagnostic development a digital line camera has been designed and fabricated at NBS. This camera is designed to be sensitive enough to allow real-time measurements along a line in these turbulent flow fields using Rayleigh light scattering. Preliminary measurements have shown that this goal has been achieved. The use of this camera will allow a much improved characterization and understanding of entrainment and mixing in turbulent flows.

An extensive study of turbulent mixing behavior along the centerline of the axisymmetric jet has been completed. Both flow visualization using shadowgraphy and Rayleigh light scattering point measurements have been used to investigate flows having jet/coflow density ratios covering the range from 0.14 to 37 . The availability of measurements over such a wide range of densities has enabled many density effects to be discerned. A manuscript describing this work is available.

\footnotetext{
"Response Behavior of Hot-Wires and Films to Flows of Different Gases" by Pitts, W.M. and McCaffrey, B.J., NBSIR $85-3203$ and Journal of FIuid Mechanics, 169 (1986), to Appear.
}

"Effects of Global Density and Reynolds Number Variations on the Mixing in Turbulent Axisymmetric Turbulent Jets" by Pitts, W.M., NBSIR 86-3340 and submitted to the journal of Fluid Mechanics.

"Chemically Reacting Turbulent Flow" by Pitts, W.M. and Kashiwagi, I. , NBSIR. 85-3299.

\section{Associated Grants and Contracts}

1. "Soot Dynamics in Flames", Richard A. Dobbins, Brown University.

2. "Chemical Pathways to Soot Formation in Diffusion Flames", J. Houston Miller, George Washington University 
CENTER FOR FIRE RESEARCH

NATIONAL BUREAU OF STANDARDS

FY 1986

Inst1tution: Argonne National Laboratory

Grant No.: 40 NANB5 11448

Grant Title: Feasibility of Field Detection and Analysis of the Toxic Products of Combustion

Principal Investigator: Dr. Solomon Zaromb, Electrochemical Engineer

Environmental Research Division

Argonne National Laboratory

9700 South Cass Avenue

Argonne, Illinois 60439

Telephone: (312) 972-6423

Other Professional Personnel: Dr.W.J. Buttmer, Electrochemical Engineer

Dr. V.C. Stamoudis, Program Manager

D. Domin, Research Participant

J. Privette, Research Participant

NBS Scientiflc Officer: Dr. Emil Braun

Technical Abstract:

Introduction. The primary objective of this work is to evaluate the applicability of chemical parameter spectrometry (CPS) and allied techniques to the design and construction of an instrument for the detection and analysis of the toxic products of combustion. The capability sought in the near term is field detection and selective quantitation of at least five toxic compounds of primary interest in the presence of other combustion products. Ultimately, the instrument will be expanded to provide analyses of all or most of the toxic products formed during combustion that present a danger to human health.

CPS consists of measuring a number of different "chemical parameters" obtalned from sensor responses to a given analyte and thus developing a characteristic response pattern or "parameter spectrum." A comparison of that spectrum with previously determined parameter spectra for a varlety of compounds may then permit identification of an unknown compound in the analyte.

The fundamental problem is to determine how CPS can be usefully applied to the identification of toxic components in complex gaseous mixtures of possibly 20 or more compounds. This problem has been addressed, after reviews of the instrument design goals and of the potentially usable instrumental techniques, by the following two-pronged approach: (1) extension of the capabilities of CPS to mixtures of up to three or four detectable compounds, and (2) fractionation of complex combustion product mixtures lnto simpler mixtures of not more than three or four of such compounds. 
Applicability of CPS to Simple Mixtures. A portable instrument based on CPS has been recently developed for detecting, identifying, and monitoring any one of 20-30 compounds in ait at concentrations in the parts per-million range. This instrument utilizes the relative strenghts of 16 sensor responses, obtained by operabing four different electrochemical sensors in four different modes, to generate response patterns characteristic of each compound. Sensor responses to electrochemically inactive compounds are obtained in three of the four operating modes. Such compounds are partly preoxidized or pyrolyzed by passing them over a noblemetal filament heated to an elevated temperature. Response patterns obtained for 16 combustion product compounds permit easy identification of each of these compounds, when present singly in air, by means of a patternmatching algorithm. An algorithm has also been developed that extends the capability of CPS to mixtures of detectable compounds. It uses preliminary screening steps that reduce the number of candidate compounds to the number of Independent simultaneous equations obtainable from the sensor response data. The concentrations of the detected compounds are then computed by solving the simultaneous equations. Error analysis is used to evaluate the probable errors in the computed concentrations. To test the effectiveness and reliability of this algorithm, sensor response patterns generated by all possible ternary and binary combinations of six representative components of combustion products $\left(\mathrm{CO}, \mathrm{H}_{2} \mathrm{~S}, \mathrm{SO}_{2}, \mathrm{NO}_{2}, \mathrm{H}_{2} \mathrm{CO}\right.$, and $\left.\mathrm{CH}_{2}=\mathrm{CN}\right)$ have been gathered on disk files. These patterns are entered into the computer as unknown samples, and the computed concentrations are compared with the actual composition of each tested mixture. The data and comparison results are currently being evaluated.

Fractionation of Complex Combustion Product Mixtures. To achieve the near term goal of field detection and quantitation of five selected compounds, e.g., $\mathrm{CO}, \mathrm{COF}_{2}, \mathrm{NO}_{2}, \mathrm{HCN}$, and $\mathrm{SO}_{2}$, it may suffice to remove most of the other combustion products by means of selective chemical filters, and use an array of sensors that are specifically responsive to these five compounds. However, such an approach could not easily lead to a field instrument that could provide analyses for all or most of the toxic compounds in combustion products.

A fractionation technique that has been successfully applied to complex mixtures is gas chromatography (GC), and several portable GC instruments are commercially available. By replacing or supplementing the non-selective detector in present GC instruments with a selective CPS sensor array, it becomes possible to unambiguously identify each simple chromatographic peak and to resolve overlapping peaks of not more than three or four components. While it may be difficule to obtain a single GC column or even a pair of columns that could iractionate a combustion product mixture into single-compound peaks, it appears to be relatively simple to obtain a single column capable of fractionating such a mixture into peaks of fewer than four compounds, and usually even fewer than three or two compounds. The previously developed pattern-matching algorithm can then serve to verify that any observed single-compound peak does indeed correspond to that deduced from its retention time. Any observed 
overlapping peak may be resolvable by the algorithm that has been developed for the analysis of simple mixtures.

Current efforts consist of passing various mixtures of compounds encountered in combustion products through a packed $G C$ column and hence through a CPS sensor array. The results of these experiments will be used to evaluate the practicality of a portable GC/CPS instrument for the field analgsis of combustion products. Figure 1 shows the non-selective response of a flame ionization detector (FID) to a mixture of benzene and acetonitrile (Fig. 1B), as well as the responses of electrochemical sensors in two modes of operation (Figs. IA and $1 C$ ). Although two distinct peak maxima were observed with the FID, baseline resolution was not obtained. In contrast, the response depicted in $1 \mathrm{~A}$ is due almost solely to benzene, whereas that depicted in $I C$ is due to acetonitrile. Thus the use of the electrochemical array improves the selectivity of the detector. Such selectivity will be crucial for mixtures whose components cannot be easily resolved by retention times alone.

\section{Papers:}

1. S. Zaromb and J.R. Stetter, "Theoretical Basis for Identification and Measurement of AIr Contaminants Using an Array of Sensors Having Partly Overlapping Selectivities, "Sensors and Actuators, 6:225-243 (1984).

2. S. Zaromb, D. Domin, and R. Battin, "Experimental Evaluation of Mixture Analysis Using an Array of Amperometric Sensors," 13 th Annual Meeting of the Federation of Analytical Chemistry and Spectroscopy Societies (1986). 

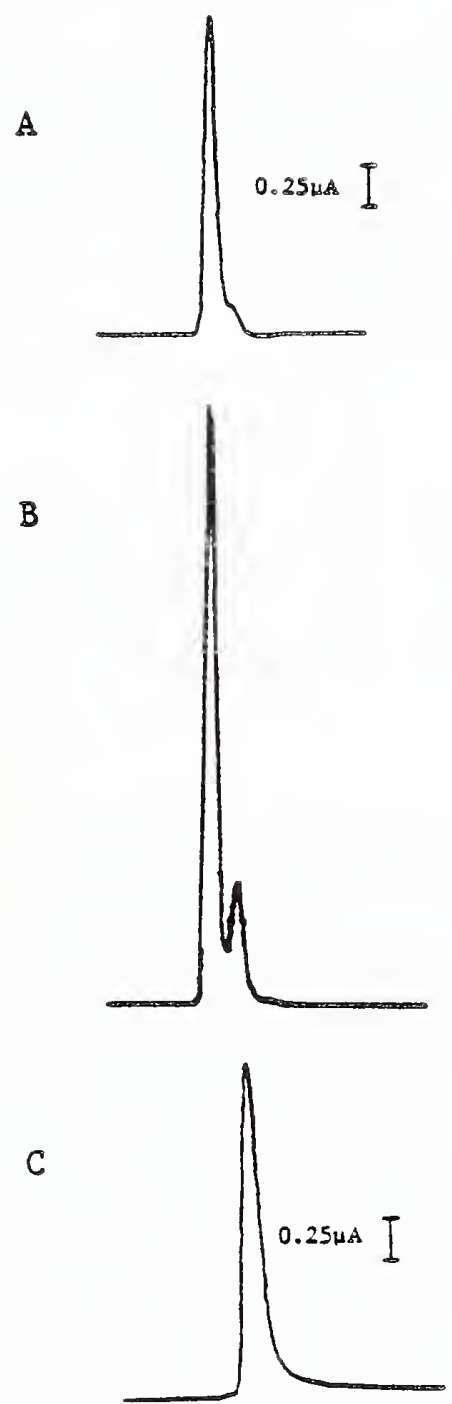

Figure 1. Illustrative CPS responses to a benzene-acetonitrile mixture. (A) Current-time response of a commercial CO detector when the GC eluent was passed over a heated platinum filament. (B) FID response. (C) Current-rime response of a gold sensor (biased to $+300 \mathrm{mV}$ vs. an air reference electrode) to the eluent from the FID. 


\section{CENTER FOR FIRE RESEARCH \\ NATIONAL BUREAU OF STANDARDS \\ FY 86}

\section{Institution: Brown University}

\section{Grant No: $\quad$ 60NANB4D0036}

Grant Title: A Study of the Effects of Oxygen Transport and Temperature History On the Chemistry of PMMA and Cellulose Pyrolysis

\section{Principal Investigator: Professor Eric $M$. Suuberg}

Division of Engineering

Brown University

Box D

Providence, Rhode Island 02912

Telephone: (401) 863-1420

\section{Other Professional Personnel: Tracy Kelly, Graduate Student}

William Lilly, Research Engineer

\section{NBS Scientific Officer: Dr. Takashi Kashiwagi}

\section{Technical Abstract:}

Introduction: The goal of this project is an elucidation of the effect of several key variables on the chemistry of pyrolysis of polymethyl methacrylate (PMMA) and cellulose. These variables include the heating rate of the sample, the partial pressure of oxygen at the surface of the sample, and sample characteristics as affect the transport of pyrolysis products out of the sample. Detailed product analysis of both vapor and condensed phase products of pyrolysis are used to infer under what conditions already established or suggested chemical mechanisms may or may not be applied to fire modeling situations. In the case of PMMA, vapor products mainly consist of monomer. The condensed phase products are characterized by gel permentation chromatography (GPC), providing information concerning the degree of polymerization as a function of cited variables. The analysis of vapor and liquid products of cellulose pyrolysis is somewhat more complex. Particular attention will be given to characterization of what are commonly called "tar" products, since these are the products that represent the most combustible vapor products. GPC will be uscd to characterize these materials, providing information about molecular weight distributions and hence, vapor pressures of the products.

This project is presently at the midpoint of its second year. The initial focus has been the pyrolysis of PMMA, and the effects of heating rate and oxygen partial pressure on observed kinetics. This work has been directed to complement the ongoing work at the Bureau, as will be described below. The work on cellulose has been initiated, but will be only briefly discussed here.

Effect of Heating Rate on Kinetics of PMMA Pvrolvsis: Among the motivating factors for further work on the global kinetics of PMMA pyrolysis was the spread of kinetic constants seen in the literature, and the concern that this might possibly be 
due to an effect of heating rate employed in the different studies. This was particularly of concern to those using slow heating rate TGA techniques of order (1 $\mathrm{K} / \mathrm{min}$ ) in which the resolution of distinct kinetic steps is easy: Could the mechanisms and kinetics observed at these low rates be extrapolated to fire conditions, involving orders of magnitude higher heating rates?

The data in Figure 1 suggest that heating rate is apparently not an important consideration at heating rates of $5 \mathrm{~K} / \mathrm{min}$ io $1000 \mathrm{~K} / \mathrm{min}$, and even up to 1000 $\mathrm{K} / \mathrm{sec}$. These data were obtained by heating thin films of PMMA (20.30km plexiglas $G)$ in the folds of an electrically heated wire mesh, under an atmosphere of inert gas (He). The constants shown in Figure 1 are for a global model of pyrolysis in which PMMA degrades by two parallel first order steps. The first step involves $10 \%$ of the material, and the second step $90 \%$ of the material. This two-step behavior is consistent with the results obtained at the Bureau on similar, though not identical, samples, and reflects the existence of at least two distinct initiation steps. The constants obtained in this study suggest a slightly faster rate than obtained by the Bureau, but the reasons for this are not entirely clear and may have to do with the difference in samples studied.

To summarize, these data clearly show no effect of heating rate on the global kinetics of pyrolysis of PMMA, from $5 \mathrm{~K} / \mathrm{min}$ to $1000 \mathrm{~K} / \mathrm{min}$, and perhaps higher.

Effect of Oxvgen Partial Pressure on Kinetics of PMMA Pvrolvsis: The Bureau had already shown that oxygen generally accelerates the rate of PMMA pyrolysis, although it has a slightly retarding effect very early in the process. The question raised was--how sensitive to oxygen partial are the kinetics of PMMA pyrolysis?

In the present study, the presence of oxygen was iikewise found to have a retarding influence early during pyrolysis and an acceleratory influence throughout the main portion of the process. It was found that the kinetics were sensitive to the presence of anv oxygen, down to the $1 \%$ levels examined thus far, but not particularly sensitive to concentration above $1 \%$ levels. The acrivation energy of the main, random scission process in the presence of any oxygen drops to about 24 $\mathrm{kcal} / \mathrm{mol}$, in low heating rate cases. In fact, it is impossible to fit data obtained at different heating rates with a single set of rate constants (in marked contrast to inert gas pyrolysis). This naturally implies a change in the global process as a function of heating rate, which in turn may imply that oxygen transport becomes limiting at higher heating rates. This is illustrated in Figure 2, which shows constants yielding a good fit to $5 \mathrm{~K} / \mathrm{min}$ data considerably overpredicting rates at $100 \mathrm{~K} / \mathrm{min}$ and $1000 \mathrm{~K} / \mathrm{min}$. In fact, at $100 \mathrm{~K} / \mathrm{min}$ heating rates, there is little difference between rates measured in air and in inert gas, as is easily seen in comparing Figures 1 and 2. The conclusion is that when the heating of the sample is so rapid, the oxygen cannot play a role in the degradation chemistry. Thus, the relevant rate in fire modeling situations in which heating rates exceed $100 \mathrm{~K} / \mathrm{min}$ would likely be the purolvsis rate in incrt gas.

Measurements of molecular weight distributions of the residue largely corroborate the above conclusions.

Rates of Diffusion of Monomer in PMMA: Some very simple experiments were performed in order to obtain estimates of the diffusivity of MMA monomer in PMMA. The rate is important in that it can determine whether mass loss is transport or kineticaly controlled, and whether the surface properties of the PMMA might be 
altered by bubble formation due to slow escape of MMA. Thus far, diffusion rates have only been examined at temperatures below the glass transition temperature of $105^{\circ} \mathrm{C}$. Not surprisingly, the diffusion in this glassy regime seemed to be matrix relaxation controlled rather than true Fickian. The rates are very sensitive to the physical characteristics of the starting sample. Naturally, in real fire situations, transport through a section of PMMA above the glass transition temperature will be of more relevance, and these measurements are now being pursued.

Cellulose Pyrolysis Kinetics: Measurements on cellulose pyrolysis kinetics have only recently begun. The work involves exactly the same techniques as those employed in the PMMA pyrolysis work. The sample of cellulose examined is identical to that in another NBS supported project at Brown under the direction of Professor Merwin Sibulkin. This is a very low ash filter paper pulp. Results thus far indicate that when pyrolyzed in a system which allows for very rapid transport of the tars away from the surface, the extent of char formation is only 3 to $4 \%$ by mass, independent of heating rate in the range $5 \mathrm{~K} / \mathrm{min}$ to $100 \mathrm{~K} / \mathrm{min}$. The very important interplay of mass transport and chemical kinetics will be examined in future work, since it is important in fire modeling to predict the fraction of mass which is retained as char as opposed to released into the vapor phase. This question is being examined by using various thicknesses of sample, in an effort to promote intrasample cracking of the tars as happens in thick, bulk samples.

\section{Reports and Papers:}

"The Effect of Oxygen Concentration and Heating Rate on the Pyrolysis Kinetics of PMMA," M.S. Thesis, Tracy Kelly.

Papers based on this M.S. thesis, which is in preparation, are expected to be completed this fall. 


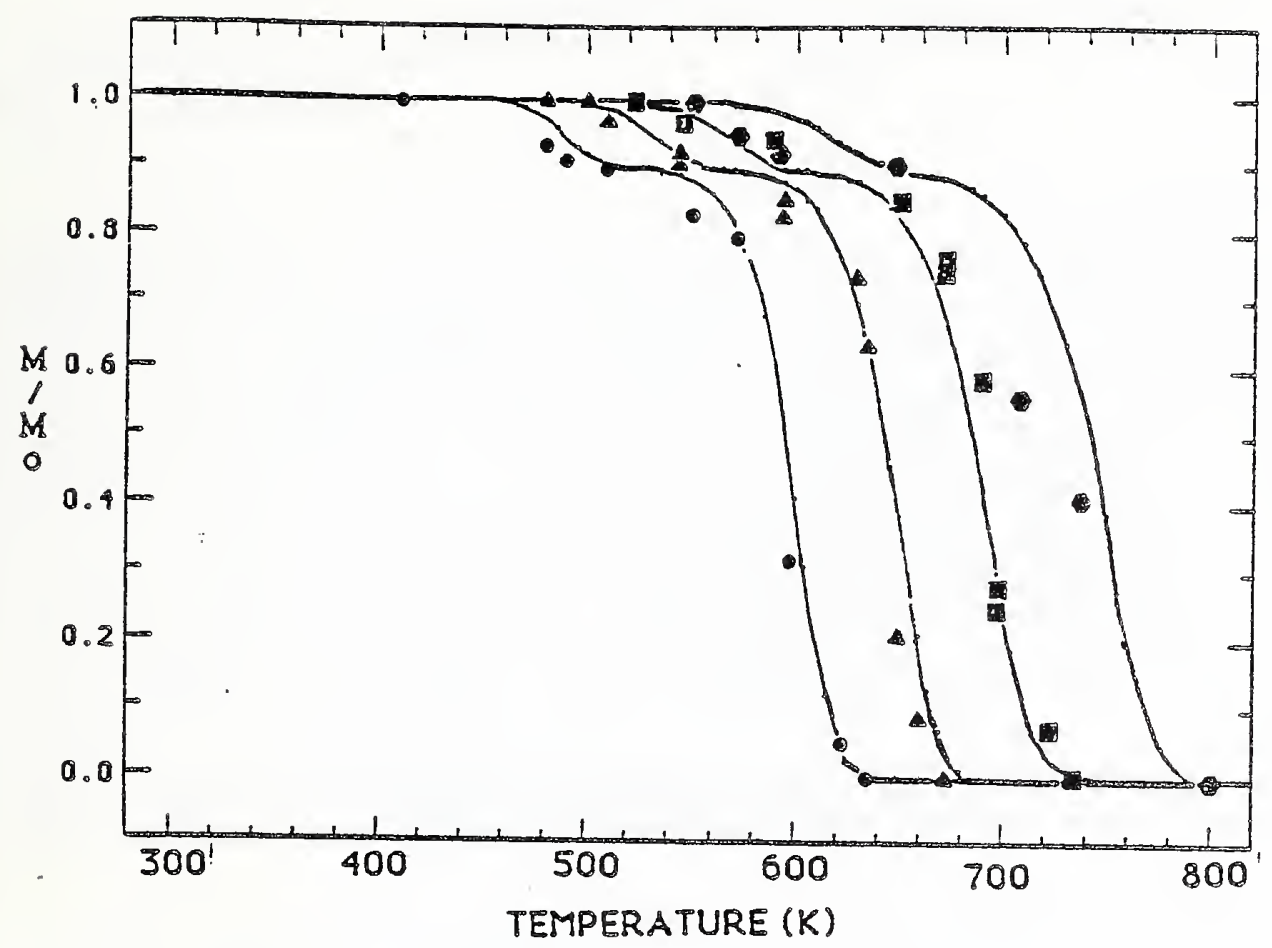

Figure 1. Degradation of PMMA in helium at various heating rates. Indicated temperature is the peak cemperature of a non isothermal experiment, and ordinate is mass remaining relative to initial mass.

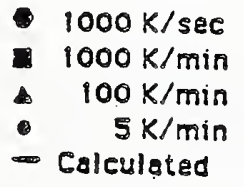

$P(1)=0.1$

$A(1)=2 E 13$

$E(1)=35 \mathrm{kcol} / \mathrm{mol}$ $i(2)=0.9$

$A(2)=|E| 4$

$E(2)=45 \mathrm{kesl} / \mathrm{mol}$

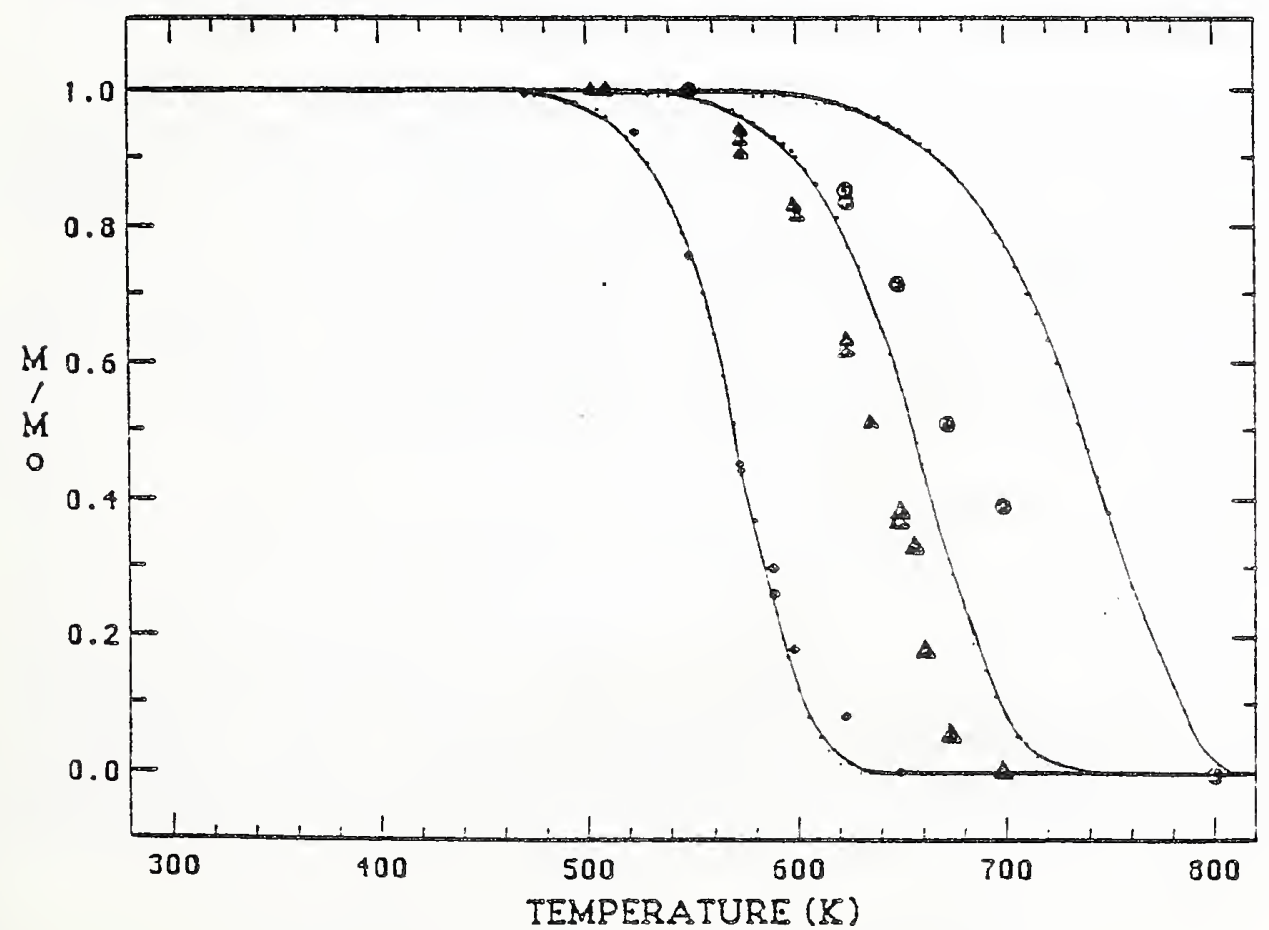

Figure 2. Degradation of PMMA in ais at various heating rates. (-) $5 \mathrm{~K} / \mathrm{min}$, ( ) $100 \mathrm{k} / \mathrm{min}$, (-) $1000 \mathrm{k} / \mathrm{min}$. Calculaced curves, as explained in Eaxt. 


\section{CENTER FOR FIRE RESEARCH \\ NATIONAL BUREAU OF STANDARDS \\ FY 86}

Institution: Brown University

Grant No: $\quad$ NBS Grant 60NANB6D0629

Grant Title: Burning of Charring Materials

Principal Investigator; Professor M. Sibulkin

Division of Engineering

Brown University

Providence, RI 02912

Telephone: (401) 863-2867

Qther Professional Personnel; Y. Chen, Graduate Research Assistant

A. Frendi, Graduate Fellow

NBS Scientific Officer: Dr. V. Babrauskas

Technical Abstract:

The objective of the present research program is to determine the effects of changes in material properties on the burning rates and extinction limits of solid fuels. In particular, we are currently looking at the effects of solid phase fire retardants on the burning of cellulose. We wish to measure the changes in material properties caused by these retardants, and to use this information to determine how these retardants act to suppress fires. This information will help in the design of materials with improved fire safety characteristics.

In a previous investigation we studied the flaming combustion of pure and fire retarded cellulose, and measured the effects of retardant concentration on burning rates and flammability limits. In the present program we wish to measure the major combustion related material properties for the same series of retarded cellulose samples. These measured properties will then be used as inputs to a mathematical model of flaming combustion. The results of these calculations for burning rates and flammability limits will be compared with the previous measurements in order to determine how the retardants act to suppress fires.

The major properties to be obtained are the heat of combustion of the combustible fraction of the volatile products of pyrolysis $\Delta$ h[comb vol], the heat of gasification of the pyrolyzing fuel $h_{\mathrm{g}}$, and the mass fraction of the volatiles which are combustible $Y_{F T}$. Measurement of the heat of combustion is being done with the use of a standard calorimeter and has progressed rapidly. The determination of the heat of gasification is not a standard measurement and requires the development of special apparatus and techniques; it is progressing slowly. The combustible fraction of the volatiles will determined by future measurements of the inert gases $\left(\mathrm{CO}_{2}, \mathrm{H}_{2} \mathrm{O}\right)$ in the pyrolysate stream using gas chromatography. 
The heat of combustion of the (total) volatiles $\Delta h[v o l]$ is determined using Hess' Law in the form

$$
\Delta h[v o l]=\left\{\Delta h[c e l+r e t]-Y_{C} \Delta h[c h a r]\right\} /\left[1-Y_{C}\right] \text {. }
$$

In this formulation $Y_{C}$ is the mass fraction of char remaining after pyrolysis, and it has been measured using the following technique. A thin (3mm) disk is cut from the end of the $25 \mathrm{~mm}$ diameter cellulose test specimen. The disk is replaced at the end of the test specimen and held there by a spring-loaded clamp to maintain tension during sample skrinkage. The composite specimen is placed in the gasification apparatus and subjected to a radiant hear flux of the same magnitude as the heat transfer rate during flaming combustion. Values of $\mathrm{Y}_{\mathrm{C}}$ are calculated from measurements of the disk weight before and after pyrolysis. For cellulose retarded with sodium hydroxide, the char fraction increases from $Y_{C}=0.11$ for pure cellulose to $Y_{C}=.32$ for a retardant mass fraction $Y_{R} \approx .03$. These char yields are somewhat greater than those found by Thermogravimetic Analysis at comparable temperatures. The difference is attributed to the effects of passing the products of pyrolysis through a hot char layer in the present experiments. This results suggests the need to study bulk samples of charring materials to determine their behavior in fires. -

The heal of combustion $\Delta$ h[celtret] of retarded cellulose samples was measured using a Parr Semimicro Calorimeter, and the results are shown in Fig. 1 . For pure cellulose the result is in agreement with literature values. The linear drop in $\Delta h$ is equal to that calculated by assuming the retardant acts as an inert material. The char samples prepared for the measurements of $Y_{C}$ were then tested in the calorimeter, and the values measured for $\Delta h$ [char] are shown in Fig. 2. The results show that a maximum of $\Delta$ h[char] occurs at $Y_{R}=0.01$. Calculations based on an assumption that the retardant remained in the char as an inert material do not explain the shape of this curve.

Combining these measurements using Eq. (1) gives the values of $\Delta$ h[vol] shown in Fig. 3 at $25^{\circ} \mathrm{C}$. Standard thermodynamic methods were used to calculate the corresponding results for $\Delta \mathrm{h}[\mathrm{vol}]$ at $400^{\circ} \mathrm{C}$. The major conclusion from this work is that retardant addition causes a drop of up to 30 percent in the heat of combustion of the (total) volatiles.

Work in progress includes measurements of char composition using an elemental analyser. These results will show to what extent the elemental composition of the char is affected by retardant addition, and will also be used to calculate the elemental composition of the volatiles [by a subtraction technique analagous to Eq. (1)]. The final determination of $\Delta h\left[\mathrm{comb}\right.$ vol] $=\Delta h[\mathrm{vol}] / \mathrm{Y}_{\mathrm{FT}}$ will be made after the future measurements of $Y_{F T}$.

\section{COMPLETED PUBLICATIONS}

"Heat of Gasification for Pyrolysis of Charring Materials," M. Sibulkin, Fire Safety Science-Proceedings of the First International Symposium, Hemisphere, pp. $391-400$ (1986). 


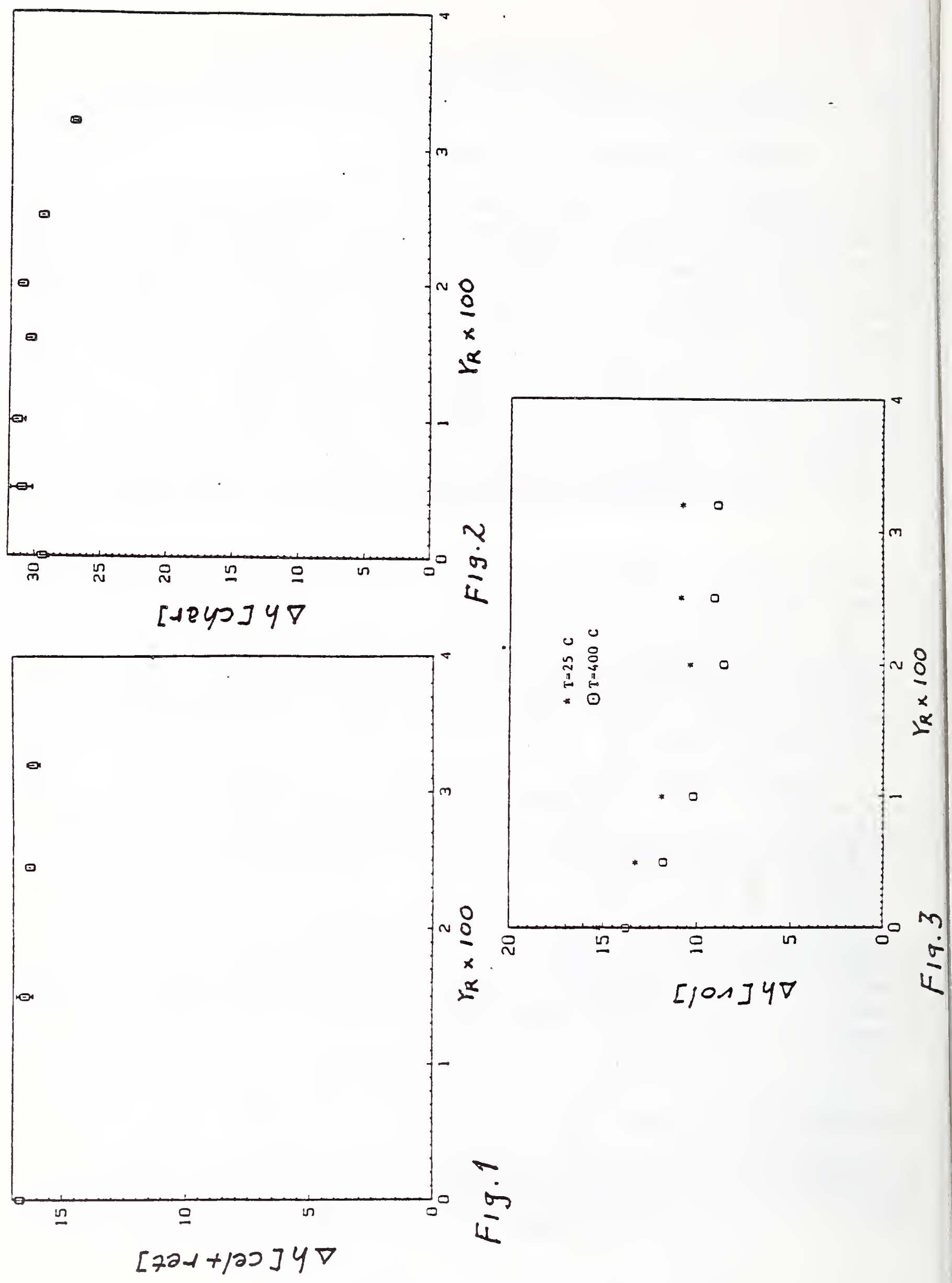




\section{CENTER FOR FIRE RESEARCH \\ NATIONAL BUREAU OF STANDARDS \\ FY 1986}

$\begin{array}{ll}\text { Institution: } & \begin{array}{l}\text { Division of Engineering } \\ \text { Brown University } \\ \text { Providence, R.I. } 02912\end{array} \\ \text { Grant Title: } \quad \text { Soot Dynamics in Flames } \\ \text { Grant No:: NB83NADA4025 }\end{array}$

Principal Investigator: Professor R. A. Dobbins

Division of Engineering

Brown University

Providence, R.I. 02912

Telephone: (401) $863-1422$

Other Professional Personnel: Mr. Constantine Megaridis, Research Assistant

NBS Scientific Officer: Dr. George W. Mulholland

Technical Abstract:

We seek a deeper understanding of the dynamic processes which control the behavior of the soot aerosol present within flames as well as in the smoke which they release. The presence of the soot aerosol in low concentrations is a widely used signal for the presence of fire. The soot released from flames in higher concentrations is a hazard to victims of uncontrolled fires. We have developed sampling methods based on thermophotetic attraction of small particles to a cold surface. These methods allow us to sample the soot aerosol in regions of the flame where the process of coagulation acts in concert with new particle formation, surface growth, oxidation or release to the environment. Morphological features which are readily determined include spherule size and state of agglomeration and size distribution in the regions where single particles are observed. Observations are compared with the predictions of solutions to the aerosol dynamic equation that include terms which describe the above processes.

\section{Experimental Work}

Thermophoretic sampling is accomplished by inserting a cold probe surface for a brief instant into a precisely defined region of a particle laden flame. Thermophoretic probes are fabricated from the materials normally used in electron microscopy, viz., circular grids and bulk specimen carriers and by combinations of these two devises. The probe is inserted into the flame by 
an electro-pneumatic probe control system in an interval of $15 \mathrm{~ms}$ and can be held by in a precisely defined region for times that vary from 30 to several hundred milliseconds. From observations conducted with this technique we are able to examine particles from three regions of the flame: $A$. The nucleation region in which the smallest particles are first formed. $B$. The agglomeration-growth region where intense agglomeration occurs and wherein primary particles that make up the agglomerates grow to their largest size. C. The oxidation region where the primary particles within the agglomerates contract even though agglomeration continues unabated. To date we have concentrated most effort on measuring the regional extent and aerosol properties low in the flame in the nucleation region. The dynamic behavior of the size distribution in this region has considerable significance and provides the initial data with which to start the simulation calculations.

Two effects have been consistently observed with a variety of probes that have been exposed for various residence times. The first of these is the strong manifestation of surface growth in the agglomeration-growth region at heights above the burner (z) varying from 10 to $40 \mathrm{~mm}$ (The flame height we use for this non smoking flame is $88 \mathrm{~mm}$.) The primary particle size of the agglomerates is observed to grow systematically from 14 to $36 \mathrm{~nm}$. This size has a maximum at $\mathrm{z}=40 \mathrm{~mm}$ where soot oxidation stants to play a more important role (see Figure 1 below). For $40 \mathrm{~mm}<z<88 \mathrm{~mm}$ the degree of agglomeration continues to increase while the primary particle size decreases. The maximum of the primary particle size coincides with the height at which optical measurements (Ref. 1) show the maximum soot concentration in the same flame.

A second interesting feature, which is found to occur in a variety of probe samples, is the presence of fine unagglomerated soot particles in the region outside the annulus of highest particle volume fraction. The region of fine particles thus coincides with this layer external to the surface of high luminosity where $\mathrm{O}_{2}$ is present and where temperature has a maximum. These fine particles can in principle be transported from lower levels where they are formed or may be created and oxidized locally by the diffusion of fuel across the streamline from the central portion of the flame. We present experimental and theoretical arguments relating to these two viewpoints on the origin of the fine particles.

\section{Coagulation Theory}

The aerosol dynamics in the lower portion of the flame are described by the aerosol dynamic equation when expanded to include the effects of new particle formation, coagulation, and surface growth. In order to implement this solution we have chosen the integral methods which have an appropriate degree of accuracy and which have the potential to yield insight into the observed data. To describe the formation of the aerosol it is advantageous to employ a bimodal distribution in which a smaller mode is used to describe the population of the nucleation mode and a larger group is used to account for the growth mode. Initially this formulation posed algebraic complexities which prevented our achieving solutions in an efficient fashion. These difficulties were overcome by introducing the variables representing the number concentrations of the two modes as primative variables in the set of 
ordinary equations describing the aerosol dynamic behavior. This modification has lead to a formulation that is compact and robust to a wide varicty of input variables. The bimodal solution decays to the monomodal solution and it also reduces in turn to the asymtotic solution corresponding the self preserving size distribution function. A publication is in progress describing this method in detail. The application of this theoretical model to the soot aerosol dynamies will be discussed.

\section{Oral Presentations and Publications}

During the past calendar year the following oral and written reports authored by $R$. A. Dobbins and C. M. Megaridis have been presented:

"Regional Soot Morphology in a Laminar Diffusion Flame", Annual Meeting of the American Association for Aerosol Research, November 20, 1985.

"Soot Morphology in a Laminar Ethene Difffusion Flame", Sixtieth Annual Meeting of the American Chemical Society, Division of Surface Chemistry, Atlanta, June 19, 1986.

"Morphology of Flame Generated Soot as Determined by Thermophoretic Sampling", submitted for publication to Langmuir, July 1986.

\section{Reference}

1. R. J. Santoro, H. G. Semerjien and R. A. Dobbins, "Soot Particle Measurement in Diffusion Flames", Combustion and Flame 51, 203 - 218 (1983).

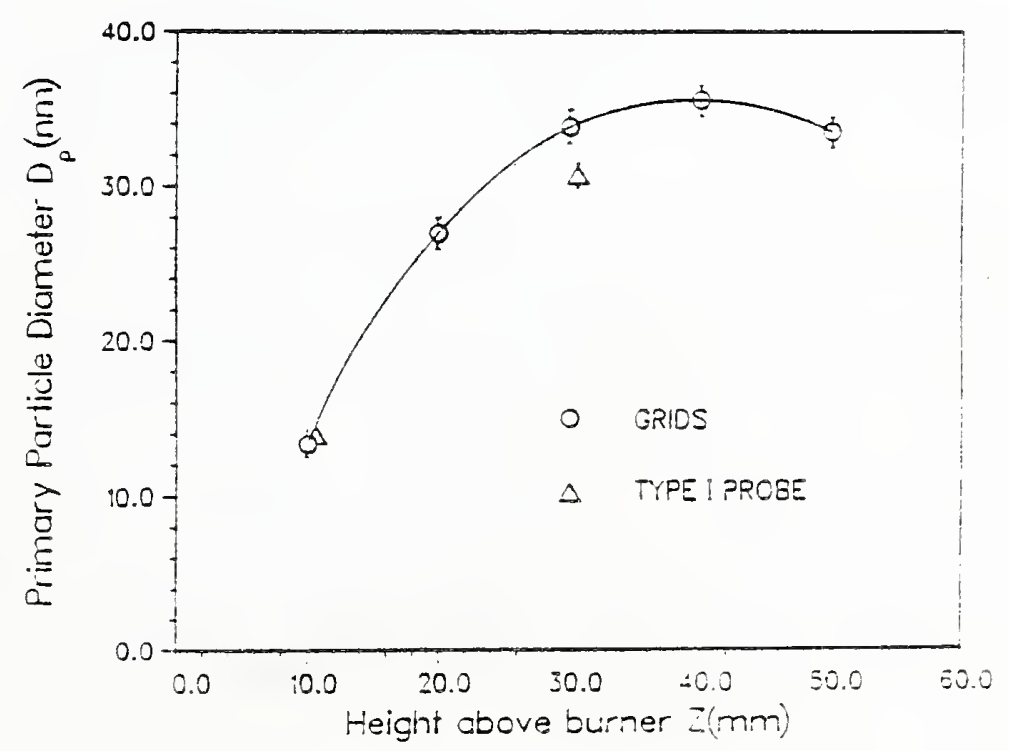

Figure 1 
CENTER FOR FIRE RESEARCH

NATIONAL BUREAD OF STANDARDS

FY 86

Institution: Califormia Institute of Technology

Grant No:- $\quad$ NBS Grant NB82NADA3033

Grant Title: Experimental Study of Enviroment and Eeat Transfer in a Room Fire

PIincipal Investigator: Professor Edward E. Zukoski 301-46

California Institute of Technology

Pasadena, CA 91125

Other Professional Personnel: Professor Toshi Rubota

Michael Chobotov, $\mathrm{PhD}$ Candidate

Stephen Toner, $\mathrm{PhD}$ Candidate

Bichard Chan, $\mathrm{PhD}$ Candidate

James Moreheart, Research Assistant

California Institute of Technology

Pasadena, CA 91125

NBS Scientific Officer: Dr. Walter Jones

\section{Technical Abstract:}

Smoke which is produced by a fire spreading through a building can act to aid in the spread of the flame by the transport of hot and perhaps combustible gas, and can be hamful to occupants because of its temperature and toxicity or because its opacity hinders the rapid movement of the occupants through the building. Under certain circumstances, the combustion of the fuel produced in the fire can occur under conditions in which the concentration of oxygen in the ambient gas is far below normal and a fuel rich mixture can be produced which will burn later in an adjacent space and aid in the spread of the fire. We are interested in developing models for the production and movement of smoke in complex structures and have been studying several fluid dynamic processes which will be described below. These processes cannot be described analytically because the flows are turbulent and are strongly influenced by turbulent mixing between streams in which buoyancy forces are predominant. The aim of the research work described here is to develop sufficient understanding of the fluid dynamic and chemical processes so that rational models can be developed for the use in two layer fire codes. 


\section{FLOW AND HEAT TRANSFER IN GRAVITY CURRENTS}

During the past year we have been primarily involved in an experinental investigation of the flow field produced by the transient motion of smoke in a horizontal hallway-like structure. The aim of this work is to obtain an understanding of the flow of hot smoke along a ceiling during the transient period in which the smoke moves as gravity current. Heat transfer from the current to the wall can affect these flows and studying the beat transfer process is an important part of the present work. A final report on the cursent status of this work will be available in October and a qualitative description of the apparatus and results is given here.

We have carried out experiments in which a gravity current of salt water flows through a duct filled with fresh water and a second set of experiments in which the gravity current of hot air flows through a duct filled with cool air. The tests in aif included both viscous and beat transfer effects and they will be discussed first.

AIR TESTS: The tests in air were carried out by creating a transient flow of hot gas along the ceiling of a square duct with a constant temperature ceiling. The velocity of the front produced by this flow, the rate of beat transfer to the ceiling, and the velocity and temperature fields of the flow are being measured.

The channel used in the gas flow experiments is a duct $0.5 \mathrm{~m}$ in height and width, and 8.6 meters in length. Hot gas can be supplied to this duct at one end from a small fumace at temperatures up to $500 \mathrm{~K}$ and with a large range of metered flow rates. Cool ais in the tunnel which is displaced by the hot "smoke" can be withdrawn from the tunnel at a number of positions so that a number of interesting flow situations can be modeled. In the work reported here, the downstream end of the duct is completely open. The side walls of the channel iave been made of heat treated glass to allow observation of the flow through shadowgraph photography or direct ooservation of. smoke which is added to the hot gas.

We have developed, for our applicaticn, a smoke-rire technique For velocity measurements which gives a good qualitative measure ó the local gas speed. However, the measurements are affected by tine buoyancy of the smoke relative to the cooler gas in the flow and do nor give a precise measure of the gas speed.

Thermocouples, with a diameter of about 0.01 and cons aquent ly with a fast time response, are used alone or in a rake to deternine the arrival of the bead of the current and to make gas temperacure measurements in the current; thin film heat transfer gages have been installed on the vall to measure heat transfer rates.

The ceiling of the apparatus in its current state $i s$ a $1.27 \mathrm{~cm}$ thick aluminum plate which was used because conduction into the plate is fast enough to keep the plate temperature rise below one degree. Thus, the surface temperature is kept far below the initial temperature of the gas in the duct and does not enter the problem. 
Given the heat transfer rates observed in these experiments, the temperature rise at the surface of a wall composed of an insulator, say one with the propertiers of plaster board, would be in the range of 20 to 50 degrees after a period of 10 to 15 seconds. Thus, the rise would still be small after the period required for the front to reach the end of our test section. However, we are very much interested in the effects of the temperature of the wall and the wall boundary layer on the heat transfer process and are modifying our apparatus to allow measurements of this type.

The initial conditions for a typical experiment include, temperature of $520 \mathrm{k}$, initial layer thickness of $6 \mathrm{~cm}$ and an initial velocity of the front $0.5 \mathrm{~m} / \mathrm{s}$. At the downstream end of the duct, the corresponding conditions are a temperature of $280 \mathrm{~K}$, a thickness of 12 $\mathrm{cm}$, and a velocity of the front of $0.2 \mathrm{~m} / \mathrm{s}$. The Richardson number based on layer thickness is about 0.9 throughout the length of the duct and the initial value is about one so that there is no initial hydraulic jump. The large velocity change observed as the current moves across the duct was the result of the change in temperature of the current produced by heat transfer to the ceiling.

The rate of heat transfer from the current to the constant temperature wall was measured in these experiments and it varies from values as large as $3000 \mathrm{~W} / \mathrm{m}$ to values as $10 \mathrm{w}$ as $60 \mathrm{~W} / \mathrm{m}$, and the maximum values are observed at the upstream end of the duct where the hot current is introduced. Because the total enthalpy flux in the current is typically 1.0 to $2.5 \mathrm{~kW}$, it is not surprising that the heat flus to the wall has a large influence on the temperature of the current and its motion.

Heat transfer rates, expressed in the form of a Nusselt number based on distance from the origin of the flow, have been found to vary linearly with the Reynolds number based on the same length scale and the local velocity; the proportionality constant is about 0.013 . These Nusselt numbers are some ten times higher than the values estimated for a laminar wall jet with the same Reynolds number and about 3 times larger than the corresponding turbulent wall jet.

We believe that the large heat transfer rates result from natural convection within the boundary layer which develops between the cool boundary layer Elow next to the wall and the hotter flow in the current below it. Large two- dimensional rolls develop which have their axis parallel to the wall and the direction of the flow, a two dimensional Benard cell. These rolls greatly enhance the heat transfer by transporting cool material away from the wall and hot material to the wall. The velocity of the front of the current depends strongly on local gas temperature and bence is strongly affected by the heat transfer.

SALT WATER TESTS: In addition to the experiments described above, we are investigating similar gravity current flows in which the current is formed between salt and fresh water. The hallway is a $15 \mathrm{~cm}$ square channel which is about $250 \mathrm{~cm}$ long and the channel can be tilted so that the long side makes an angle with respect to the horizontal of 0 
to 35 degrees. The influence of the angle and of the fluid dynamic variables on the resulting gravity currents are being investigated.

When the channel is horizontal, the flow is similar to that described above except that heat transier effects are absent and consequenty the velocity of the bead is constant. The influence of Reynolds number and the development of the boundary layer between the current and the wall are under investigation.

The angle makes a qualitative difference in the flow even when it is as smali as one degree. For large angles, the nising between the current and the fluid under it becomes important and for angles of 20 degrees can completely fill the duct behind the bead of the current with mixed fluid. In the horizontal case, the current mass flus and velocity and head geometry were constant; in contrast, when the ceiling was tilted, these parameters grow rapidly with distance from the origin.

MODELING: We are developing a computational scbene which will be used to describe the flow described above and the data are being used to guide its development. The model uses an integral method based on the Howarth transformation of the vertical dimension to describe the conditions in the flow behind the head of the gravity current. The boundary layer approximation is used in the description of the flow and the effects of buoyancy, beat transfer, and viscosity are taken into account. The model gives a good prediction of the flow when the experimental correlation for the heat transfer coefficient is used and successfully predicts that the local Richardson number wil be close to one.

\section{Reports and Papers}

Zukoski, E. E., Cetegen, B. M. and Kubota, T., "Visible Structure of Buoyant Diffusion Flames," presented at 20 th Combustion Symosium, Aug. $12-17,1984$.

Zukoski, E. E., "Fluid dynamic aspects of room fires," Fire Safety Science - Proceedings of the First International Symosium, 1-33, 1986 
CENTER FOR FIRE RESEARCH

NATIONAL BUREAD OF STANDARDS

FY86

Institution: Case Festern Reserve Oniversity

Contract Number: NB82NADA3028

Contract Title: Experimental and Analytical Study of Fire Sprinkler Scaling Laws

Principal Investigator: Joseph M. Prah1, Ph.D., P.E.

Professor of Engineering

Department of Hechanical and Aerospace

Engineering

Case Festern Reserve University

Cleveland, Ohio 44106

Other Professional Personne 1: Bruce Hendt, M.S.

Htun Tin, M.S.

Case Festern Reserve Dniversity

Cleveland, Ohio 44106

NBS Scientific Officer: David D. Evans

Technical Abstract:

The objective of this project is to develop an experimental base that wil delineate the relevant scaling parameters that govern the performance of a wide class of fire sprinklers. The sheet trajectory, sheet breaknp, and subsequent droplet size distribution and droplet trajectories are related to the mechanical and thermal properties of the 1 iquid and gaseous fluids, the geometry and the initial dynamics of the liquid and gaseous streams.

Experimental data for water has been obtained on an apparatus developed to study the axisymmetric jet impingement on a flat disk which can be vibrated axially at a given frequency and chosen amplitude, shown schematically in Figure 1. The sheet of water leaving the disk is allowed to breakup without interference over the full $360^{\circ}$, whereas the discharge subsequent to sheet breatup is masked off to a 22.5 o sector for the purpose of determining the droplet radial discharge distribution. The she $t$ brearap radius is determined by direct observation and the radial discharge from the sector is collected in a series of rain gutters spanning the floor of the sector normal to the midangle radial direction. Variation of disk size and disk surface characteristics show no measurable effect on either sheet breakup radial location or on the measured discharge distribution. 


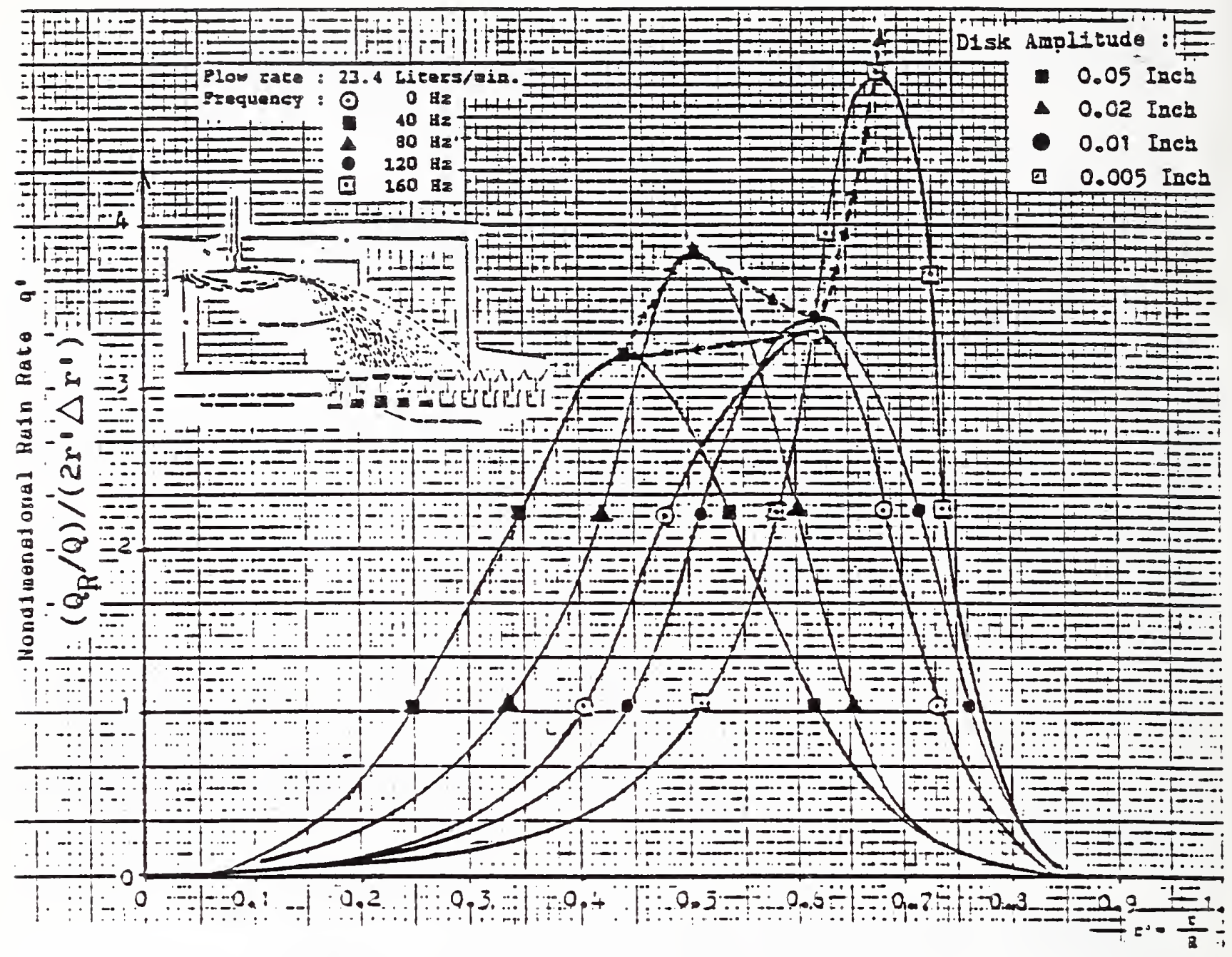

Figure 2. F1ow Rate Patterns as a Function of Disk Disturbances

Figure 3 illustrates the point that the ratio of the sheet breakup radius at a given driving frequency to that at zerodriving frequency appears to correlate with the ratio of the driving frequency to the frequency for marimum growth of sinuous waves, for a given amplitude of disk oscillation. Figures $4 a-b$ illustrate the apparent correlation of flow distribution with ratio of driving frequency to frequency of maximum growth of sinuous yaves.

The droplet trajectory model combined with a Rosin-Rammler distribution function for the droplet diameters gives qualitative agreement with measured flow distributions. The model is sensitive to the initial conditions of the droplets at the point they leave the sheet breakup location. If the sheet is flapping sinuously pith large amplitude, it causes the flow distribution to be mach broader than if the sheet is relatively flat at the breakup point as can be seen by predicted flow distributions from the computer nodel shown in Figures $5 a-b$. 


\section{Reports and Publications:}

1. B. Hendt and J. H. Prahl, 'Discharge Distribution Performance for an Axisymetric Hodel of a Fire Sprinkler Head' Department of hechanical and Aerospace Engineering. Case Testern Reserve Oniversity, Cleveland, Ob: 44106, Aqg. 1986, FTAS/TR-86-184.

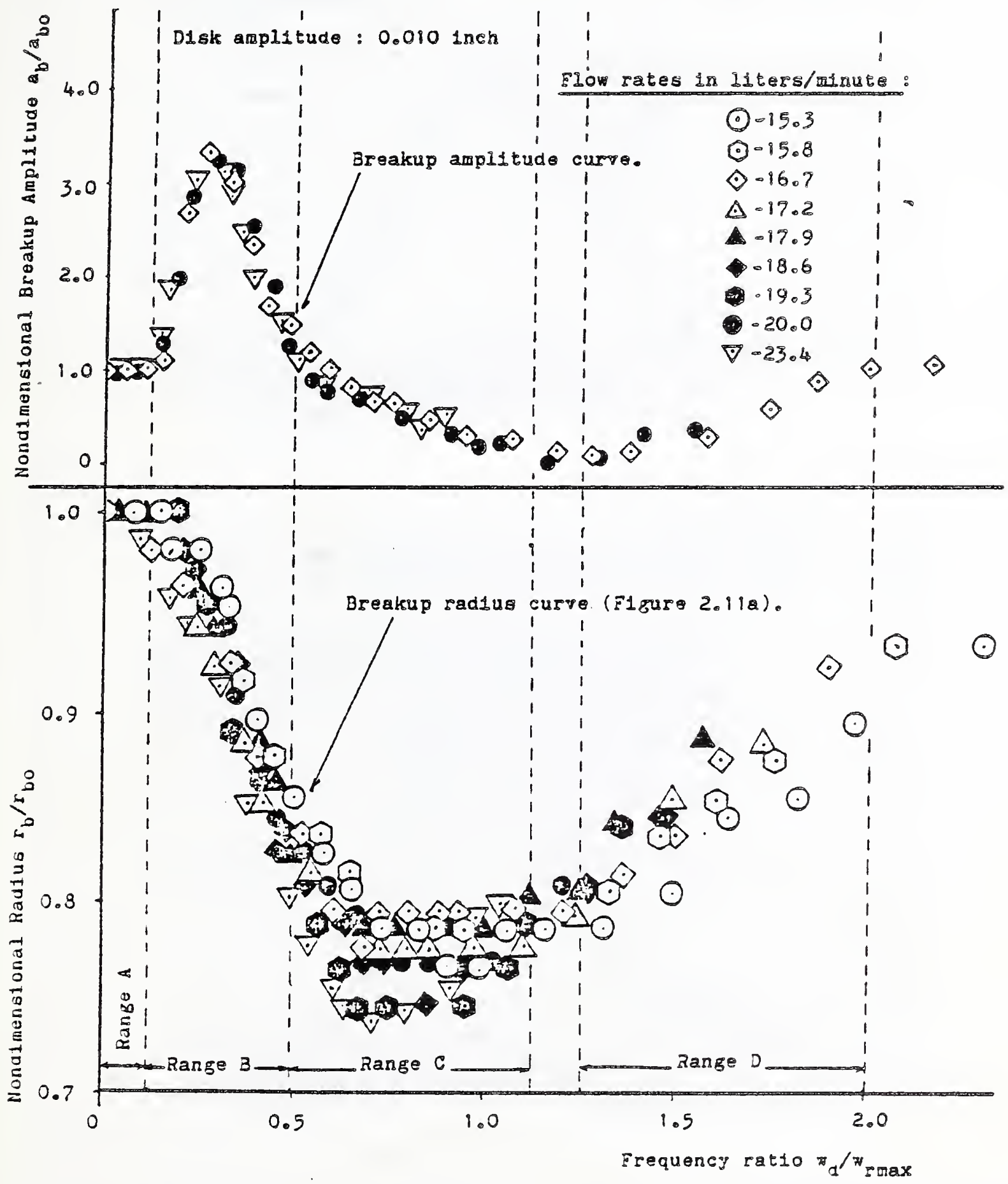

Figure 3. Experimenta 1 Discription of the Sheet Structure. Nondimensional Rreakup Radius and Nondimensional Breaknp Amplitude of Dominant Sheet Haves Plotted Versus Frequency Ratio 

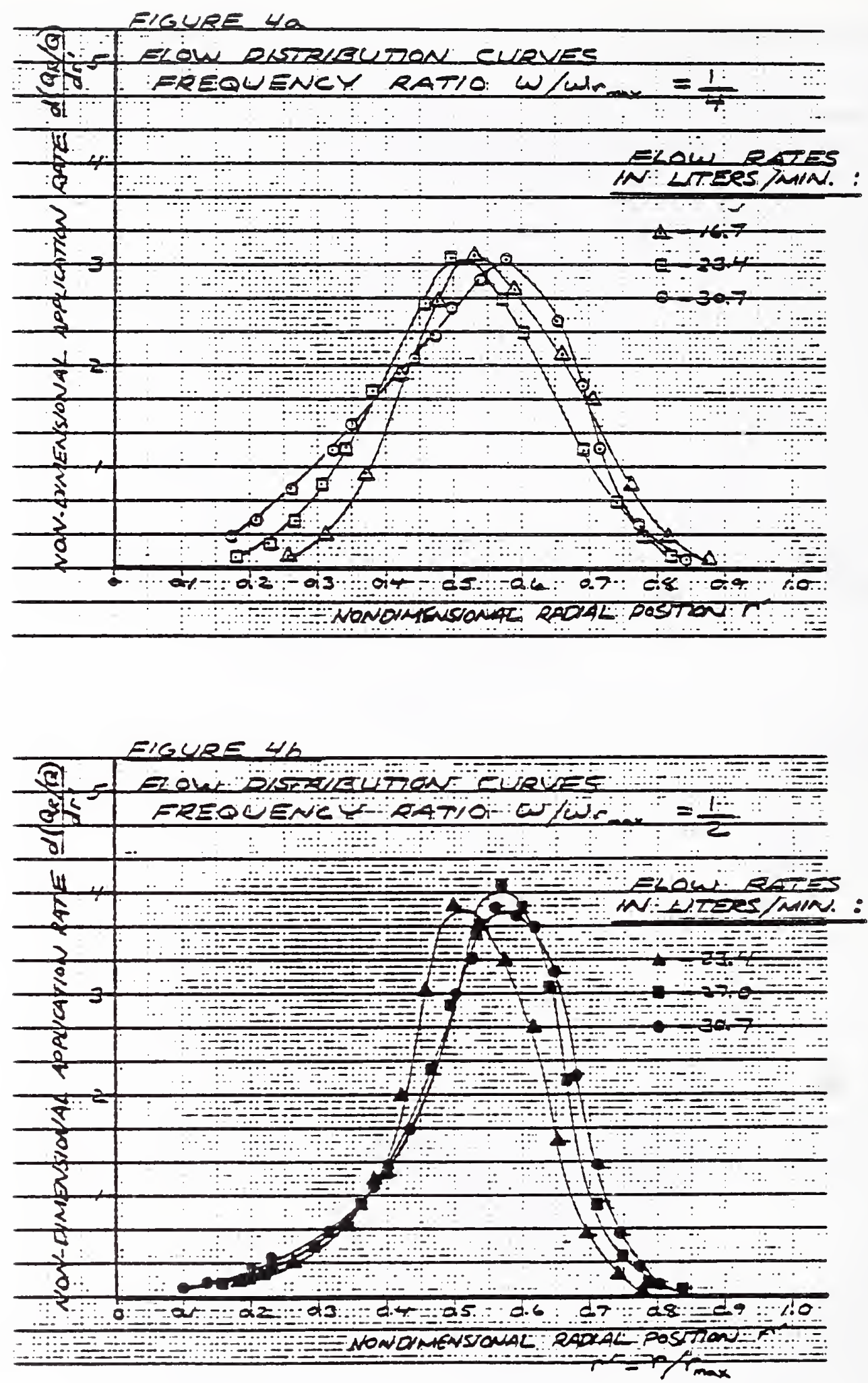

Figure 4. Flow Distribution Carves for Frequency Ratios of $1 / 4$ and $1 / 2$. 

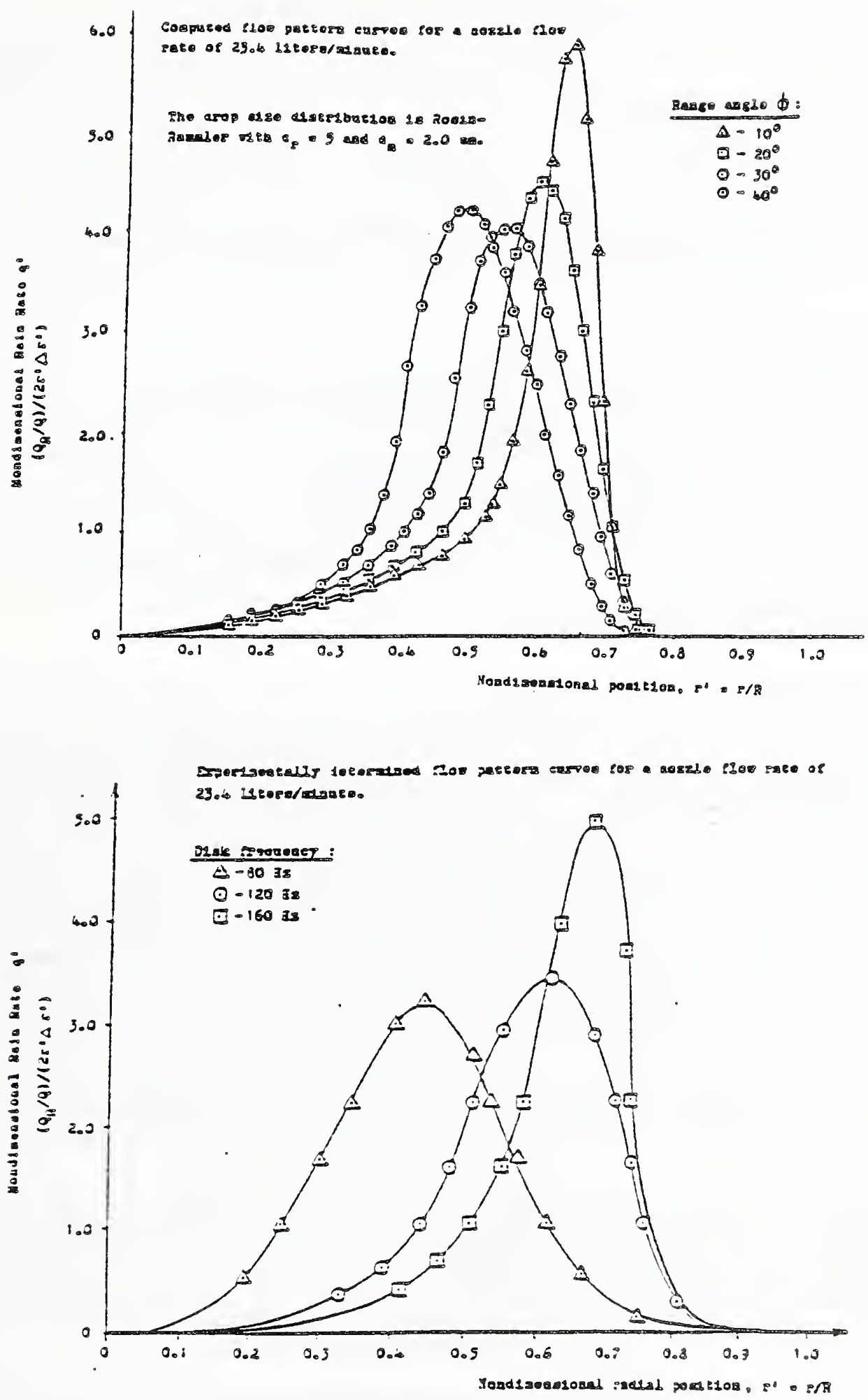

Figure 5. A Comparison of Analytical and Experimental Flow Patteris. 


\section{CENTER FOR FIRE RESEARCH \\ NATIONAL BUREAU OF STANDARDS}

FY 86

Institution: Clemson University

Grant No: 60 NANB6D0627

Grant Title: Graphical Presentation and Numerical Analysis of Fire Data for Model Validation

Principal investigator: James P. Jarvis

Department of Mathematical Sciences

Clemson University

O-104 Martin Hall

Clemson, SC 29634-1907

Telephone: (803) 656-5214

Other Professional Personnel: Melissa Bowers, Graduate Assistant

NBS Scientific Officer: Sanford Davis

Technical Abstract:

Introduction: The primary objective of this research is the development of computational procedures for graphical and numerical analysis to assist in the validation problem for fire models. The validation problem concerns the question of whether ifre models are in sufficient agreement with experimental data to be of use in predicting fire behavior in alternative scenarios. Validation is a difficult, but essential, part of mathematical modeling with no universally applicable procedures. In the context of fire modeling, the validation problem is further complicated in two respects. First, large scale fire models and experiments typically generate enormous amounts of data. Data collected from a single burn conducted at NBS might consist of one hundred fifty independent channels and one hundred derived channels of 250 observations each. Second, fires are described by a multiplicity of variables. In one context, smoke and toxic gases might be the most important consideration; in another, temperature and heat flux. Hence, validation of a fire model must include some provision for dealing with differing assessments of the importance of each variable.

The effort is focused on three areas: (1) completion of flexible graphics software to facilitate examination and presentation of fire data; (2) systematic treatment of statistical uncertainties associated with experimental data and sensitivity analysis of the fire simulation models in conjunction with the development of well-defined, systematic validation procedures; and (3) a preliminary investigation of how subjective assessments can be incorporated into the validation process.

As a test case, these approaches are being investigated in the specific context of the "FAST" model for the transport of fire, smoke, and toxic gases developed by the Center for Fire Research and empirical data gathered from instrumented burns conducted at NBS. 
Graphical Analysis: An important tool in validating a model is the visual inspection of data. The volume of data generated by an instrumented burn experiment or a computer simulation must be handled in a consistent and flexible framework to permit a comprehensive examination. Typical problems which must be addressed are the compatibility of units of measurement and manipulation and display of subsets of variables over specified time frames. In order to address these issues, a software package for graphics analysis is being developed. The initial version of this software is designed to run on an IBM PC with screen displays and hardcopy output to a Hewlett-Packard pen plotter or dot matrix printer. The software is written in FORTRAN to maintain portability to mini and mainframe computers.

It is important to note that while the graphics software will be useful for general scientific plotting, its focus is analysis specific to the fire validation problem. The software will accept data in the format generated by FAST and RAPID (the software developed at CFR for peduction of experimental data). A simple use of the graphics software would be simultaneous display of corresponding model and experimental data. In addition, any validation procedures which affect how data should be displayed could be incorporated into the graphics software. For example, data smoothing, normalization, or weighting techniques developed as part of the validation process could be incorporated directly into the graphics routines to facilitate examination of the data.

Data Manipulation: The basic issue in the validation problem is the comparison of experimental and model data. This involves the preparation of both experimental and model data for comparison. In the case of the experimental data, some smoothing to remove noise will be required. Also, estimates of statistical uncertainty in the observed values must be made. Finally, the data will require some "normalization" to adjust for biases introduced by ambient conditions or starting times. Since the initial conditions can be specified for FAST, the same problems do not arise for model data. However, model sensitivity must be considered. If the model was particularly sensitive to changes in certain parameters, that information should be included in the decision as to whether model and experiment are in satisfactory agreement. Effects of statistical uncertainty of data, model sensitivity, and comparison of multidimensional data will be integrated into a flexible framework and interfaced to the graphics routines.

Validation Procedures: The effort outlined here is somewhat speculative. Fires are described by a multiplicity of variables, not all of which are relevant in every situation. For this reason, it does not appear appropriate to attempt to produce a single number which would measure the "accuracy" of a fire model. A more useful approach is to establish which variables are important in a particular situation and then ask whether the model accurately predicts those variables. To this end, techniques of decision analysis and multi-attribute utility theory will be investigated in the context of the fire model validation problem. Such techniques can be used to incorporate individual assessments of risk into a unified measure. The important idea is reflecting the model user's priorities in the validation process.

Research Status: An initial version of the graphics software has been completed. Techniques for data analysis are being incorported into the software. Research in model validation and incorporation of subjective assessments is continuing. 
CENTER FOR FIRE RESEARCH

NATIONAL BUREAU OF STANDARDS

FY 86

Institution: Clemson University

Grant No.: : 60NANB4D0033

Grant Title: Ternary Reactions Among Polymer Substrate-Organohalogen-Antimony Oxides in the Condensed Phase Under Pyrolytic, Oxidative and Flaming Conditions

Principal Investigator: Dr. M. J. Drews

School of Textiles

Clemson University

Clemson, South Carolina 29634-1307

Other Professional Personnel: Dr. C. W. Jarvis, Co-Principal Investigator

Dr. G. C. Lickfield, Research Associate

Ms. K. McCoy, Graduate Assistant

NBS Scientific Officer: Dr. W. Schaub

Technical Abstract:

The objective of this work was to determine the chemical mechanisms for the solid phase interactions which occur in antimony oxide/organohalogen/ thermoplastic polymer substrate compositions during combustion. The formation of intermediate flame retardant decomposition products and the role of the polymer substrate in the generation of the volatile antimony compounds were of special interest, with regards to the relative importance of the solid state chemistry to the overall chemistry of degradation and combustion. Data on the combustion chemistry were obtained from laboratory scale flaming combustion experiments conducted at the Center for Fire Research of the National Bureau of Standards.

The small scale degradation studies employed isothermal and dynamic thermal analysis, as well as isothermal tube furnace experiments. Sample sizes ranged from the milligram to the gram scale depending on the apparatus. Antimony analysis and bromide ion monitoring were used in the initial stages of the work to develop a temperature profile for the antimony volatilization and extent of reaction. In the latter stages of this work, capillary gas chromatographic analysis of the trapped volatiles was used to more completely define the extent of reaction. Throughout the course of this investigation a basic experimental sequence consisted of the study of the individual components, followed by a study of component mixtures under identical degradation conditions.

Initially, three polymers and three organobromine compounds of significantly different thermal stabilities and primary decomposition pathways were chosen as model polymer substrates and halogen sources. The polymer substrates were poly(ethylene terephthalate) (PET), polypropylene (PP) and poly(methyl

methacrylate) (PMMA). The organobromine compounds were decabromodiphenyl oxide 
(DBDPO), tetrabromobisphenol-A (TBBPA) and hexabromocyclododecane (HBCD)。As the work progressed, two additional polymer substrates, linear high density polyethylene (HDPE) and poly(butylene terephthalate) (PBT) and additional halogen sources including an acyclic organochlorine compound and the chlorine analog to DBDPO were included. The study was also extended to include additional antimony compounds and other metals.

In the previous antimony/halogen synergism literature, at least three different mechanisms have been proposed to account for the antimony volatilization which has been observed in degradation and combustion studies. These reaction mechanisms could generally be separated into two categories according to whether or not the organohalogen component could undergo an intramolecular dehydrohalogenation. For those compounds which could undergo intramolecular loss of halogen and form HX directly, the principal route to the generation of volatile antimony species has been thought to involve the reaction of the HX with antimony oxide. In the absence of a simple intramolecular reaction to form $\mathrm{HX}$, alternative reaction schemes involving either the indirect formation of $\mathrm{HX}$ or unspecified intermediates have been proposed. Even in these alternative reaction schemes, the necessity for HX formation is implied if not explicity included.

Based on the results of the small scale degradation experiments with DBDPO, it was concluded that at least one previously unreported mechanism exists for the antimony volatilization which does not involve HX formation. Confirmation of this was obtained from experiments with antimony metal/DBDPO mixtures at temperatures measured for the pyrolyzing polywer substrates during combustion (400C). In this experiments, the measured antimony volatilization was comparable in magnitude to that observed for polymer/antimony oxide/organohalogen mixtures at the same temperatures. Attempts to identify the presence and measure the concentration of $\mathrm{Sb}$ in pyrolysis mixtures of polymer substrate and antimony oxide using Mossbauer and ESCA were unsuccessful. Similar experiments with bismuth and zinc have indicated that the proposed reaction is not unique to antimony and may be rather general for certain organohalogen structures.

Based on a comparison of the results obtained from tube furnace experiments to those from thermogravimetric analysis experiments, it would also appear that the extent of reaction in organohalogen/antimony oxide/polymer substrate mixtures can be significantly influenced by physical factors related to the preparation of the sample. In particular, these results may be interpreted in such a manner as to possibly explain some of the observations which have previously been made in the literature regarding the difference in the efficiencies of antimony trioxide versus antimony pentoxide. Finally, the data from a series of experiments with several organophosphorus compounds has provided some insight into the nature of the phosphorus/antimony antagonism which has been proposed in the literature.

Three partial sets oi laboratory scale combustion experiments were completed during the course of this work. In addition to the burning parameters which have been measured during these combustion experiments, smoke samples have been collected for condensable volatiles analysis by capillary GC. This work will be completed as soon as the necessary mass spectral confirmation of the tentative degradation product GC assignments is obtained. These data will form the basis for a comparison of the combustion efficiency of not only the 
polymer substrate, but also the organohalogen volatiles generated during the burns. These data are potentially very significant for certain organohalogen sources from an overall fire safety, risk and hazard assessment perspective. The most important conclusion which has been drawn from the analysis of the available combustion data is that there are clearly small, but significant, differences in the combustion efficiencies of the different halogen sources in the different polymer substrates. Consequently, it can also be concluded that antimony/halogen flame retardant systems are not completely substrate independent, as has often been implied in the flame retardant literature.

The results of this systematic investigation into the solid state chemistry of organohalogen/antimony oxide flame retardants have yielded new, basic information with respect to fire retarded and fire resistance thermoplastics; the mechanisms for the formation of volatile antimony species from the reaction of antimony oxides and other antimony compounds in the presence of organohalogens; the controlled combustion of thermoplastics containing this important class of flame retardants. It was also the first work to identify the presence of the potentially hazardous degradation products of DBDPO which are given off during combustion, which have been the subject of such interest in the recent literature.

\section{Reports and Papers:}

1. "Organobromine/Antimony Oxide/Polymer Substrate Interactions in the Solid Phase. Part I. Binary Interactions," Second Chemical Congress of the North American Continent, Las Vegas, Nevada, August 1981.

2. "Antimony Oxide/Organohalogen Flame Retardant Systems, Are they Really Synergistic?", Polymer Products Res., DuPont, Wilmington, Delaware, February, 1981 .

3. "Organohalogen/Antimony Oxide/Polymer Substrate Interactions in the Solid Phase. Part I. Binary Interactions," M. J. Drews, C. W. Jarvis, and E. A. Leibner, Organic Coatings and Plastics Preprints, 43, 181 (1981).

4. "Fire and Smoke Retardants," Prepared for Director Snell for the 1982 U.J.N.R. Conference, M. J. Drews.

5. "Progress Report. Organobromine/Antimony Oxide/Polymer Substrate Interactions in the Solid Phase," M. J. Drews and C. W. Jarvis, Fifth Annual Conference on Eire Research, National Bureau of Standards, Washington, D.C., August 19-21, 1981.

6. "Thermally Initiated Solid State Reactions in Polymer Substrates Containing Antimony Trioxide," T. L. Gilstrap, Masters Thesis, Clemson University, May 1984.

7. "A Thermal Analysis and Calorimetric Investigation of Antimony Oxide/Organohalogen Flame Retardant Systems," Great Lakes Chemical Corp., West Lafayette, Ind., July 1985.

8. "Organohalogen/Antimony Oxide/Polymer Substrate Interactions in the Solid Phase. Part I. Small Scale Degradation Studies of Simple Mixtures," M. J. Drews, C. W. Jarvis, and E. A. Leibner, in preparation for submission to J. of Fire Sciences, 1986. 
9. "Organohalogen/Antimony Oxide/Polymer Substrate Interactions in the Solid Phase. Part II. A Thermal Analysis Study of the Thermally Initiated Reactions," M. J. Drews, C. W. Jarvis and t. I. Gilstrap, in preparation for submission to J. Appl. Polym. Sci., 1986.

10. "The Use of Cone Calorimetry to Measure the Efficiency of Antimony Oxide/ Organobromine Flame Retardants in Polypropylene and Poly(methylmethacrylate)," M. J. Drews and C.W. Jarvis, in preparation for submission to the J. of Fire Sciences, 1986.

11. "Polymer Substrate Interactions with Metal Oxide/Organohalogen Flame Retardant Additives," Annual Conference on Fire Research, National Bureau of Standards, Washington, D.C., November 3-7, 1986.

12. "Combustion Products in the Presence of Antimony Trioxide," M. J. Drews, C. W. Jarvis and G. C. Lickfield," Fire Retardant Chemical Association Technical Conference, Charleston, S.C., October 19-22, 1986. 


\section{CENTER FOR FIRE RESEARCH \\ NATIONAL BUREAU OF STANDARDS \\ FY 86}

\begin{tabular}{|c|c|c|}
\hline $\begin{array}{l}\text { Institution } \\
\text { Grant No: } \\
\text { Title: }\end{array}$ & $\begin{array}{l}\text { Factory Mu } \\
\text { 6ONANB4D-0 } \\
\text { Developmen } \\
\text { Fire Prope }\end{array}$ & $\begin{array}{l}\text { Atual Research Corporation } \\
0043 \\
\text { at of a Model to Provide Comprehensive } \\
\text { erty Data }\end{array}$ \\
\hline Principal Investig & ator: & $\begin{array}{l}\text { Dr. A. Tewarson } \\
\text { Factory Mutual Research Corporation } \\
1151 \text { Boston-Providence Turnpike } \\
\text { Norwood, Mass } 02062 \\
\text { Telephone: }(617) 762-4300 \times 2950\end{array}$ \\
\hline ther Professional & Perso & Ms. J. Steciak, Advanced Research Scier \\
\hline
\end{tabular}

Technical Abstract:

The objective of this research effort is to improve predictions for fire properties, which include combustion efficiency $\left(x_{A}\right)$ and its convective and radiative components ( $\chi_{C}$ and $x_{R}$ respectively) and generation efficiencies of gaseous, liquid, and solid compounds $\left(f_{j}\right)$. Such improvements are expected to enhance the ability of models to assess fire hazard and protection requirements.

In this study, relationships are being sought between fire properties and 1) smoke point height of materials $\left(z_{S}\right)$ such that voluminous literature data on $\ell_{S}$ can be used; 2 ) nature of chemical bonds in materials; 3 ) molecular weight of materials; 4) fire ventilation; and 5) Pire size.

Reactivity in combustion of about 250 materials including polymers has been examined. Figures 1 to 6 show some examples. The decrease in combustion reactivity is followed by: 1 ) decrease in $x_{A}$ and $x_{C}$; and 2) increase in $x_{R}$ and $\hat{f}_{j}$, where $j$ represents compounds associated with incompleteness of combustion such as $\mathrm{CO}$, total gaseous hydrocarbons (CH), particulates (S), and mixture of unidentified chemical compounds (C).

The reactivity in combustion decreases with increase in bond unsaturation, for example, $\chi_{A}$ value is highest for normal alkanes $\left(C_{n} H_{2 n+2}\right)$ and is lowest for arenes (materials with benzene rings in the structure). $x_{A}$ decreases from normal alkanes $\left(\mathrm{C}_{n} \mathrm{H}_{2 n+2}\right)$ to normal alkenes $\left(\mathrm{C}_{n} \mathrm{H}_{2 n}\right)$ to normal alkynes and dienes $\left(\mathrm{C}_{n} \mathrm{H}_{2 n-2}\right)$.

The reactivity in combustion appears to depend on the relative degree of unsaturation in the pyrolysis compounds. A combustion reactivity parameter, $\bar{\xi}$, has thus been defined, which is the ratio of the sum of yields of alkanes, alkenes, and $\mathrm{H}_{2}$ to the sum of the yields of alkynes, dienes, arenes, and butylene. Some selected relationships are shown in Figures 5 and 6 for polymers.

This study is continuing, where a general understanding of resistance to thermal decomposition and formation of pree radicals for oxidation by various monomers, oligomers, and their smaller fragments and validity of the combustion reactivity parameter are being sought such that in conjunction with theoretical calculations, the predictions for fire properties can be established firmly. 


\section{Reports:}

1. A. Tewarson, "Predictions of Fire Properties of Materials, Part I: Aliphatic and Aromatic Hydrocarbons and Related Polymers" National Bureau of Standards, Center for Fire Research, Gaithersburg, MD, Technical Report Grant NO. 6ONANB4D-0043, July 1986.

2. A. Tewarson, "Predictions of Fire Properties of Materials, Part II: Oxygenated Materials and Related Polymers" National Bureau of Standards, Center for Fire Research, Gaithersburg, MD, Technical Report Grant No. 60NANB4D-0043. August 1986 (to be issued).

3. A. Tewarson, "Predictions of Fire Properties of Materials, Part III: Nitrogen and Sulfur Containing Materials and Related Polymers" National Bureau of Standards, Center for Fire Research, Gaithersburg, MD, Technical Report Grant No. 60NANB4D-0043, October 1986 (to be issued).

4. A. Tewarson, "Fire Properties of Materials and Their Applications to Multi-Room/Corridor Enclosures and Chemical Modeling of Gaseous Species in Turbulent Fires" National Bureau of Standards, Center for Fire Research, Gaithersburg, MD, Technical Report Grant No. 60NANB4D-0043, (to be issued). 


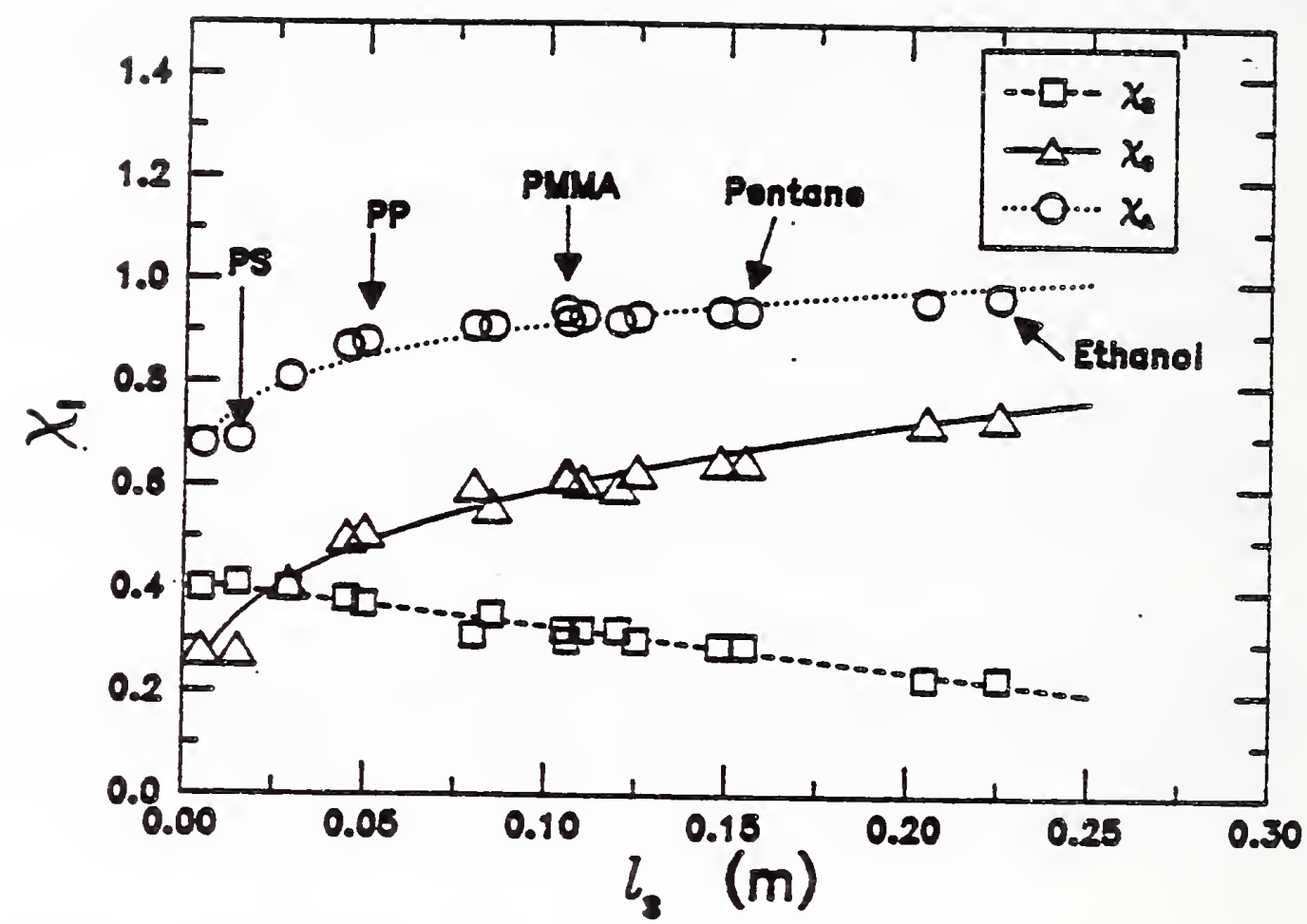

P1gure 1 Relationship between combustion effictency, its convective and radiative components, and smoke point helght

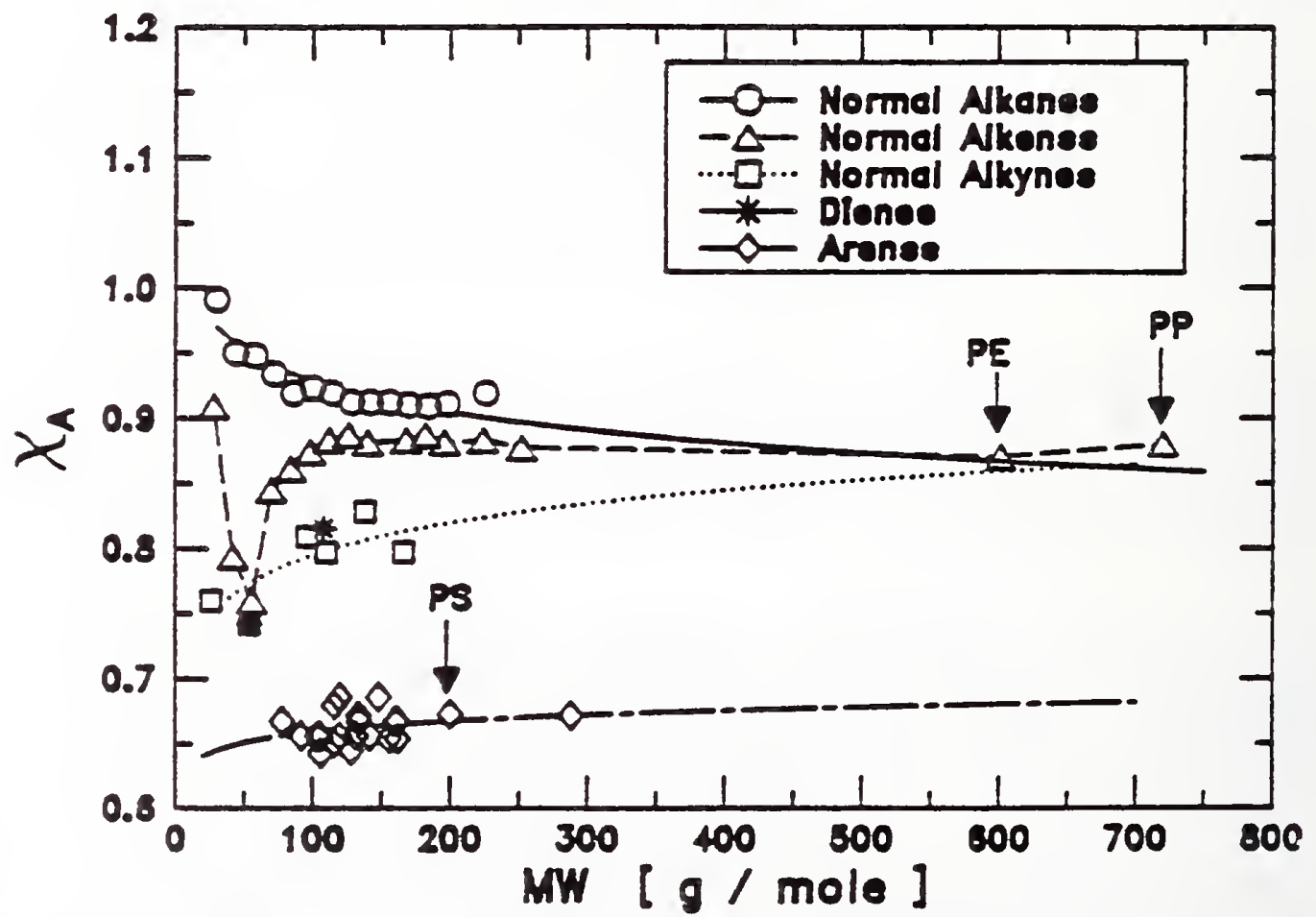

Pigure 2 Relationship between combustion effictency and molecular welght of hydrocarbons and polyethylene, polypropylene and polystyrene olfgomers 


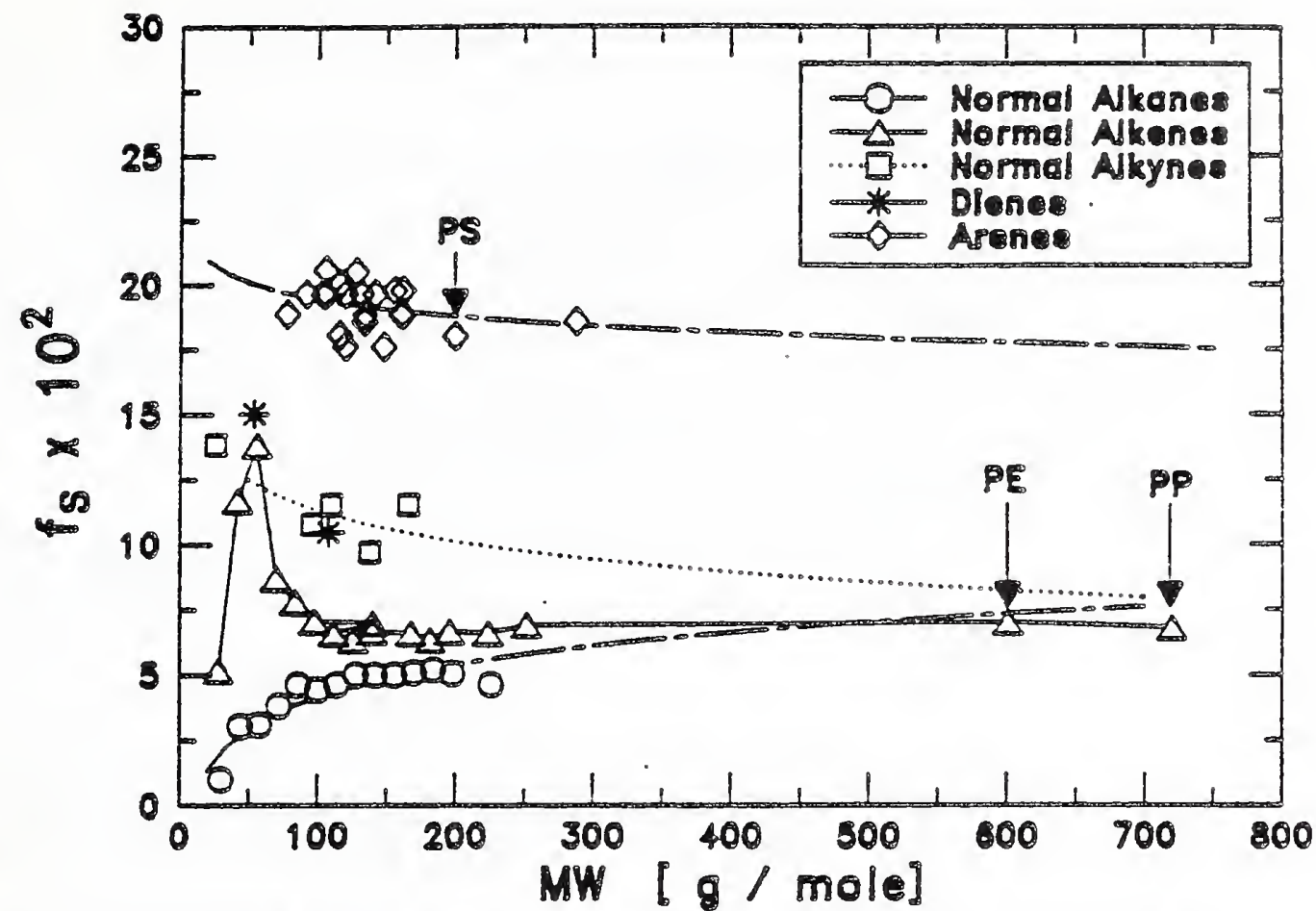

Figure 3 Relatlonship between generation effleleacy of particulares and molecular weight

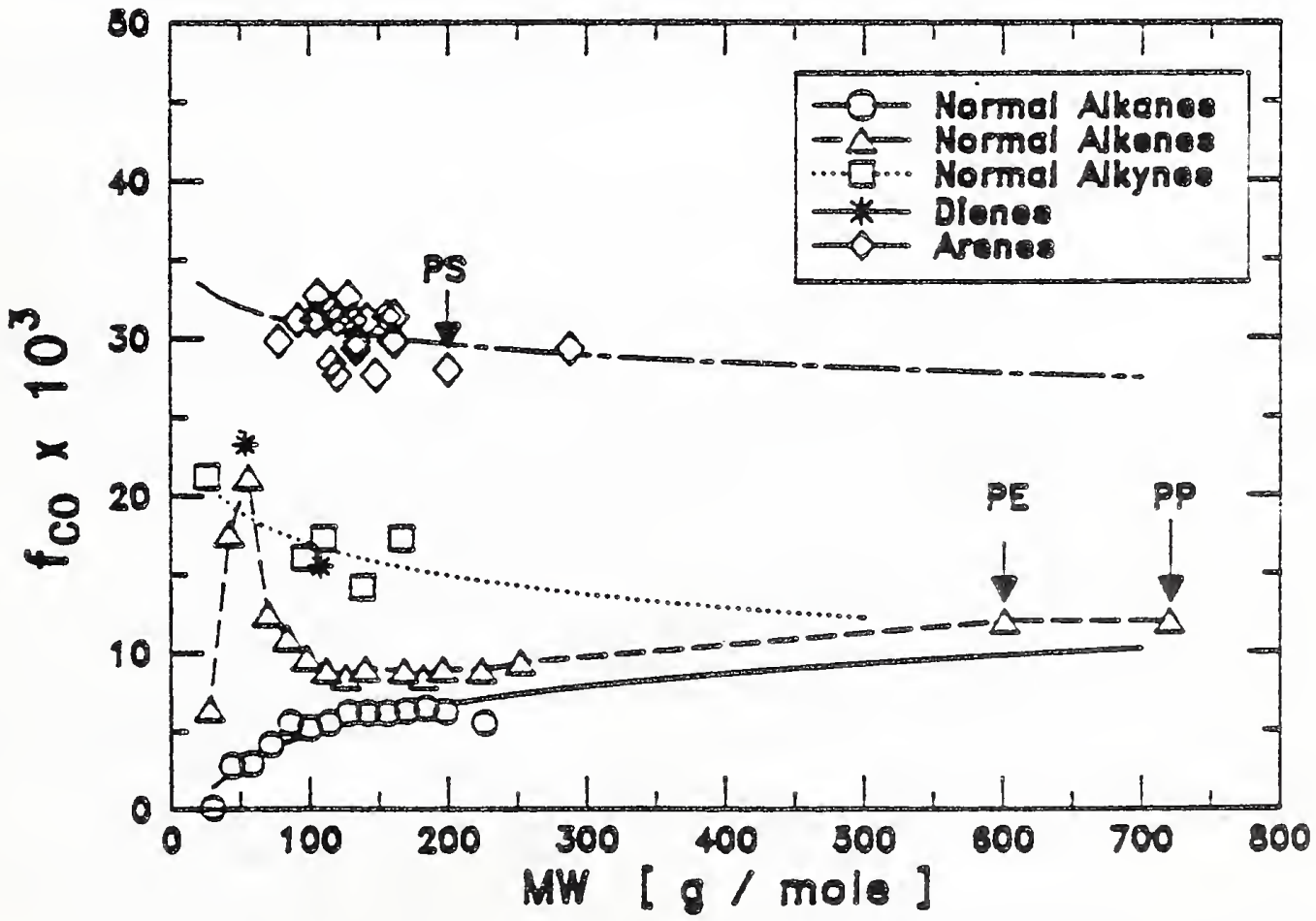

Pigure 4 Relationship between generarion efflctency of $c 0$ and wolecular weight 


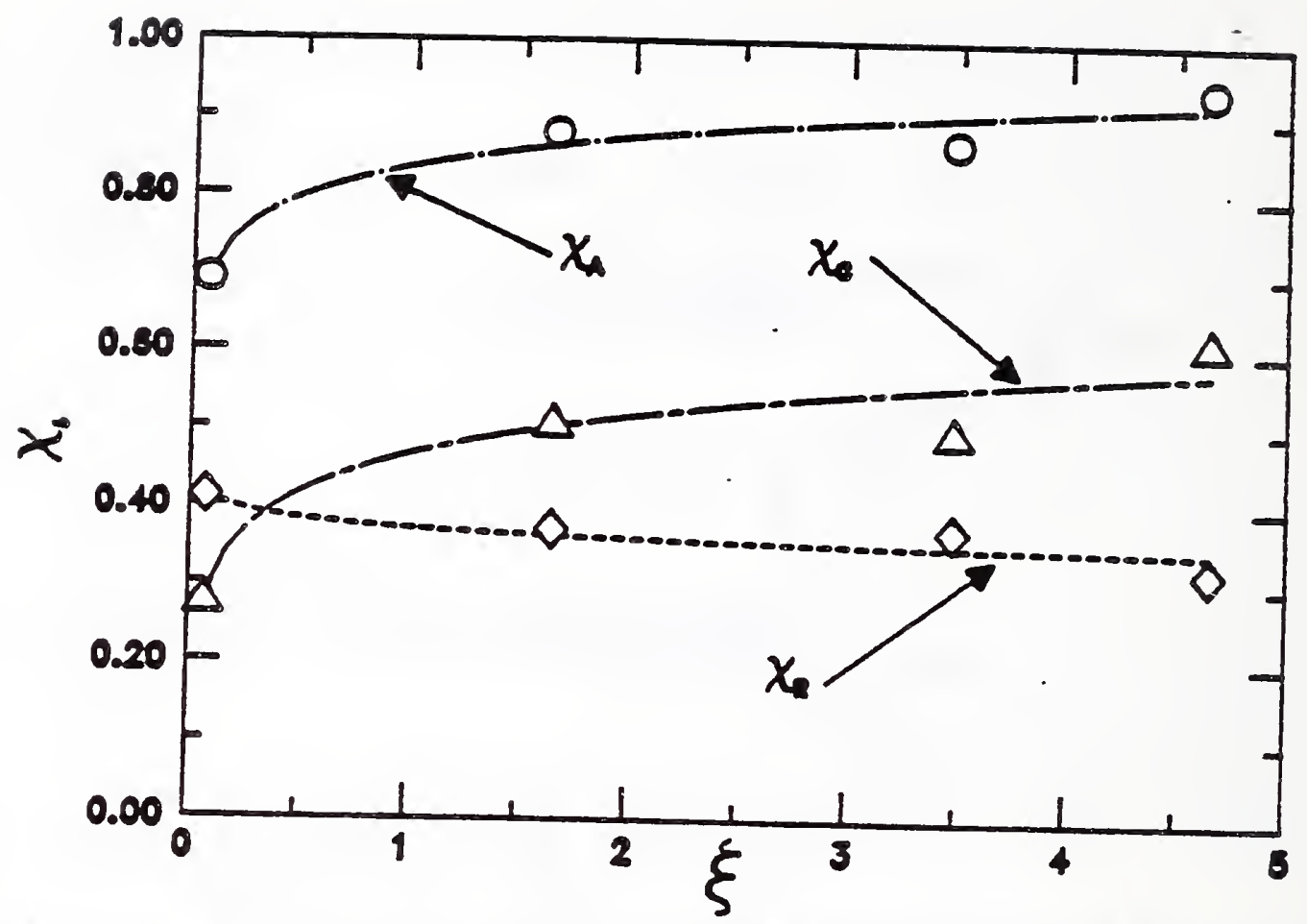

Figure 5 Combustion efficiency and 1 ts convective and radlative components for polymers as functions of combustion reactivity parameter (Calculated from the pyrolysis data at $1200^{\circ} \mathrm{C}$ )

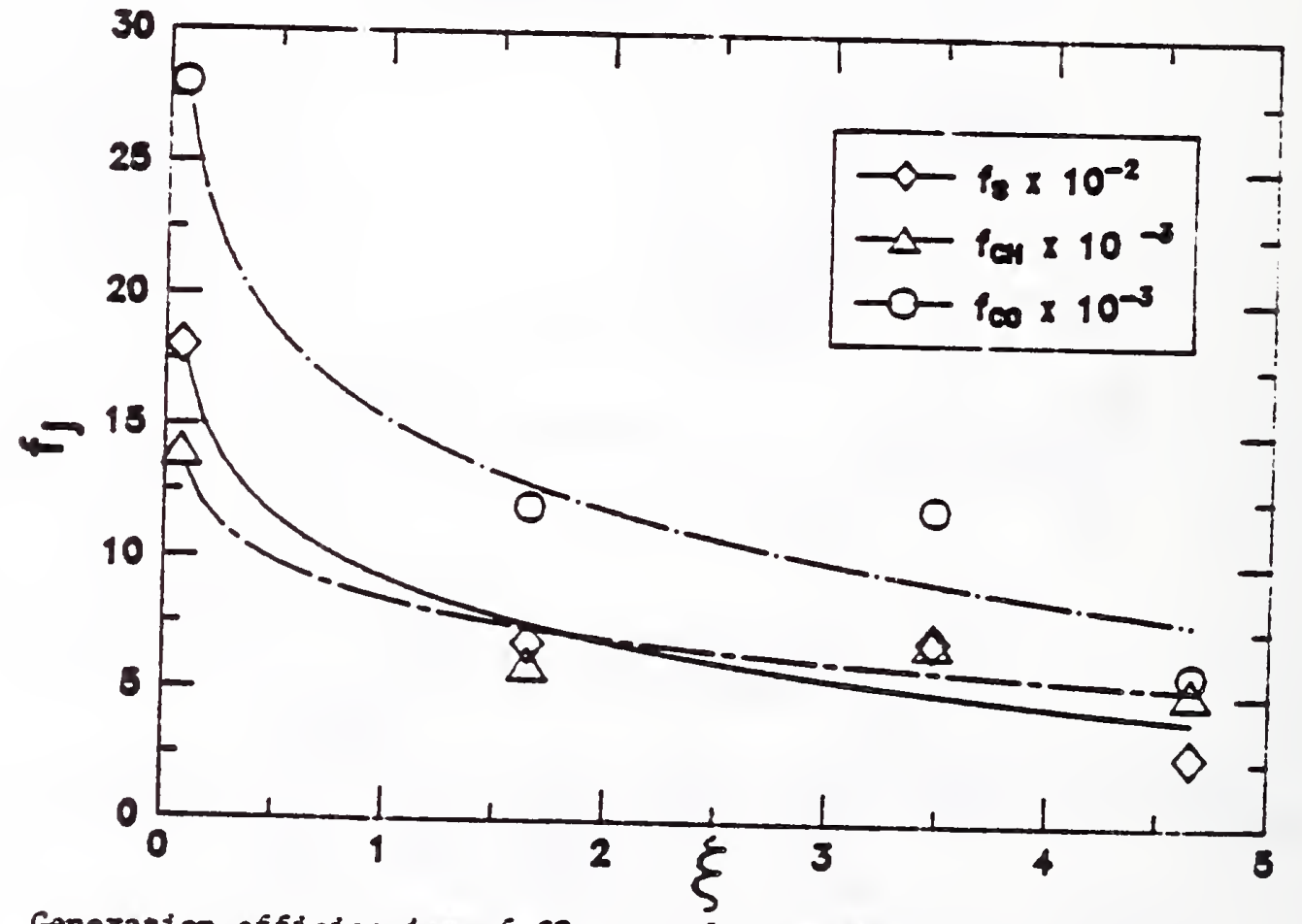

Flgure 6 Generation efficiencies of $\mathrm{CO}_{2}$, total gaseous hydrocarbons and particulates in the combustion of polymers as functions of combustion reactivity parameter (Calculaced from the proolysis data at $1200^{\circ} \mathrm{C}$ ) 


\section{CENTER FOR FIRE RESEARCH \\ NATIONAL BUREAU OF STANDARDS \\ FY 86}

Institution:

Grant No:

Title:

Principal Investigators:

Other Professional Personnel:

NBS Scientific officer:
Factory Mutual Research Corp., Norwood, MA 02062 6ONANB5D0560

Prediction of Fire Dynamics

Raymond Eriedman (617)762-4300, ext. 2890

Howard W. Emons (617) $495-2847$

R. L. Alpert

M. A. Delichatsios

J. de Ris

G. H. Markstein

L. Orlorf

B. McCafirey and Ho Mitier

Technical Abstract:

This work is divided into four tasks.

Task 1. Prediction of Fires in Buildings (H.W. Emmons)

The major topic of research during this grant period has been the Theory of the ceiling jet.

Several possible hydraulic type theories have been developed for the front of the spreading jet. If the mechanical energy loss along the floor is $n$ times that along the jet front interface, the velocity of the lower fluid relative to the front is given by

$$
\begin{aligned}
& U_{D O}=\left(\frac{\Delta(2 n-\Delta)}{n-\Delta^{2}}\right)^{1 / 2} \quad \text { where } \quad \Delta=\frac{\delta}{H}=\frac{\text { jet depth }}{\text { duct hejgint }} \\
& U_{D O}=\frac{U_{D O}}{\sqrt{g^{\prime} H}}=\frac{\text { velocity }}{\sqrt{g \frac{\Delta \rho}{\rho} H}}
\end{aligned}
$$

If there are no losses along the bottom (ignoring bottom friction), $n=0$, this formula reduces to $U_{D O}=i$, derived earlier on this project. While if $\eta=1$, the loss along the bottom is equal to that along the separating streamIine, and the equation reduces to that of Benjamin $[1]$.

The development of a suitable hydraulic type jump formula was impeded by the necessity of evaluating the pressure difference across the jump. The open channel flow jump does not present this difficulty because there is atmospheric pressure on each side. In a duct, the determination of the pressure dis. Perence requires an additional relation. The physical laws are not adequate for a hydraulic type theory. A number of assumptions were tried, and those made by $Y$ in and Guna[2], and Chu and Baddourt3] were found adequate to the extent that present experimental results are able to discern.

A report on the Transient ceiling jet-Part 1 has been finished. This report presents the details of the 4 quadrants of hydraulic jumps in a twofluid stratified flow in a duct. This type of flow includes the ceiling jet from a fire moving down a corridor with a cold lower layer flowing toward the ire. 
The theory of celling jet flow with a jump following a front has been computed in detail for an air "celling jet" entering a tube filled with water while the water runs out below. This jump-pront flow is combined with the theoretical performance of a flow control at the open end of the tube (other end closed) consisting of a slot above for air entry and a slot below for water discharge.

This theory explains in a stralghtforward way the observed three types of ceiling jet, observed experimentally as water is discharged from a horizontal tube.

This theory was presented at the IUTAM Symposium in honor of G.I. Taylor's looth birthday. Following. my presentation, I visited Prof. Paul Linden and retired Prof. John Simpson of the Department of Applied Mathematics and Theoretical Physics at Cambridge University. They are planning some experimental work on the Fire Ceiling Jet. I have sent them the ceiling jet inlet plows from the calculations of the MGM Pire, and Prof. P. Linden has visited me here in the U.S. to clarify further details.

On March 5-6, at the SFPE Symposium on "Quantitative Methods for Life Safety Analysis", I presented a paper in which some new thoughts on fire safety calculation were presented. The quantitative prediction of a fire can include the production of a Hazard Map (FIg. 1) for each escaping occupant. On this map, the path of the escapee can be drawn, and from this the point of incapacitation and death can be computed. By this method, the fire safety of all occupants can be calculated.

The use of any material of construction having toxic fire products can be checked by this method for fire safety in the proposed use. This is the essential knowledge required for a performance code as soon as validated computer codes are developed and sufficient handbook type data are obtained.

An important further use for this quantitative method of toxic gas analysis as soon as it is avallable is the use of some of the 6,000+ pire deaths in the U.S. each year as "toxicity tests with humans". At present, all but qualitative accidental fire data on toxicity is lost for want of an adequate method of analysis.

The calculation of fire in an unfirestopped wall space connected top and bottom to another open wall space has been stalled by numerical instabilities. These are slowly being understood and removed, but it will take some time yet to develop a good working computer program.

The section of the SFPE Fire Science Handbook on Vent Flows submitted last fall has been reviewed and corrected and returned to the section editor (Craig Beyler) for publication.

References

1. Benjamin, T.B., "Gravity Currents and Related Phenomena," J. Fluid Mechanics, 31, p. 209-248 (1968).

2. Yih, C.S., Guha, C.R., "Hydraulic Jump in a Fluid System of Two Layers," Tellus, 7, p. 358-366 (1955). 
3. Chu, V.H., Baddous, R.E., "Surges, Waves, and Mixing in Two Layer Density Stratified Flow," Proc. 17 Cong. Intl. Asso. Hydraulic Res., 1, D. 303-310 (1977).

\section{Lectures}

"The Needed Fire Science," Eirst International Symposium on Fire Sarety Science, oct. 7-11, 1985.

"Fire Spread Beyond the Room of Origin," SFPE Symposium on Quantitative Methods for Life Safety Analysis, March 5-7, 1986.

"The Transient Ceiling Jet," IUTAM Symposium on Fluid Mechanics in the Spirit of G.I. Taylor, March 24-28, 1986.

"Why Eire Model?" Guise Award Lecture, SFPE Annual Meeting, May 20-21, 1986.

\section{Reports}

Fire Detectors for Public Fire Safety, Report \#79

Eire Safety of Buildings and Building Gccupants, Report \#72

Why Fire Model? The MGM Fire and Toxicity Testing, The SFPE Guise Award Lecture, Report \#73

The Transient Ceiling Jet-Part 9 , Report \#74 


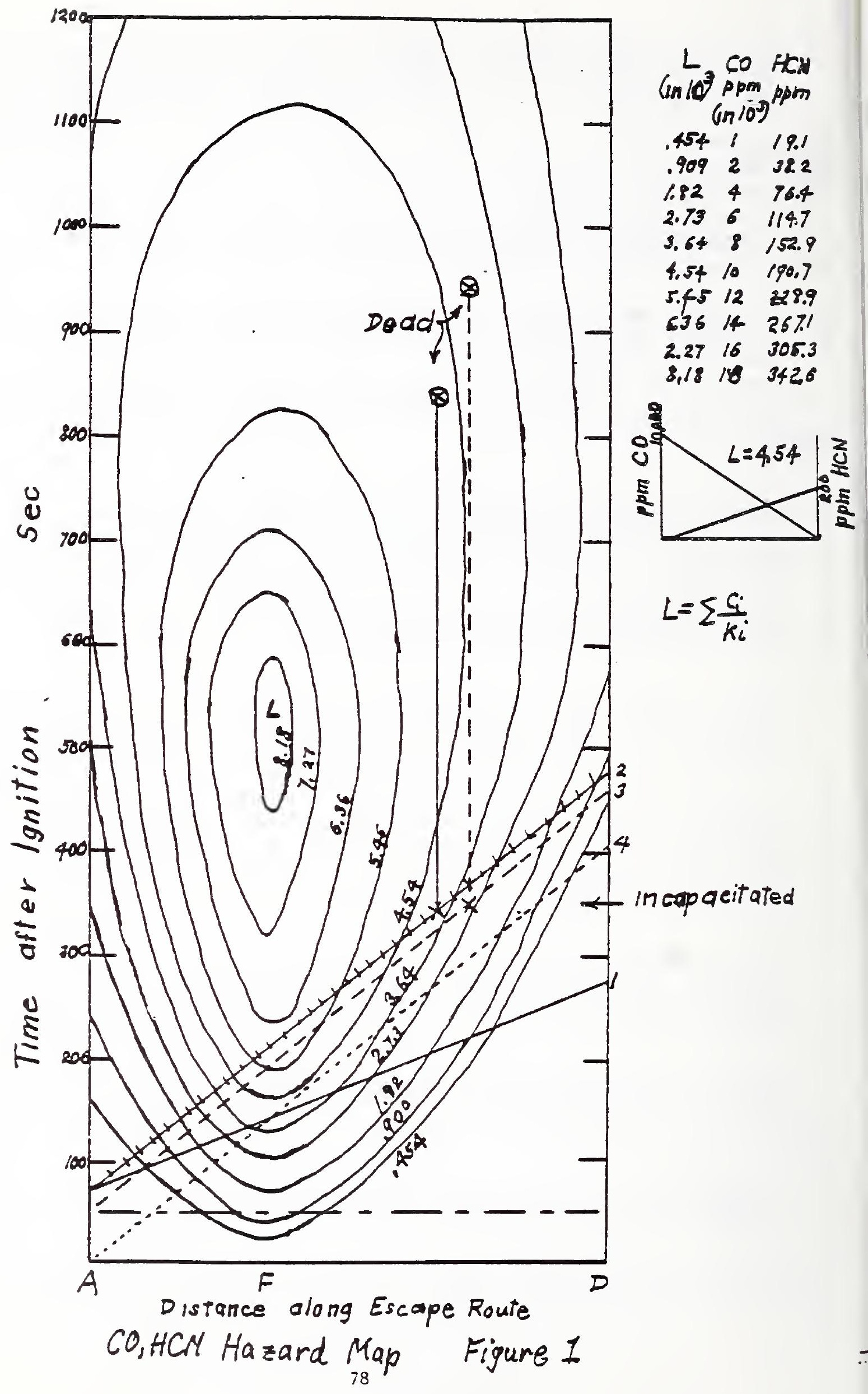


Task 2. Radiative Properties of Vitiated Flames

\section{(L. Orloff, M.A. Delichatsios, J. de Ris)}

The main objectives are the measurement and characterization of flame radiation from fires in a vitiated environment and the development of integral models for fluid mechanics - combustion interactions including radiation losses. Such models for flame radiation and turbulent combustion are needed in advanced computer codes to predict accurately fire growth in a vitiated environment; for example multiroom fires.

The study of vitiated flames uses gaseous buoyant jet flames burning inside a water-cooled enclosure to eliminate any wandering of the flames and provide the required vitiation environment. Different size nozzles ( $96 \mathrm{~mm}$, $28 \mathrm{~mm}, 35 \mathrm{~mm}$ ) are being used for investigating effects of the initial exit flow on llame radiation. The vitiated burning experiment is designed to explore the effects of various vitiation parametars on radiation: 1) oxygen concentration in the ambient; 2) ambient temperature; 3) fuel mixture temperature; and 4) fuel composition.

The fuel mass flow rate and its concentration by dilution is set automatically by mass flow controllers. The nozzles have been designed for preheating the gas just before the nozzle exit. Ambient air vitiated by $\mathrm{CO}_{2}$ and $\mathrm{H}_{2} \mathrm{O}$ (1521 oxygen mole percent) is supplied from the exhaust gases of two commercial burners. These exhaust gases pass first through heat exchangers and filters before entering the enclosure as a highly quiescent flow. Total radiant emission from the fires is measured by a conventional wide-view-radiometer and a slit radiometer. The burner moves vertically in front of the slit radiometer by means of a piston automatically controlled. Because of space considerations, the radiometer requires parallax corrections. Such corrections were established theoretically and were checked (within an error of 5\%) by integrating the output of the slit radiometer.

Eigure 1 shows plots of normalized radiant output per unit height for vitiated flames in terms of a normalized height (e.g. flame height). It is remarkable that these plots are essentially independent of the heat release rate and the depletion of ambient oxygen. Note some dissimilar effects at the lower half of these plots. The nozzle size for these experiments was $28 \mathrm{~mm}$. Experiments with other nozzle sizes $(16 \mathrm{~mm}, 35 \mathrm{~mm})$ are planned to investigate near source effects on the radiation field.

Figure 2 shows the variation of radiant fraction with ambient oxygen concentration. Extrapolation of these results indicates that extinction occurs at approximately $14.5 \% \mathrm{O}_{2}$ which is consistent with extinction limits inferred from laminar smoke point measurements.

This work continues in order to extend previously established relation ships for fire radiation and smoke puint height to vitiated flames.

A parallel effort has been made for modeling turbulent combustion. We have made significant progress by proposing a hypothesis for the key parameters that control the flow dynamics of turbulent fires. This hypothesis leads to results which are corroborated by experimental data. $[1,2]$

The key ingredients of the prssent model can be summarized briefly. One may observe that in turbulent fires local turbulence is generated by two 
buoyancy forces: 1 ) the buoyancy flow rate similar to that in buoyant thermal plumes involving no combustion, and 2) a buoyancy force arising from hot eddies burning near peak plame temperatures. One may argue that these two buoyancy sources are determined by a) the maximum buoyancy flow rate, $b$ ) the buoyancy forces at peak laminar flame temperatures, 3) the stolchiometric mass air to fuel radio, $S$, and d) the turbulence length scales - both Kolmogorov (molecular) and macroscale. Existing evidence, however, suggests that for fast chemical reactions, the Kolmogorov scale does not affect the rate of heat release, which depends only on macroscale mixing. Therefore, only the turbulent macroscales, which are determined by the fire geometry, affect the fire dynamics. The Kolmogoror scale controls the radiative characteristics of the flames.

The main results from this work are summarized in Figure 3 wherein theoretical entrainment predictions in the pire region are compared with experiments. Our work in this area continues with the development of integral stochastic models for mixing and combustion (see, e.g., ref. 4)

Publications

1. Delichatsios, M.A., "Air Entrainment into Buoyant Jet Flames and Pool Fires," to be published in Fire Science Handbook, C. Beyler, Editor.

2. Orloff, L., de Ris, $J_{.}$, and Delichatsios, M.A., "Chemical Modeling of Gaseous Species in Turbulent Fires," accepted to the 21 st International Symposium on Combustion, 1986.

3. Delichatsios, M.A., "On the Modeling of Strong (Variable Density) Turbulent Buoyant Plumes and Ceiling Jets," presented at the Eastern Section Meeting of the Combustion Instituté, Philadelphia, Nov. 4,5,6, 1985.

4. Delichatsios, M.A., "A PDF Method Por Predicting Major Species Concentrations in Turbulent Fires," presented at the Eastern Section Meeting of the Combustion Institute, Philadelphia, Nov. 4,5,6, 1985. 


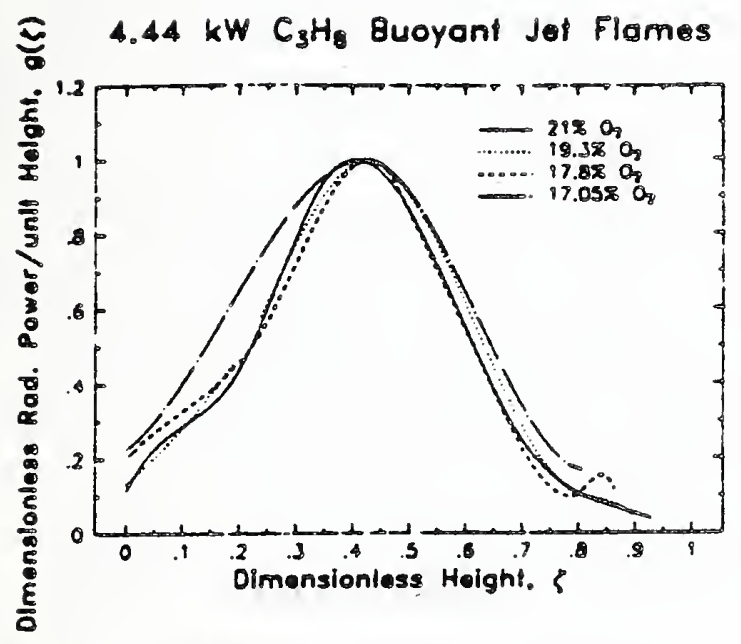

F18. 1: Normal1zed radlant output per unit helght vs. normalized distance from bhe source

\section{$\mathrm{C}_{3} \mathrm{H}_{3} \quad 4.44 \mathrm{~kW}$ Vitiated}

Quoyont Turbulent Flomes in Red Tank

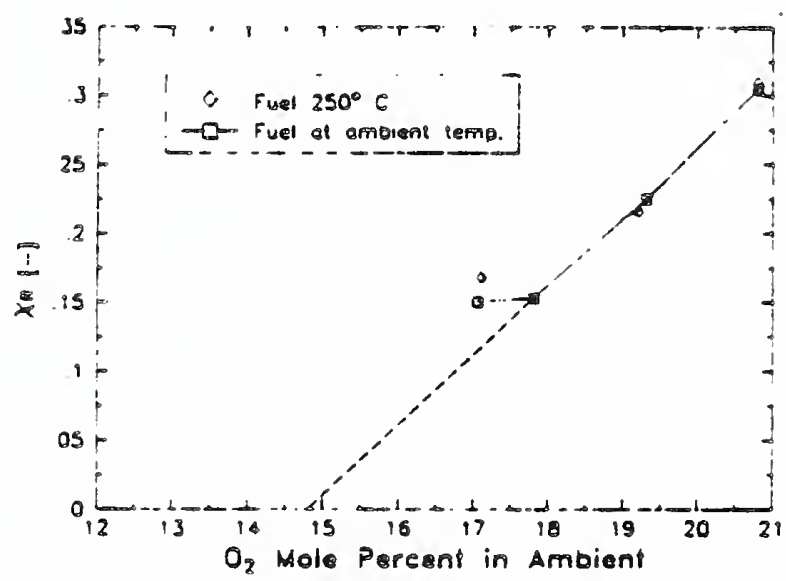

F18. 2: Varlation of radians fraction wth oxygen concentracion in amblent ais

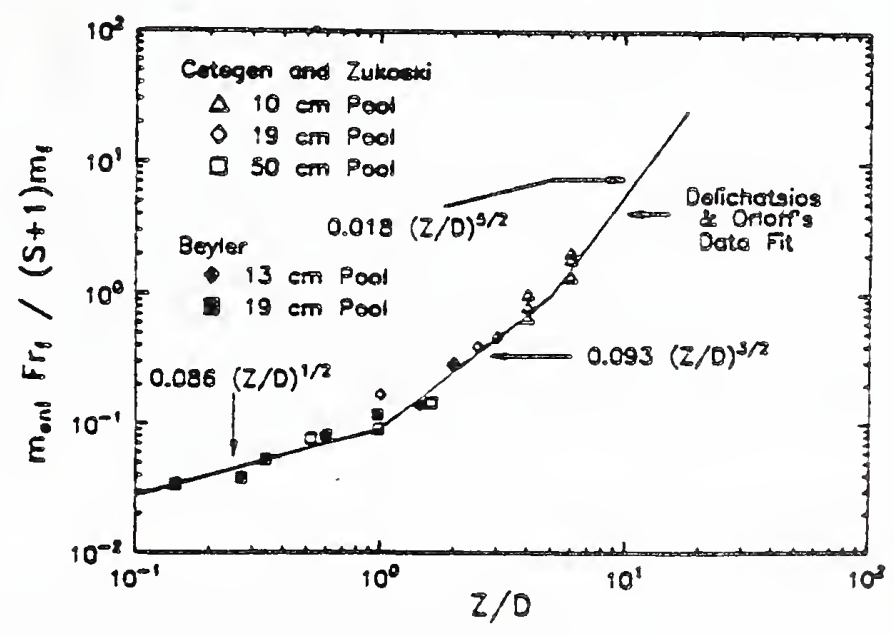

F1g. 3: Normalized encrainment vs, hedghe

in the burning zegion of pool fires 
Task 3. Wall Fire Flame Radiation (G.H. Markstein, J. de Ris)

The main objective is the extension of previously established relationships for fire radiation to fires burning on vertical walls. The significance of studies of fire radiation rests on the fact that in many fires energy transfer from the flame to the fuel and to the surroundings occurs predominantly by thermal radiation. The rate of fire growth and the spread of fire to new fuel elements depends critically on this energy transfer, and its quantitative assessment is thus essential for predicting fire behavior.

The study of wall fires under this task uses gaseous fuels burning on a water-cooled, vertical porous-metal surface, permitting steady-state burning, and, if desired, simulation of a range of mass transfer ( $B$ ) numbers of solid fuels. The pyrolysis height can be varied by a choice of the number of burner panels that supply fuel to, the fire. The work thus far performed uses a previously developed burner[1] consisting of six 380-mm wide and 220-mm high sintered-metal panels, individually water-cooled, stacked vertically and topped by a water-cooled 380-mm wide and 520-mm high metal plate. Water cooled sidewalls of 160-mm depth are attached over the entire height. Fuel is supplied to the individual panels by electronic flow controllers. The heat transferred to each panel is determined from the temperature rise of the cooling water.

The fuel mass flow rate and the rate of heat transfer define, in turn, an effective mass transfer number, B, so that solid or liquid fuels of given Bnumber can be simulated by adjusting the flow rate of the gaseous fuel [1]. In the present work, a digital control loop was used to set the fuel flow for each burner panel supplying fuel independently to the specified B-number. The number and position of burner panels supplying fuel to the fire can be selected arbitrarily. Total radiant emission from the fires was measured with a conventional wide-view-angle radioweter employing a spectrally plat thermopile sensor. In addition, the vertical distribution of radiant power per unit height emitted by narrow horizontal slices across the width of the fire was measured with a scanning slit radiometer. The scan was obtained by means of an electromagnetically deflected plane front-surface mirror operated in a linear ramp mode. Each scan comprised 500 data points recorded during a traverse of the height of the burner in $50 \mathrm{~ms}$. A Past-response spectrally lat pyroelectric sensor was used in this instrument. Mean profiles of radiant power per unit height were obtained by averaging 125 individual scans in each run.

Since the fine-grained sintered metal of the present burner is susceptible to clogging by soot, the work has been performed exclusively with ethane, which produces relatively small amounts of soot. The B-numbers ranged from 0.5 to 3, with fuel supplied from one to three panels. Results for a representative run are shown in Fig. 1. The plot shows on the left a schematic of the burner panels with indication of the fuel flow rates, further to the right the heat fluxes into the panels, and on the right the vertical profile of radiant power per unit height. The total rate of heat release, total radiant power, and radiative fraction are also indicated.

The most important result of the work concerns the radiative fractions of total heat release rate, which were found to vary from about 12 percent to about 17 percent, increasing both with B-number and with the number of fuelsupplying panels. These values are well below that of free-burning buoyant 
turbulent ethane jets, whose radiative fraction is about 21 percent, indepen dent of fuel flow rate over a wide range of flow rates. The value of 21 pepow cent, obtained in several previous studies, was confirmed by measurements on fuel jets with the present instrumentation.

In contrast to the present results, in a wall-fire study in which the fuel was supplied by an uncooled slot burner at the base of the wall, Kulkarni [2] measured radiative fractions that agreed with those of free-burning fuel jets. A slot burner, similar to that used by Kulkarni, has been built recentiy. Measurements with this burner placed close to the wall at its base have yieldo ed radiative fractions of about 19 percent, for total heat release rates ranging from about 16 to $59 \mathrm{~kW}$. Thus, although our slot-burner results are somewhat below the values for free-burning jets, they are essentially in agreement with Kulkarni's findings, and suggest that the amount of soot formed in the flame depends critically on the competition between pyrolysis and oxidation processes that occur near the fuel source, which, in turn, depends strongly on the geometry of the fuel supply.

As shown in Fig. 2, further examination of the radiation results including the slot burner data, showed that the total radiant emission Qpad (kiw) satisiled the empirical relationship

$$
\dot{Q}_{\text {rad }}=0.1905 \dot{Q}_{\text {TOT }}-2.442 \mathrm{~L}_{?}^{9 / 2}
$$

where $\dot{Q}_{\text {Tot }}(\mathrm{kW})$ is the total theoretical heat release rate of the fire and $L_{p}$ (m) the pyrolysis height. The latter is defined as the total height of the fuel-supplying panels, and was assumed to be zero for the slot-burner runs. Because of the scarcity of the present data, further work is required to substantiate the validity of this relationship.

The present measurements of heat transfer to the wall, both in and above the fuel-supply region, agreed well with those of various earlier studies of wall fires. $[2-4]$ Einally, as shown in Fig. 3, flane heights were obtained from the intermittency of the scanning data by determining the height at which half the data were below and half above a small threshold value. Fig. 4 shows

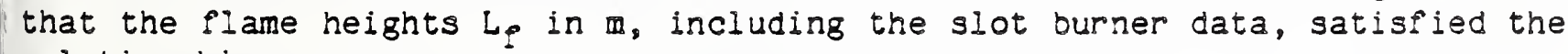
relationship

$$
L_{f}=0.059 \dot{Q} \cdot 2 / 3
$$

where $Q^{\prime}$ is the total heat release rate per unit burner width ( $\mathrm{kW} / \mathrm{m}$ ). This result agrees with other experimental and theoretical indings. [4,b] Combining eqs. (1) and (2), one obtains an expression for radiative fraction

$$
x_{\text {rad }}=x^{*}-L^{*} L_{p}^{1 / 2} L_{f}^{-3 / 2}
$$

with the characteristic values $x^{*}=0.1905$ and $L^{*}=0.092 \mathrm{~m}$ for ethane.

Although the preceding vaiuable results have been cbtained with the burner described above, a new burner incorporating several improvements has been designed and is now under construction. The nost important change is the use of an outer layer of coarse-grained porous sintered metal in front of the fine-grain inner layer, to prevent permanent clogging of the burner surface by soot. This design feature will pernit work with more sooty fuels than ethane. 
The height of the panels of the new burner has been reduced to $127 \mathrm{~mm}$ to provide improved resolution of simulated pyrolysis height $L_{p}$. As another new feature, heat transfer instrumentation will be incorporated in the solid-metal plate above the burner panels.

As a further improvement of the instrumentation, a new scanning slit radiometer employing spherical mirror optics has been designed and built. Initial evaluation has confirmed the expected improvement of signal-to-noise ratio and of angular resolution in the scanning direction. Means for eliminating some nonuniform response with respect to horizontal and vertical angular deflection are currently under study.

After completion of the new burner, it is planned to continue this study, particularly with extension to more sooty fuels. The results will be compared with existing theoretical models of wall-fire combustion, $[3,5-7]$ and will be used for possible modification of such models, as well as for extensign to wall fires of correlations between flame radiation and fuel smoke points. [8]

\section{REFERENCES}

1. de Ris, J. and Orloff, L., "The Role of Buoyancy Direction and Radiation in Turbulent Diffusion Flames on Surfaces," Fifteenth Symposium (International) on Combustion, p. 175, The Combustion Institute, 1975.

2. Kulkarn1, A., "Radiative Heat Transfer from Wall Fires," Fall Technical Meeting, Eastern Section, The Combustion Institute, Paper No. 28, 1984.

3. Ahmed, T. and Faeth, G.H., "Turbulent Wall Eires," Seventeenth Symposium (International on Combustion, p. 1149, The Combustion Institute, 1979.

4. Kulkarni, A., Harkleroad, M., and Quintiere, J., "Heat Feedback and Flame Height Measurements on Burning Vertical Surfaces," Fall Technical Meeting, Eastern Section, The Combustion Institute, Paper No. 33, 1983.

5. Delichatsios, M.A., "Turbulent Convective Flows and Burning on Vertical Walls," Nineteenth Symposium (International) on Combustion, p. 1075, The Combustion Institute, 1983.

6. Delichatsios, M.A., "Flame Heights in Turbulent Nall Fires with Significant Flame Radiation," Combustion Science and Technology, 39, 195, (1984).

7. Mitler, H.E., "Wall-Fire Algorithms for Mark 5.n.," Appendix C, Minutes of Ad Hoc Mathematical Fire Modeling Working Group Meeting, oct. 1984.

8. Markstein, G.H., "Relationship Between Smoke Point and Radiant Emission from Buoyant Turbulent and Laminar Diffusion Flames," Twentieth Symposium (International) on Combustion.

PUBLICATIONS

1. Markstein, G.H., "Radiant Emission from Wall Fires," Fall Meeting, Eastern Section, The Combustion Institute, Philadelphia, PA, Nov. 1985.

2. Markstein, G.H., "Radiant Emission and Smoke Points for Laminar Diffusion Flames of Fuel Mixtures," 21 st Symposium on Combustion, Munich, Aug. 1986; FMRC Technical Report RC86-BT-4 (June 1986). 


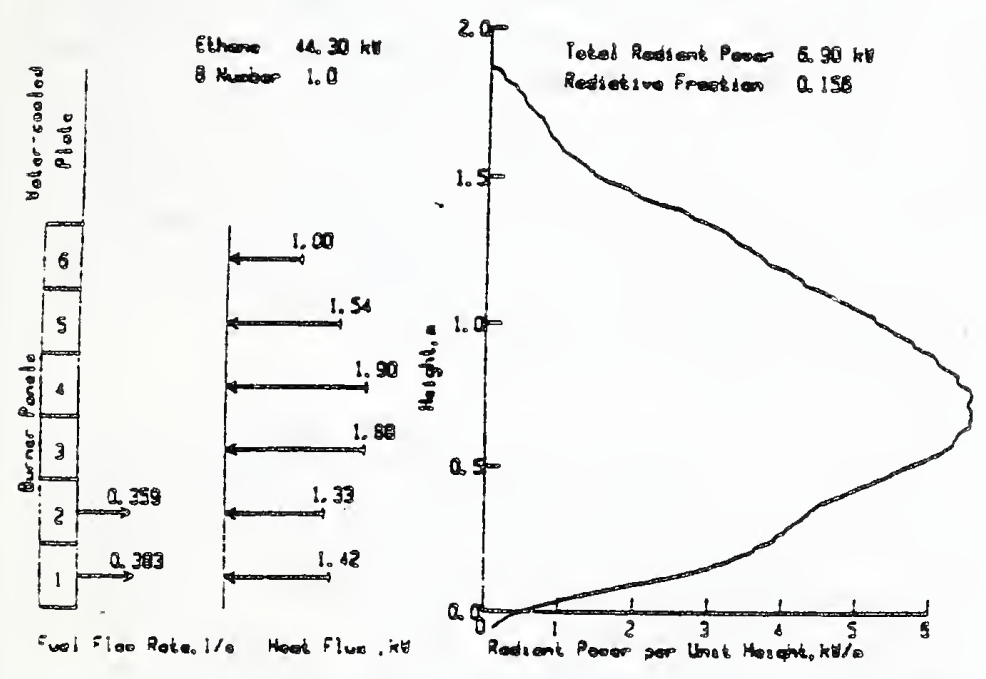

Fig. 1: Wall-fire radiant emission and heat transfer

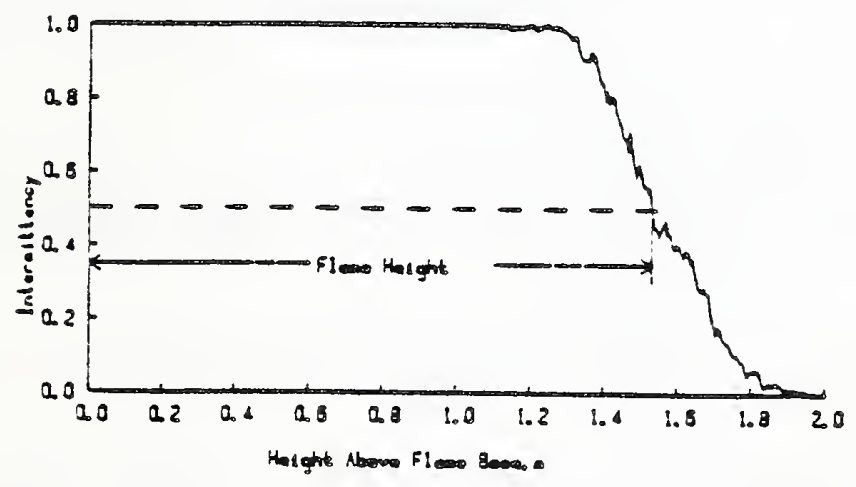

Fig. 3: Detemination of flame height from intermittency of scanning radiometer daca

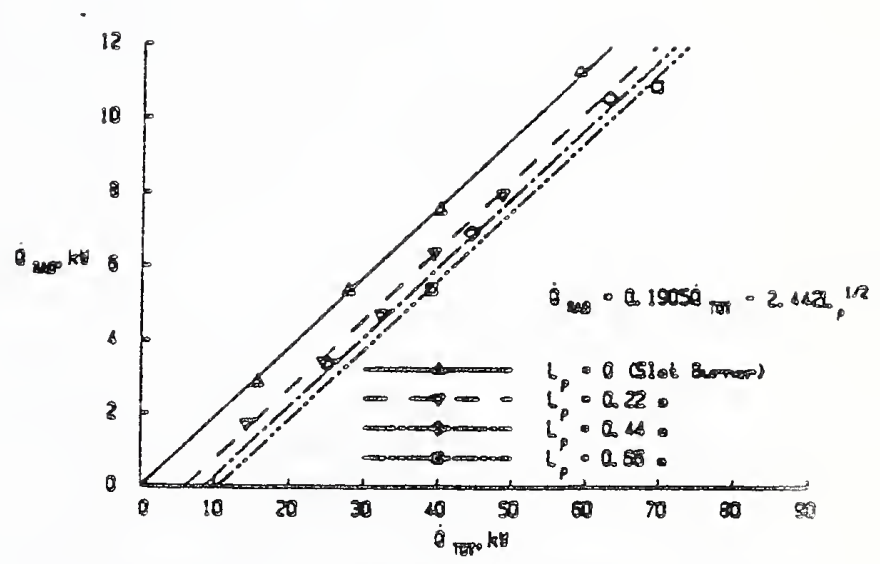

Fig. 2: Correlation between cotal radiane power and total heat release rate for ethane wail fires

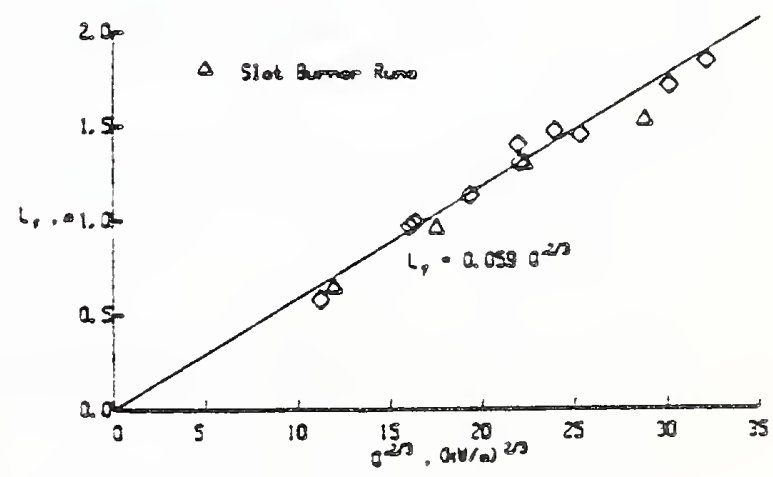

Fig. 4: Flame heigh: us. heat release rate per unit comer width 
Task 4: Transient Pyrolysis and Flame Radiation from Charring Fuels

(R.L. Alpert, M.A. Delichatsios, J. de Ris)

The objective is to measure and model the following two key plammability properties required for predicting flame spread on any material: 1) charring pyrolysis and 2) flame radiation. These properties cannot be currently characterized in a way to be easily incorporated in an advanced fire code.

We have completed the construction of a sophisticated experimental apparatus carefully designed to obtain accurate measurements for the transient pyrolysis rate of charring materials as well as for the flame radiation from the burning of their pyrolysis gases. Shakedown experiments have been performed and have verified that heat fluxes onto the target area are uniform (see Fig. 1). The external heat flux can be provided either by quartz heaters or by a cone-shaped heater (very similar to that in the NBS cone calorimeter) to investigate possible selective spectral absorption of imposed radiation by a given material. (Quartz heaters emit predominantly short-wave length infrared radiation, while the cone heater emits blackbody radiation.)

Based on analytic pyrolysis models for charring and noncharring materials as well as the experfmental results from the new apparatus, we are looking for "equivalent" properties to characterize the transient pyrolysis of charring materials. To provide credibility and validate our analytical model, we have developed a new numerical program to calculate transient pyrolysis of charring materials under the assumption of a thin pyrolysis zone. Cubic splines have been used to represent spatial variations and transform the differential equations to FDE by collocation at the nodes. The program has been applied successfully for predicting the transient pyrolysis rates for noncharring materials (e.g. PMMA) wherein an exact solution is known. The program has been documented and debugged. Sample numerical results are shown in Fig. 2 .

The flame radiation is characterized by measuring in our apparatus the radiant fraction of a buoyant turbulent flame supplied by the puel jet of hot pyrolysis vapors. From these simple measurements of radiant fraction, radiant emission in full-scale wall pires as well as the normal smoke point can be inferred (cf with Tasks 2 and 3 ).

Publications

1. Delichatsios, M.A., de Ris, J., "An Analytical Model for the Pyrolysis of Charring Materials," Eactory Mutual Research Corporation, Report RC84-BT 4 (1984).

2. Delichatsios, M.A., "Pyrolysis of Charring and Noncharring Materials," Ad Hoc Meeting on Charring Pyrolysis, Dec. 1984, Florida.

3. de Ris, J., Mathews, M.K., Delichatsios, M.A., Factory Mutual Memo: "Stefan Problem for Pyrolysis - Revised," June 15, 1986

4. de Ris, J., "Effects of Dilution on Cooling in Flame Radiation," Appendix B, NBS Proposal, "Prediction of Eire Dynamics," March 1984.

5. de Ris, J., "Flammability Testing: State of the Art," Fire and Materials, Vol. 9, No. 2, June 1985, pp. 75-80. 


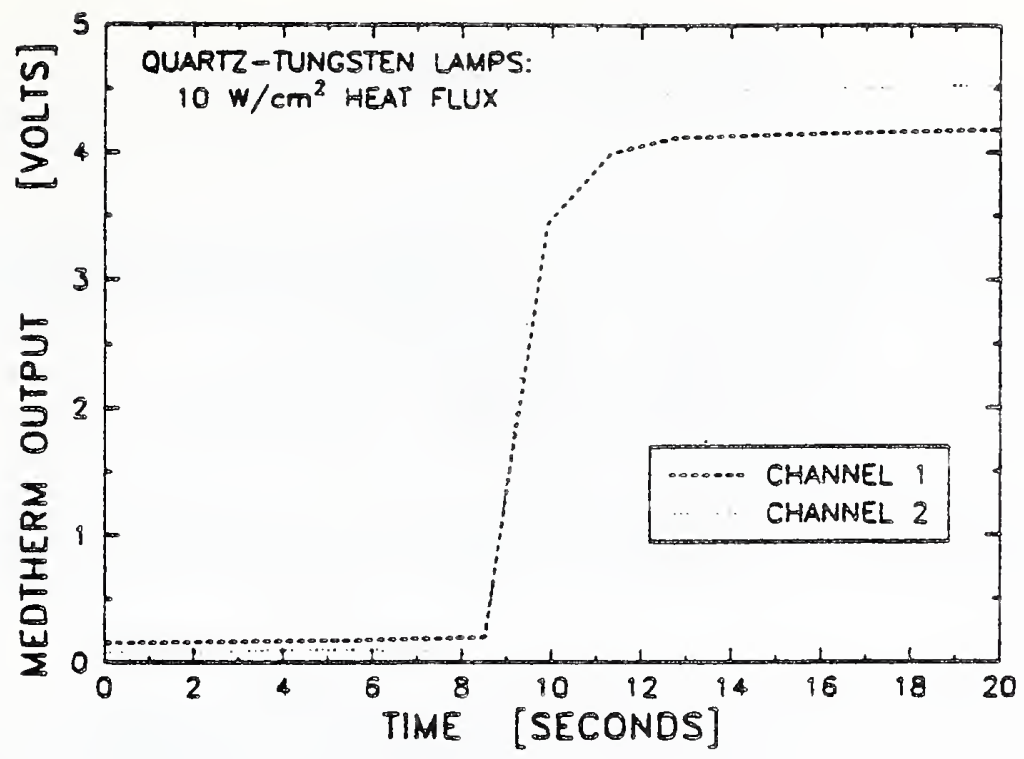

Fig. 1: Time-variation of heat flux at location of fuel sample during initiation of experiment: Channel 1 - Radial distance of 51 from axis, peak output of $8 \mathrm{~W} / \mathrm{cm}^{2}$; Channe 12 Radial distance of 19 from axis, peak output of $8.6 \mathrm{~W} / \mathrm{cm}^{2}$.

PYROLYSIS POSITION AND VELOCITY

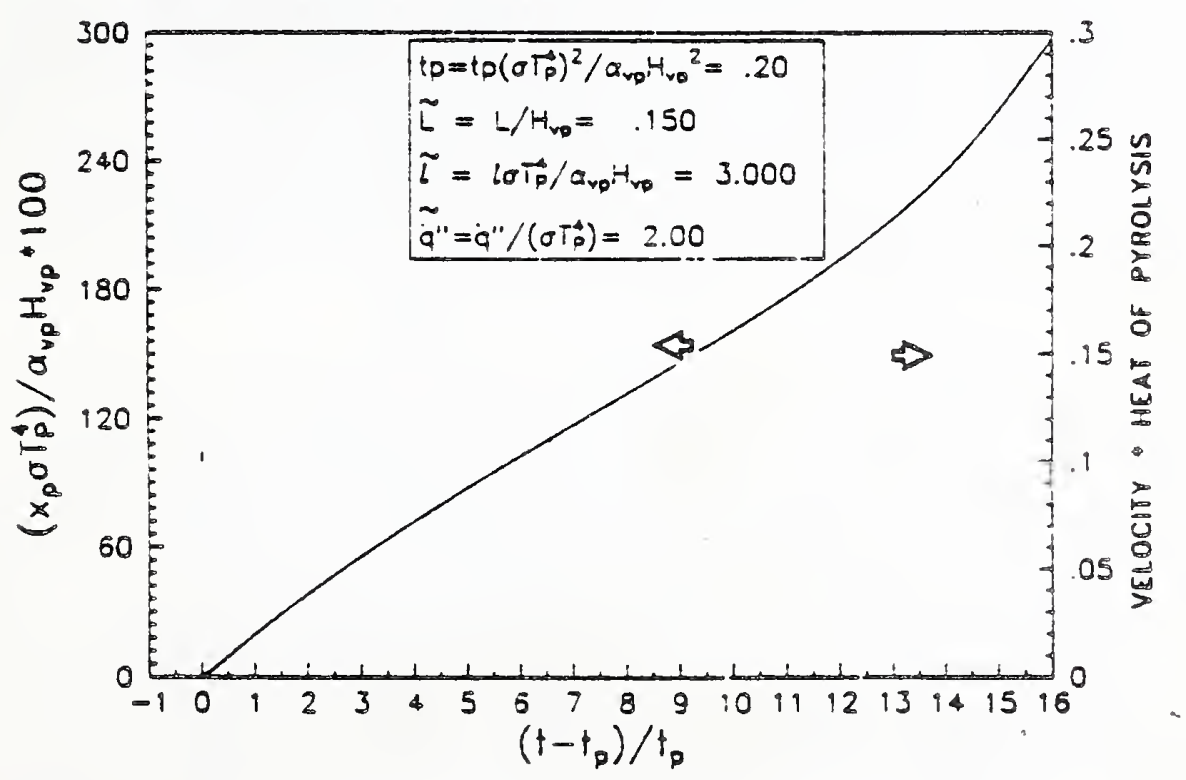

Fig. 2: The pyrolysis history of a sample with finite depth exposed to a constane heat Elux 
Institution: The George Washington University

Grant Number: 60NANB6D0625

Grant Title: Chemical Pathways to Soot Formation in Diffusion Flames

Principal Investigator: Professor J. Houston Miller

Department of Chemistry

The George Washington University

Washington, DC 20052

(202) $676-7474$

Other Professional Persomel: Dr. Anthony Hamins, Postdoctoral Research Assoc. NBS Sclentific Officer: Dr. Kermit C. Smyth

\section{Technical Abstract:}

The chemistry of the combustion of simple hydrocarbons to form carbon dioxide and water has been extensively studied and is generally well established. Our level of understanding of the chemistry which leads to the formation of polynuclear aromatic hydrocarbons ( $\mathrm{PAH}$ ) and soot particles is less fully developed. To further our knowledge of these more complicated processes, an extensive set of concentration data has been collected in shock tubes and premixed flames operating under rich conditions. Chemical modelling of this data might then help to elucidate dominant pathways for the formation of aromatic rings. Unfortunately, in fires leading to loss of property and life, fuel and oxidizer are initially separated from one another, and the transport processes which bring them together influences the combustion event. In order to build an understanding of soot formation in systems where mixing is important, our laboratory has been studying the structure, both spatial and temporal, of laminar diffusion flames.

So far, most of our work has concerned sampling in a laminar methane/air diffusion flame burning on a Wolfhard-Parker slot burner. Over the past two years we have collected profiles of species concentrations, convective velocity, and temperature. Because of the steady state nature of this flame, the temporal and spatial data can be combined to calculate the net rates of chemical reactions which affect a particular species' concentration. This concentration and production rate data then provides a very complete data base for the validation of proposed chemical models for the formation of aromatic rings and soot particles. These studies have resulted in some important conclusions about the chemistry of diffusion flames:

$\square$ Harris and coworkers from the General Motors Research Laboratory have argued the importance of acetylene addition to soot particles as the dominant mechanism for particle growth in premixed flames. Their conclusion was based on somewhat circumstantial evidence: only acetylene is present in high enough concentrations to account for the observed particle mass gain. We have been able to show through our production rate analysis that there is a loss process observable for acetylene which spatially coincides with small soot particles. (see Figure 1) Understanding particle growth is extremely important: the ultimate size obtained by particles will affect the radiation from the particles, and consequently, the temperature at the flame tip. Santoro has shown that subtle variations in temperatures in the flame oxidation region may determine the likelihood of soot emission from the flame. 
- The key factor which affects the variation in concentration of soot formed in flames of different fuels is likely to be the rate at which new particles are formed. To understand this inception process, it is important to have a understanding of the hydrocarbon pyrolysis chemistry which leads to the formation of aromatic rings. There are a number of detailed mechanisms which have been proposed for this process. Presently, the most widely accepted mechanisms involve two-carbon free radicals as key intermediates. Specifically, the vinyl radical, $\mathrm{C}_{2} \mathrm{H}_{3} \bullet$, and the ethynyl radical, $\mathrm{C}_{2} \mathrm{H} \bullet$, have both been proposed as the first molecular radical formed in the reaction pathway leading to benzene. We have been able to select between these two species by comparing the maximum rate at which these species are formed with the observed production rate of benzene. The results indicate the dominant role for vinyl in particle inception in our diffusion flame (Figure 2). There is not likely to be one mechanism for aromatic formation in all combustion systems: under slightly different conditions of temperature and local species concentrations, different pathways will dominate. However, it can be argued that a laminar diffusion flame more accurately mimics the conditions found in real fires than do shock tubes and low pressure pre-mixed flames. Thus our results provide an important conclusion about particle inception in naturallyoccurring fires.

The slot burner has proved to very useful in our studies over the last few years. However, it suffers from stability problems which make sampling results higher than two centimeters above the burner surface extremely noisy. We have an interest in extending our profile measurements to the entire flame, including soot particle oxidation regions. Further, we presently don't have a detailed understanding of the soot particle field in the methane/air flame supported on the slot burner. For these reasons, we are presently performing probe studies in an axially-symmetric diffusion flame burner identical to that used by Santoro in his particle field measurements. The presence of particles poses a serious experimental obstacle to probe sampling measurements: clogging of the probe orifice. Over the last few months we have developed a rapid insertion technique for the determination of species' concentrations in sooting flames. This technique will enable us to not only extend our understanding of soot formation, growth, and burnout in methane diffusion flames, but also extend our results to flames of different fuels. 
Publications:

1) Kermit C. Smyth, J. Houston Miller, Robert C. Dorfman, W. Gary Mallard; and Robert J. Santoro, "Soot Inception in a Methane/Air Diffusion Flame as Characterized by Detailed Species Profiles."

Combustion and Flame 62, 157 (1985).

2) J. Houston Miller, "Chemical Production Rates of Intermediate Hydrocarbons in Diffusion Flames: Preliminary Results for Acetylene."

Fall Technical Meeting of the Eastern States Section of The Combustion Institute. (1985).

3) J. Houston Miller and Kermit C. Smyth,

"The Chemical Structure of Methane/Air Diffusion Flames: Concentrations and Production Rates of Intermediate Hydrocarbons."

Symposium entitled "Chemical Mechanisms associated with Combustion". American Chemical Science National Meeting, April 1986.

4) J. Houston Miller, W. Gary Mallard, and Kermit C. Smyth, "Chemical Production Rates of Intermediate Hydrocarbons in a Methane/Air Diffusion Flame."

Twenty-first Symposium (International) on Combustion, to be published.

5) J. Houston Miller and Philip M. Taylor, "Methyl Radical Concentrations and Production Rates in a Laminar Methane/Air Flame."

Combustion Science and Technology, to be published.

6) J. Houston Miller and Robert S. Santoro, "Soot Particle Formation in Laminar Diffusion Flames." Langmuir, submitted for publication. 
Flgure 1: Profiles of the net chemical production rate for acetylene at two heights in the methane/air diffusion flame. Fuel is emitted from the slot burner from lateral positions 0 through $4 \mathrm{~mm}$. Air flows out in an adjacent slot (lateral positions $>4 \mathrm{~mm}$ ). The major destruction feature (negative destruction rates) is due to oxidation of acetylene molecules which diffuse outwards. At heights greater than 9 wo above the burner surface, a new destruction feature is observed. This feature is due to acerylene addition to rapidly growing soot particles, whose profile at the 13 mom height is shown as a dashed line.

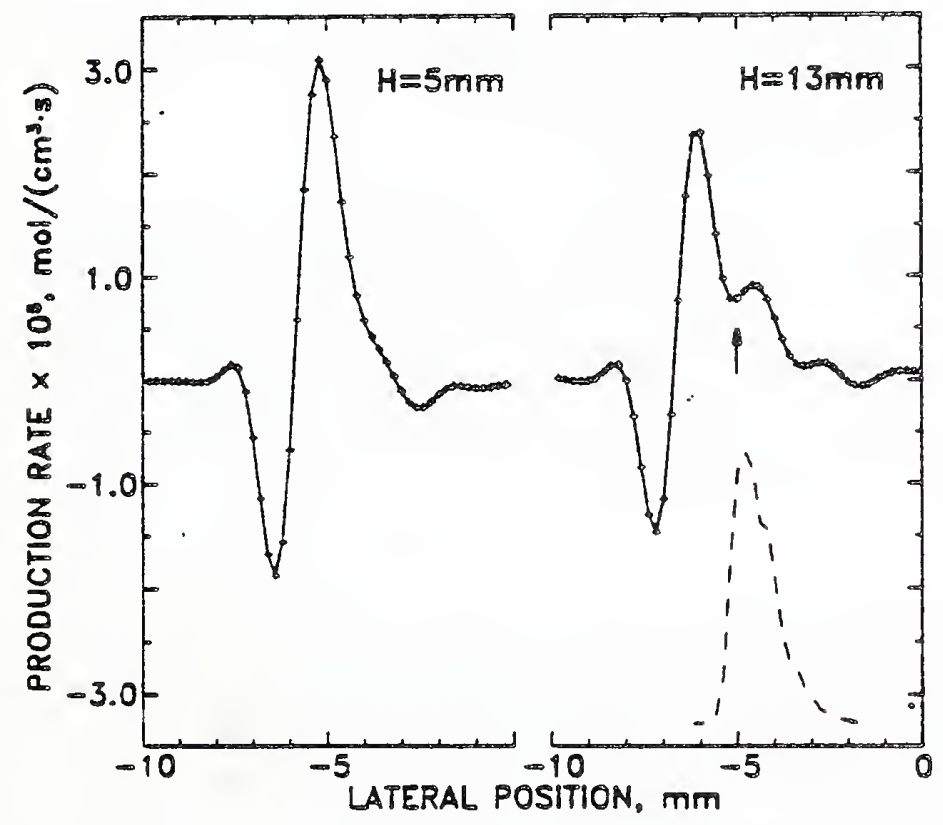

Figure 2: Comparison of the experimental net chemical rate of benzene (-0-) with the maximum production rates of vinyl radicals (-..) and ethynyl radicals (-.) at $9 \mathrm{~mm}$ above the burner. These results indicate the dominant role played by vinyl in hydrocarbon growth chemistry in the methane/air flame.

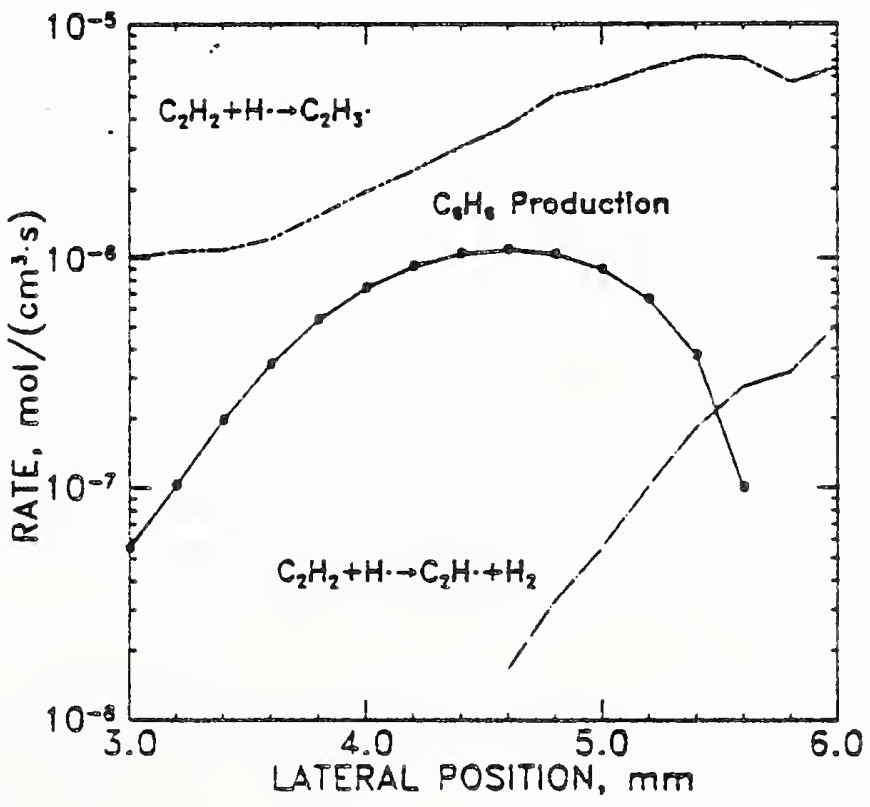


CENTER FOR FIRE RESEARCH

NATIONAL BUREAU OF STANDARDS

FY 86

Institution: Marquette University

Grant No.: 60 NANB6D0602

Grant Title: Thermal Stabilization of Polymers by Cross-Link Formation

Principal Investigator: Charles A. Wilkie

Department of Chemistry

Marquette University

Milwaukee, WI 53233

Telephone: (414) 224-7239

Other Professional Personnel: C.E. Brown, co Principal Investigator

S. Sirdesai, Research Associate

T. Suebsaeng, Graduate Assistant

B. Chang, Graduate Assistant

NBS Scientific Offices: Dr. W.G. Mallard

Technical Abstract:

Introduction. The objective of this investigation is to understand the chemical basis of pyrolysis reactions of polymers and to use that knowledge to make possible processable polymers that will convert to more stable materials under pyrolysis conditions. The strategy that has been developed is a strategy of cross-linking polymer chains to promote the formation of non-volatile, noncombustible char which will effectively prevent burning. Reactions are typically carried out at as low a temperature as practical, since it is desired to intervene in one of the initial steps in the pyrolysis reaction. The polymers under investigation are poly(methyl methacrylate), PMMA, and poly(ethylene terephthalate), PET. Present research is focused on cross-linking reactions in these two polymer systems.

PMMA. In earlier work it had been noted that PMMA forms an anhydride ring upon reaction with red phosphorus, the phosphorus containing by-products are methylmethoxy phosphonium ions. It should be noted that this anhydride ring is a second bond between a pair of methacrylate monomers and thus represents a type of cross-link and this system is more thermally stable than the starting material. Current work is directed towards identifing other reagents that will also generate this anhydride ring and probing the mechanism of this reaction. It is very difficult to probe the mechanism of reaction of a polymer, according model studies are utilized for this purpose. Two models are currently being used, methyl myristate and dimethylgluturate. Both of these models contain the ester linkage, which is the site of reactivity of PMMA. Both are also stable and have low vapor pressures under reaction conditions, $250-325^{\circ} \mathrm{C}$.

Additives currently undergoing investigation are Wilkinson's salt, $\mathrm{Rh}\left(\mathrm{PPh}_{3}\right)_{3} \mathrm{Cl}$, and $\left[\mathrm{CpFe}(\mathrm{CO})_{2}\right]_{2}$. Both additives undergo decomposition under reaction conditions, the rhodium compound produces benzene, triphenylphosphine 
and two, as yet unknown, rhodium compounds. The iron compound decomposes to produce carbon monoxide, carbon dioxide, a pentadiene, ferrocene and iron. The work is thus complicated by the necessity to also investigate the decomposition reactions of the additives. Both materials react with PMMA to produce an an hydride, the mechanistic pathway for this reaction is very uncertain and accordingly, model studies are under investigation. Several products are produced for both additives with either of the model compounds. Current work is directed towards an understanding of these model siudies.

It should be recognized that a thodium compound is a very unlikely candidate for a commercial flame retardant, this work is being undertaken to probe the mechanism of the reaction and the chemical requirements of a putative flame retardant.

The formation of the anhydride is the initial step in this work, true cross-inking requires that two or more of the polymer chains be bonded; this is the second step of this work, no work has as yet been done on this step.

PET. The decomposition of PET has been reported, in previous work, to produce a highly cross-linked product, formed by alkylation of a benzene ring with a vinyl ester moiety produced from the breakdown of PET. This reaction appears to occur spontaneously upon heating, it is also promoted by the presence of additives such as red phosphorus and zinc salts. The requirement for some decomposition to produce an additive that can then provide stabilization (see scheme I) is less than satisfactory. A better approach is to seek an additive that will cross-link with the PET before any PET decomposition occurs. This additive will ideally be a divinyl moiety that can add to two chains of PET and thus lead to cross-linking. As above it is desirable to model this reaction with small molecules that can be completely characterized. The model that has been chosen for PET is dimethyl terephthalate, DMT, and the vinyl compound that has been studied is peryllic alcohol. The expected reaction is an alkylation of the benzene ring of the DMT by the vinyl moiety and this reaction does occur. Current work is directed towards the complete mechanistic understanding of this reaction and its extension to other vinyl and divinyl systems.

The reaction of PET with some putative flame retardants is also under investigation. The goal is to understand the mechanism of the reaction. The identification of the locus of the reaction, both for the polymer and for the additive, will allow one to identify the iunctionality necessary in the additive for a successful flame retardant. Once again, model studies are helpful in allowing the characterization of the important reaction steps.

The reaction of PET with triphenylphosphine produces triphenyl-phosphine oxide and several other, low molecular weight, products. This reaction is most easily understood through model studies using methyl myristate. The reaction involves either a carbene or free radical intermediates producing alkanes and aikenes, $\mathrm{C}_{12}-\mathrm{C}_{16}$. Triphenylphosphine is a poor flame retardant for $2 \mathrm{ET}$, nonetheless valuable information may be obtained from an understanding of the reaction mechanism. Current research is extending these reactions to other putative flame retardants. 


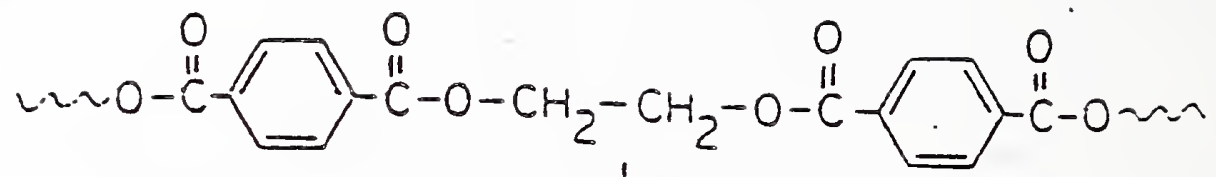

$$
\begin{aligned}
& -\mathrm{ZnCl}_{2}
\end{aligned}
$$

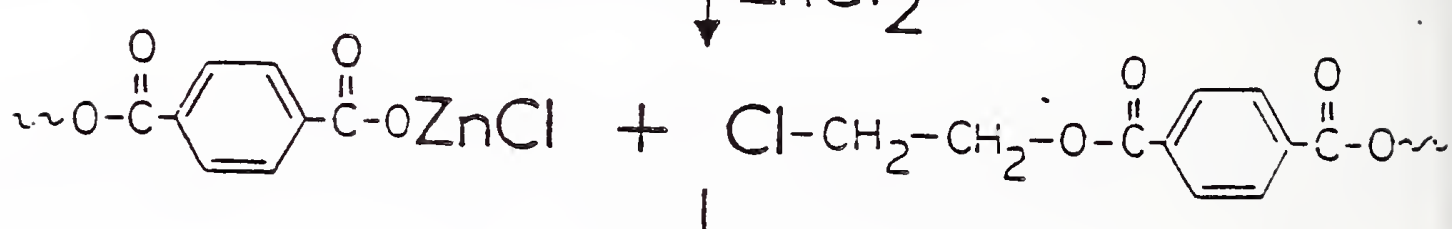

$$
\begin{aligned}
& 1
\end{aligned}
$$

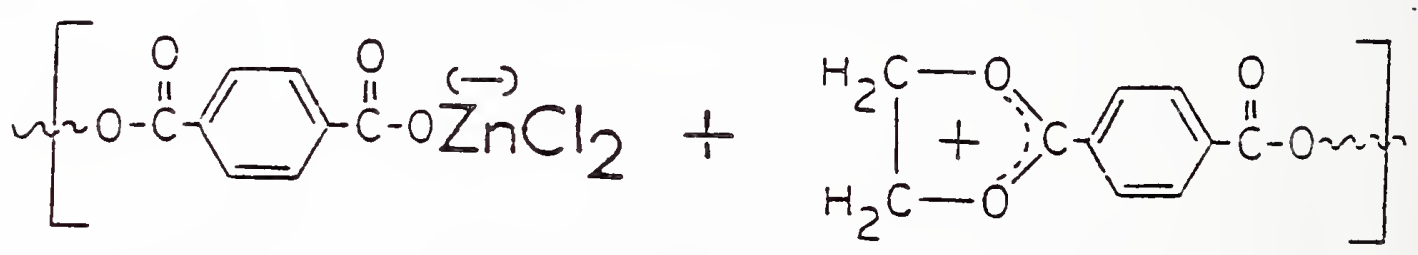

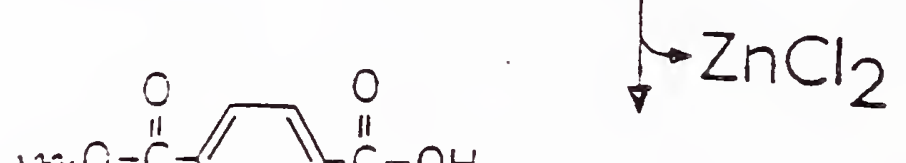

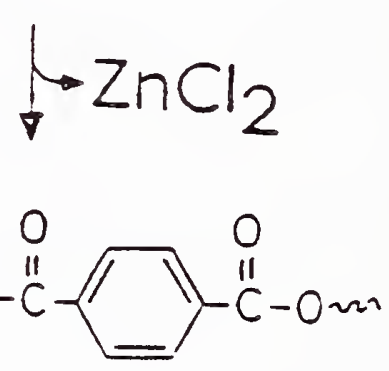

$$
\begin{aligned}
& \mathrm{ZnCl}_{2}+\mathrm{ZnCl}_{2}
\end{aligned}
$$

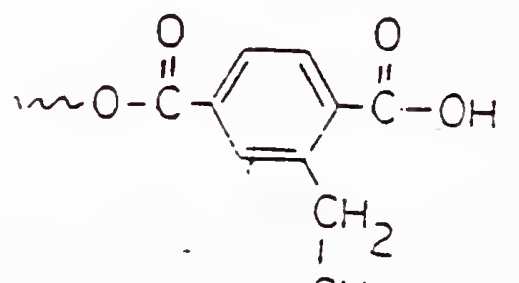

$$
\begin{aligned}
& \mathrm{HO}_{10} \mathrm{C}_{-\mathrm{C}-\mathrm{O}}^{\mathrm{C}}
\end{aligned}
$$




\section{Reports and Papers:}

1. T. Suebsaeng and C. A. Wilkie, "Reactions of Triphenylphosphine and Related Compounds with Poly(ethylene terephthalate), "20th Great Lakes Regional Meeting American Chemical Society, Milwaukee, WI., June, 1986 
Institution: Michigan State University

Grant Number: 60NANB500578

Title: Effect of Water on Ignition of Cellulosic Materials

Principal Investigator:

\author{
Arvind Atreya \\ Assistant Professor \\ Department of Mechanical Engineering \\ Michigan State University \\ East Lansing, MI 48824 \\ Te1. No. (517) 3536356
}

Other Professional Personnel: M. Abu-Ziad, Ph.D. candidate

Lin-Shyang Tzeng, Ph.D. candidate

NBS Scientific Officer: Dr. David D. Evans

\title{
TECHNICAL ABSTRACT:
}

The objective of this work is to experimentally and theoretically investigate the effect of water on the piloted ignition of cellulosic materials. This work is divided into two parts. In the first part, the effect of adsorbed water (which can be up to $30 \%$ of the oven-dry weight) on piloted ignition is being experimentally investigated in a controlled atmosphere combustion wind tunnel as a function of sample moisture content, external radiation, gas speed and gas composition. A fundamental theoretical model with finite rate gas and solid phase chemical kinetics is also being developed. In the second part, transient cooling of the surface of a hot porous solid by impingement of water droplets is being experimentally investigated by using an instrumented porous ceramic block. This work will be useful in determining the onset of ignition and subsequent fire growth rate under different relative humidity conditions. It will also provide information on the water application rate required to contain the fire growth.

EXPERIMENTAL WORK:

On the experimental side, we have primarily been involved in the design, construction and calibration of a combustion wind tunnel that will permit control of gas composition, gas speed and external radiation incident on the sample. This facility has been constructed and is currently being calibrated. It is essentially a small duct $\left(5.75^{\prime \prime} \times 4^{\prime \prime}\right.$ cross-section; The cross-sectional view is shown in Figure 1) capable of providing a flat plate boundary layer flow on the sample surface. This wind tunnel is operated strictly at atmospheric pressure to avoid leakage. The external radiation is provided by electrical radiant heaters configured as shown in Figure 1 . These heaters have a maximum black body radiation temperature of $1300 \mathrm{~K}$ and are therefore well suited to simulate external radiation in building fires. The temperature of the heating elements is measured by a temperature probe shown in Figure 1 . 
Two water cooled blackened aluminum plates are used to intercept the radiat. ion during the heater warm-up period. These plates are suddenly removed at the start of the experiment to provide external radiation on the sample surface. This radiation is transmitted via. the infrared optical glass windows that form the top of the tunnel.

Prior to the experiments the samples are conditioned in a temperature and humidity controlled chamber. This chamber (Model TH-3, BMA Inc.) has a controllable humidity range of 10 to $98 \% \mathrm{RH} \pm 2 \%$ RH and a controllable temperature range of 2 to $85^{\circ} \mathrm{C}$. The moisture content of the sample is then determined by the difference between its "dry" and "wet" weight.

Work on studying the effect of water droplets on transient cooling of a porous solid is also under way. The objective is to simulate a porous material like wood. Thus an inert porous ceramic sample will be casted around a matrix of thermocouples. Preliminary tests have shown that castable MgO (KF-95) is ideally suited for the purpose. This material has excellent water absorption properties and its high temperature thermophysical properties ( up to $1200^{\circ} \mathrm{C}$ ) are available from Sandia National Laboratories[1].

THEORETICAL WORK:

The basis of the theoretical model is the piloted ignition of a cellulosic solid subjected to a constant external radiant heat flux. When exposed to external radiation, the solid will release combustible gases and water vapor depending on both the magnitude of the external fiux and the thermophysical and thermochemical properties and its moisture content. Once evolved, the volatiles mix with the oxygen in the surrounding air producing a combustible mixture that can be ignited by a pilot flame, and through which a premixed flame may subsequently propagate. Ignition is considered to occur when a self. sustaining trailing diffusion flame exists behind the advancing premixed flame front. This eliminates consideration of the initial transient flashes, that are observed experimentally, as ignition events.

The problem being considered here is inherently two-dimensional and transient. For purposes of simplification, in the initial formulation, buoyancy is discarded, the gas-phase thermophysical properties are assumed constant, a one-step irreversible Arrhenius reaction is assumed, and the surrounding gas is assumed quiescent. Transverse velocities (normal to the plane of the sample) are also ignored and the fuel is assumed to diffuse from the constant temperature lower surface into the gas. The boundary layer approximation is not employed, because streamwise diffusion is essential for both the piloted ignition and the flame spread processes. The pilot flame is modeled as a constant-heat-flux line source located near the origin. The corresponding nondimensional equations and boundary conditions are shown in Figure 2 . Note that the model configuration is symmetrical about the plane $x=0$, and that the far-field boundary conditions in $y$ are applied at $y=1$, since the steady state of this system is known to be a flat one-dimensional diffusion flame. As a check of the numerical solution, first transient calculations of the flame speed through a premixed mixture were performed and its large-time steady-state value was compared with the analytical results obtained by activation energy asymptotics[2]. This comparison is shown in Figure 3 . It can be seen that for Zeldovich $\#>7$, Vanalytical/Vnumerical approaches unity. This result is the same as that of Rogg's[3]. 
In addition to the numerical model, a simplified analytical model for piloted ignition has also been developed [4]. Figure 4 shows the model calculations for three different levels of external radiation $(2,3$ and $4 \mathrm{~W} / \mathrm{cm} 2)$ and two different values of the nondimensional pre-exponential factor ' $A$ ' $\left(10^{9}\right.$ and $\left.10^{10}\right)$. The intersection of the curves marked gas-phase $(M)$ and the curves marked solid-phase (M) is the ignition point which yields a unique solution for the fuel mass flux and surface temperature at ignition. Given the surface temperature at ignition, the time for piloted ignition is obtained from the bottom graph. It is interesting to note that the predicted ignition temperatures lie within the measured range and that for a given set of parameters they indeed are very nearly constant. Also even though the nondimensional fuel mass flux ' $M$ ' shows a considerable variation with external radiation, its dimensional counterpart is almost constant and has a value of $1.8 \mathrm{gm} / \mathrm{m} 2 \mathrm{sec}$. Furthermore, variations in the decomposition kinetics (change in $A$ from $10^{9}$ to $10^{30}$ ) seems to cause a large variation in the surface temperature at ignition, but only a minor change in the critical fuel mass flux at ignition.

\section{REFERENCES:}

1. Taylor, R.E. and Groot, H. "Thermophysical properties of cast MgO, "Report to Sandia National Laboratories, Purdue University, August 1985.

2. Williams, F.A. "Combustion Theory," The Benjamin/Cummings Publishing Co. Second Edition, 1985.

3. Rogg, 8. "On the Accuracy of Asymptotic Flame Speed Predictions for TwoReactant Flames," Combustion Science and Technology, 45, 1986.

4. Atreya, A. and Wichman, I.S., "Heat and Mass Transfer during Piloted Ignition of Cellulosic Solids," To be published in the 2nd ASME-JSME Thermal Engineering Joint Conference, 1987.

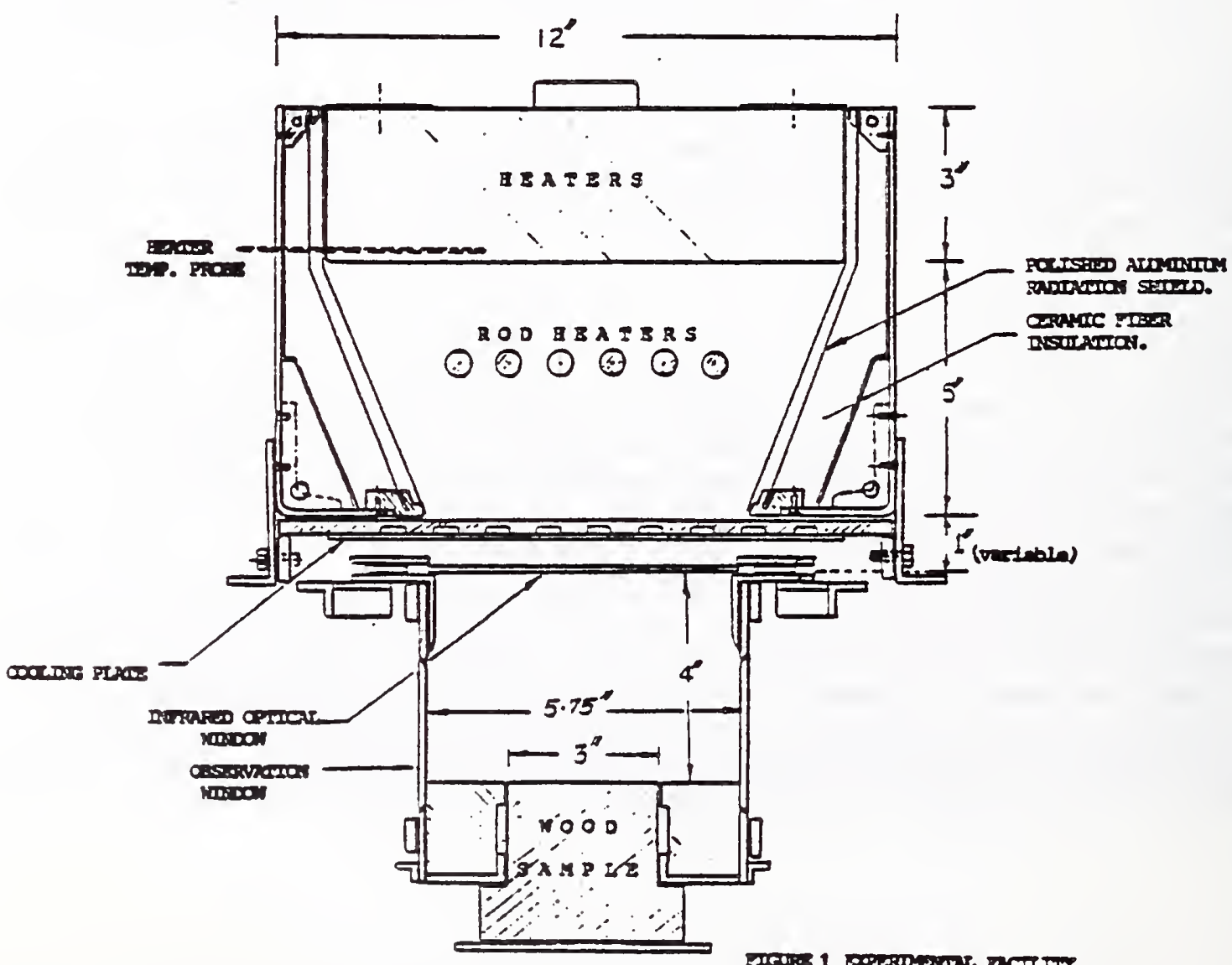



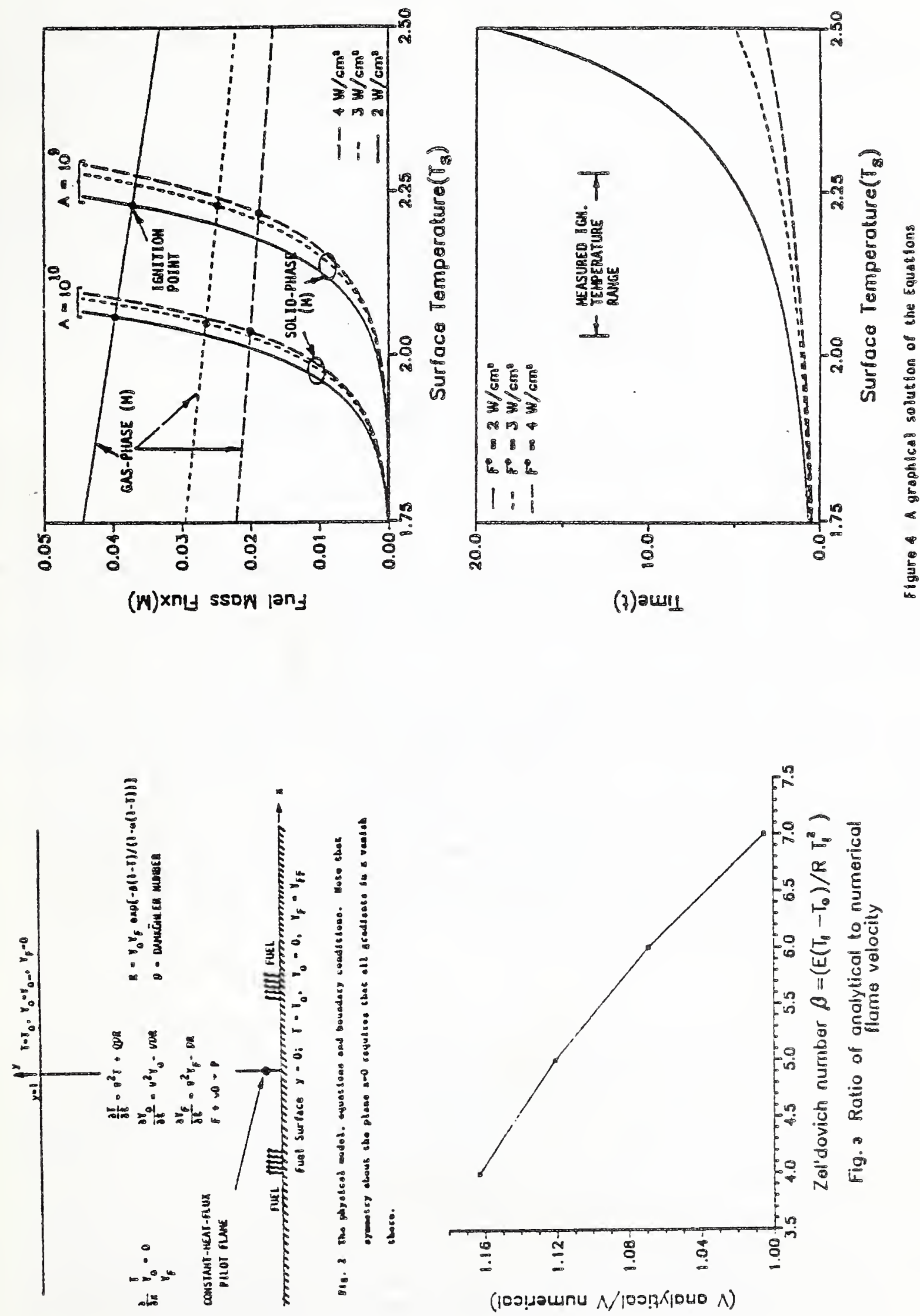
CENTER FOR FIRE RESEARCH

NATIONAL BUREAU OF STANDARDS

FY 1986

Institution: The Pennsylvania State University

Grant No.: $\quad$ 60NANB4D0037

Grant Title: Vertical Wall Fire in a Two-Layer Stratified Atmosphere

Principal Investigator: Professor A. R. Kulkarni

Department of Mechanical Engineering

The Pennsylvania State University

313 Mechanical Engineering Building

University Park, PA 16802

Telephone: (814) 865-7073

Other Professional Personnel: J. J. Hwang, Research Assistant

S. L. Chou, Graduate Assistant

NBS Scientific Officer: Mr. Ken Steckler

Technical Abstract:

Introduction: In a typical compartment fire, the interior atmosphere becomes stratified with a hot, oxygen-deficient layer of gases on the top and a relatively cool, oxygen-rich layer of fresh air on the bottom. The overall objective of this investigation is to study the effect of the stratified ambient atmosphere on the vertical wall fire. We are specifically interested in finding out how the burning rate and the flow of gases are affected.

Further, we wish to determine whether a linear superposition of results based on studies assuming nonstratified ambient conditions is adequate for predicting behavior of wall fire in a stratified atmosphere. In the first phase we analyzed the problem using a comprehensive mathematic model. In the present research we have conducted an experimental study of the vertical wall fire in a stratified atmosphere and extended the analysis further. Results from the overall investigation are expected to provide a better understanding of the behavior of a typical vertical wall fire in a compartment, which is also useful as an input to multiroom buildings.

Experiments:

A test apparatus has been designed and built to study characteristics of a wall fire in a stratified atmosphere. Since this is the first attempt for investigating the problem experimentally and since the mathematical model developed last year was for a laminar boundary layer fire flow, the scale of experiments is small and restricted to a mostly laminar wall fire. After some trial designs and modifications, the experimental setup was erected as shown schematically in Figure 1. The basic aim was to create a stratified atmosphere in front of a wall fire. A sample of $15 \mathrm{~cm} \times 7.5 \mathrm{~cm} \times 1.27 \mathrm{~cm}$ is mounted on a vertical panel. It is surrounded by a ceiling plate with an adjustable slot opening, two side panels of high temperature-resistant glass, and a front panel. Relative positions of all the panels are adjustable in order to create different types of stratified ambient atmosphere in front of the sample. A vertical rake of fifteen chromel-alumel thermocouples is 
mounted on a sliding platform to measure the temperature profile with height in front of the sample at various locations. Oxygen concentration is measured by a Beckman oxygen analyzer using a water-cooled probe as a function of height in the stratified atmosphere. A schlieren/shadowgraph optical system using two front surface concave mirrors is also setup for flow visualization. The sample is ignited such that the entire front surface burns simultaneously.

Figure 2 shows temperature measured at $8.0 \mathrm{~cm}$ in front of the sample using the thermocouple rake, as a function of the helght measured from the leading edge of the sample at various time intervals. Also, some preliminary measurements of oxygen concentration are shown in the same figure. A stabiy stratified atmosphere is clearly apparent. The measured temperature variation with height in trial experiments shows that we can simulate tine stratified conditions of a compartment interior reasonably well (Quintiere, et. al., Comb. Sci. Tech. 26, 1981; Cooper, et. al., J. Heat Trans. 104, 1982). Eurther tests are in progress.

In order to measure the mass burning rate, a vertical strip of approximately $1 \mathrm{~cm}$ width is cut from the center of the burnt sample and then cut into several pieces. These pieces are milled, weighed, and their dimensions are measured carefully. Knowing the weight of pieces from a reference sample and the duration of burning, local mass burning rate is calculated. Initial set of results for the simultaneous measurements of ambient temperature, ambient oxidizer concentration, and local burning rates have been obtained recently and they are being analyzed.

Analysis:

We have completed calculations for a laminar vertical wall fire in a stratified ambient atmosphere having various types of temperature and oxidizer concentration profiles. The analytical investigation is extended to include the following problems.

(a) Integral Soldtion: In order to obtain quick soldtions to the probiem of a vertical wall pire in a stratified atmosphere, an integral solution is proposed. Up to third order profiles are assumed for the vertical velocity $(U)$, and combinations of temperature $(T)$, flel mass fraction $\left(Y_{F}\right)$ and oxidizer mass fraction $\left(Y_{O}\right)$. Results obtained using the integral solution were compared with the numerical solution. Although the comparison was not very close, further refinement of this solution is in progress.

(b) Model for a Laminar-Transitional-Turbuient, Natural Convection Flow: Before extending our laminar flow model for a vertical wall fire in a stratified atmosphere to include turbulence, we decided to first study a similar flow, but without the complications of fire. A nodel for laminar-transitional-turbulent, natdral convection flow over a not, isothermal wall in a stratified, quiescent ambient atmosphere was formulated. The modal adapted here is a combination of turbulence models proposed by Cebeci and Khattab (J. Heat Transfer, 1975, ?. 469) and Price and Harris (NASA TM $x-2458,1 \overline{972) . ~ T h e ~ n o d e l ~ w a s ~ s o l v e d ~ d s i n g ~}$ Keller 3ox finite difference technique and results have been obtained. Effect of various types of stratification was studied on the velocity field, temperature profiles and heat transier to wall. It was found that 
the upstream memory in the natural convection boundary layer flow in a stratified ambient atmosphere affects the velocity field more slgnificantly than the temperature.

\section{Reports and Papers}

1. A. K. Kulkarni, and J.J. Hwang, "Vertical Wall Fire in a Stratified Atmospheren, presented at the 21st International Symposium on Combustion, August 1986.

2. A. K. Kulkarni, H. R. Jacobs, and J.J. Hwang, "Similarity Solution for Natural Convection Flow over an Isothermal Vertical Wall Immersed in a Stratified Medium", Int'l. J. Heat and Mass Transfer, in press.

3. A. K. Kulkarni and S. L. Chou, "Turbulent Natural Convection Elow over a Vertical Wall in a Stratifled Medium", being submitted to $\mathrm{j}$. Heat Iransfer.

4. A. K. Kulkarni and J. J. Hwang, "Free Convection Vertical Wall Fire in Various Types of Stratifled Ambient Atmospheren, paper no. AIAA-86-0577, presented at the AIAA 24 th Aerospace Sciences Meeting, Reno, Nevada, (1986).

$Y_{0, \infty}(\%)$

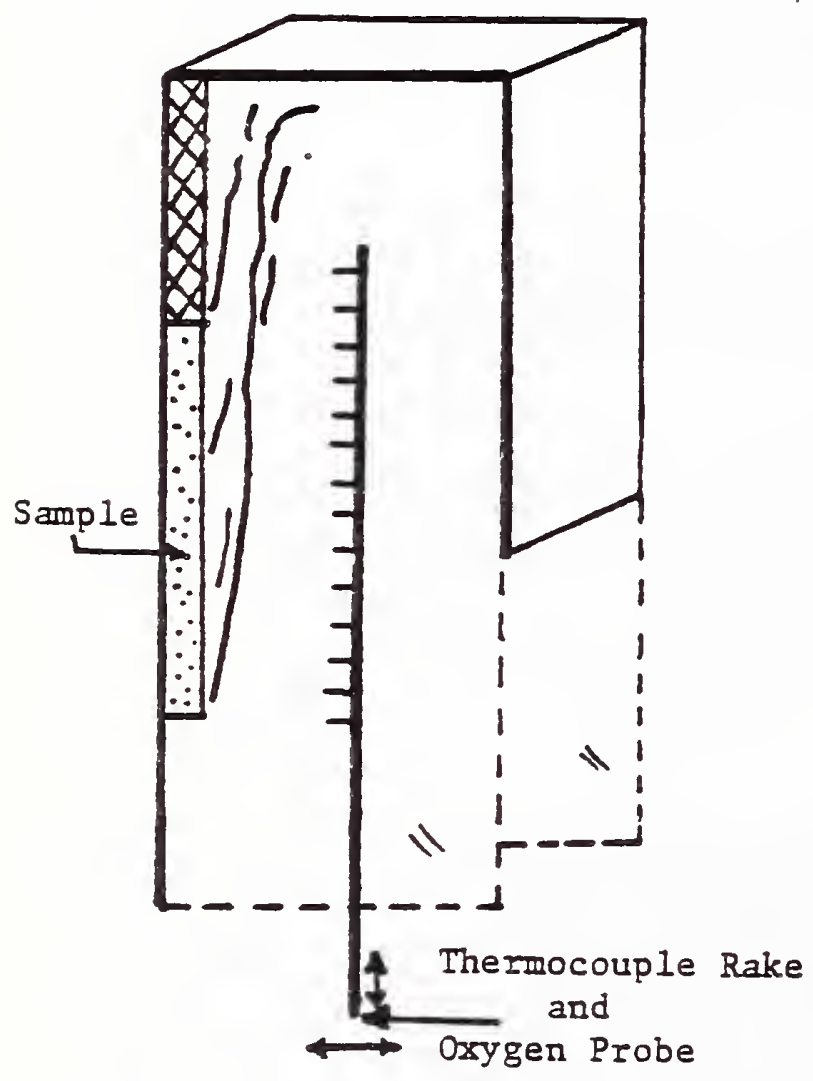

Fig. I Sideview schematic of experimental apparatus

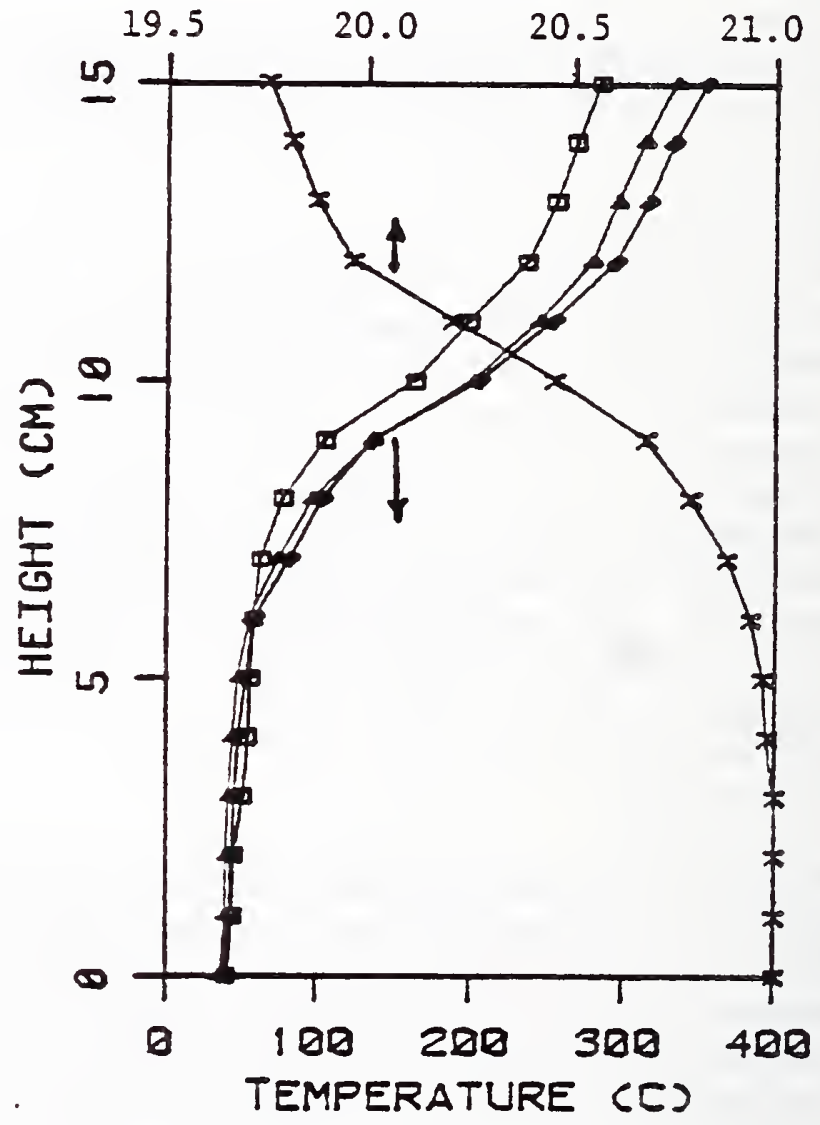

Fig. 2 Typical measured data for oxidizer mass fraction $(x)$ and temperature in front of the burning sample. Temperature profiles are shown at $t=8$ min (a), $11 \mathrm{~min}(\Delta)$ and $12 \mathrm{~min}(0)$ after ignition. 
Institution:

Grant No.:

Grant Titie:

Principal Investigator:
Rutgers, The State University of New Jersey New Brunswick, New Jersey

\section{NB83NADA4047}

Negatively Buoyant and Penetrative Flows Generated in Enclosure Fires

Professor Yogesh Jaluria

Department of Mechanical \& Aerospace Engineering Rutgers, The State University of New Jersey

New Brunswick, New Jersey 08903

Telephone: (201) $932-3652$

\section{Other Professional Personnel:}

NBS Seientific officer:
K. Kapoor (Post-Doctoral Fellow)

A. Abib (Ph.D. Student)

Or. Leonard Y. Cooper

\section{Technical Abstract:}

Introduction. The objective of this study is to study experimentaliy the negatively buoyant and penetrative fiows that are generated at the early stages in the growth of an enclosure fire. The flow driven by the fire plume spreads over the ceiling and turns downward at the corners, generating a two-dimensional wall jet with opposing buoyancy effects. Similarly, wall fiows generated in the upper layer of the enclosure are injected across the interface into the lower iayer where they become negatively buoyant. The project is directed at such negativeiy buoyant and penetrative flows. The present effort is focused on two main topics: (1) the characteristics of a negatively buoyant wall jet in an extensive environment, and (2) the penetration of wall flows across the interface between a hot upoer zone overlying a cooler iower iayer. The first topic has been studied in detail, providing very imoortant induts for the zone mode: anaiysis of enciosure fires. A swostantial amount of progress nas also been made on the second topic. The results obtained in the two lases have been correlated with edch other and with the zone model results for enciosure fires.

Neqativeiy Buoyant we 71 jets. A detailed experimental study of the penetration deptn sp, total entrainment of ambient fiuili inco the downward dicharged jet, the heat transfer at the wall which is maintained at a uniform temperature $T_{S}$ and the resulting velocity and thermai fields has been carpied out. Uetails of the experimental arrangement are given in the publications listed at the end of this report. Several important carrolations have been derived in terms of the mixed convection parameter Gr/Re ${ }^{2}=g B\left(T_{0}-i_{\infty}\right) D / U_{0}{ }^{2}$, where 0 is the width of the discharge slot, Uo the average discharge velocity, $t_{0}$ the jet discharge temoeracure. To the ambient temoerature, s the coefficient of thermal expansion of the fluid and g the gravitational acceleration.

Figures 1 and 2 show some of the resultis obtained. The penetration distance $\delta_{p}$ and the total mass flow rate $\dot{n}_{\text {out }}$ at the levei of the jet are we i? correlated by the equations 


$$
\delta_{p} / D=4.424\left(G r / R^{2}\right)^{-0.389}
$$

and,

$$
\begin{aligned}
\dot{\mathrm{m}}_{\text {out }} / \dot{\mathrm{m}}_{\text {in }}=0.037+60.967\left(\mathrm{Gr} / \mathrm{Re}^{2}\right) & -238.056\left(\mathrm{Gr} / \operatorname{Re}^{2}\right)^{2}+485.018\left(\mathrm{Gr} / \mathrm{Re}^{2}\right)^{3} \\
& -381.352\left(\mathrm{Gr} / \mathrm{Re}^{2}\right)^{4}
\end{aligned}
$$

Here, $\dot{m}_{\text {out }}=\dot{m}_{\text {ent }}+\dot{m}_{j n}$, where $\dot{m}_{\text {ent }}$ is the total entrainment into the flow and $\dot{m}_{i n}$ the discharged flow rate. More extensive measurements are being taken for a wider range of conditions and a more convenient form of the correlation for $\dot{m}_{\text {out }}$, Eq. (2), is being derived. These results have also been applied to the buoyancy driven wall flows in an enclosure fire, as shown in Fig. 3. A very large amount of entrainment into the flow is observed and the penetration distances are found to be physically realistic. Heat transfer rates at the wall have also been measured and a correlating equation is being derived.

Pentration Across the Interface in a Two-Layer System. An extensive modification of the present experimental system was undertaken to generate a two-layer, stably stratified environment. Employing a specially designed diffuser, heated air was discharged at very low velocity over the entire top of the enclosure and allowed to exit at the far end. This gave rise to a very stable stratification in the tank, as shown in Fig. 4. The stratification is essentially a two-layer system and can be maintained almost indefinitely. This is a very encouraging result since such a system can be used to study a wide variety of penetrative flows in enclosure fires.

The penetration of a buoyancy induced flow, generated adjacent to a cooled plate in the upper layer into the lower region was studied. The penetration depth, the heat transfer and the resulting flow fieids were studied. It was found that the flow buoys back toward the interface and stays near it, giving rise to a thicker intermediate layer. A typical measurement of the resulting thermal field is shown in Fig. 5. The work is being continued and it is expected that correlating equations for the penetration depth, entrainment and heat transfer will be obtained. These can then be used as submodeis for the zone model analysis of enclosure fires.

\section{Reports and Papers}

1. Jaluria, Y. and Goldman, D., "Transport Due to Flows with Opposing Bunyancy Arising in Room Fires," Fati Tech. Meet., Eaștern Sect. Combust. Inst., Philadeiphia, PA, Paper No. 39, 1985.

2. Go? dman, D. and Jaluria, Y., "Effect of Opposing Buoyancy on the Flow in Free and Wall Jets," J. Fluid Mech., 166́, 41-56, 1986.

3. Jaluria, Y., "Buoyancy-Oriven Wall Flows in Enclosure Fires," accepted for publication in 2lst Symb. (Int.) on Combustion, Combust. Inst., 1986.

4. JaTuria, Y., "Hydrodynamics of Laminar Buoyant Jets," in Encyciopedia of Fluid Mech., Gulf Pub. Co., Ch. 12, 317-348, 1986. 

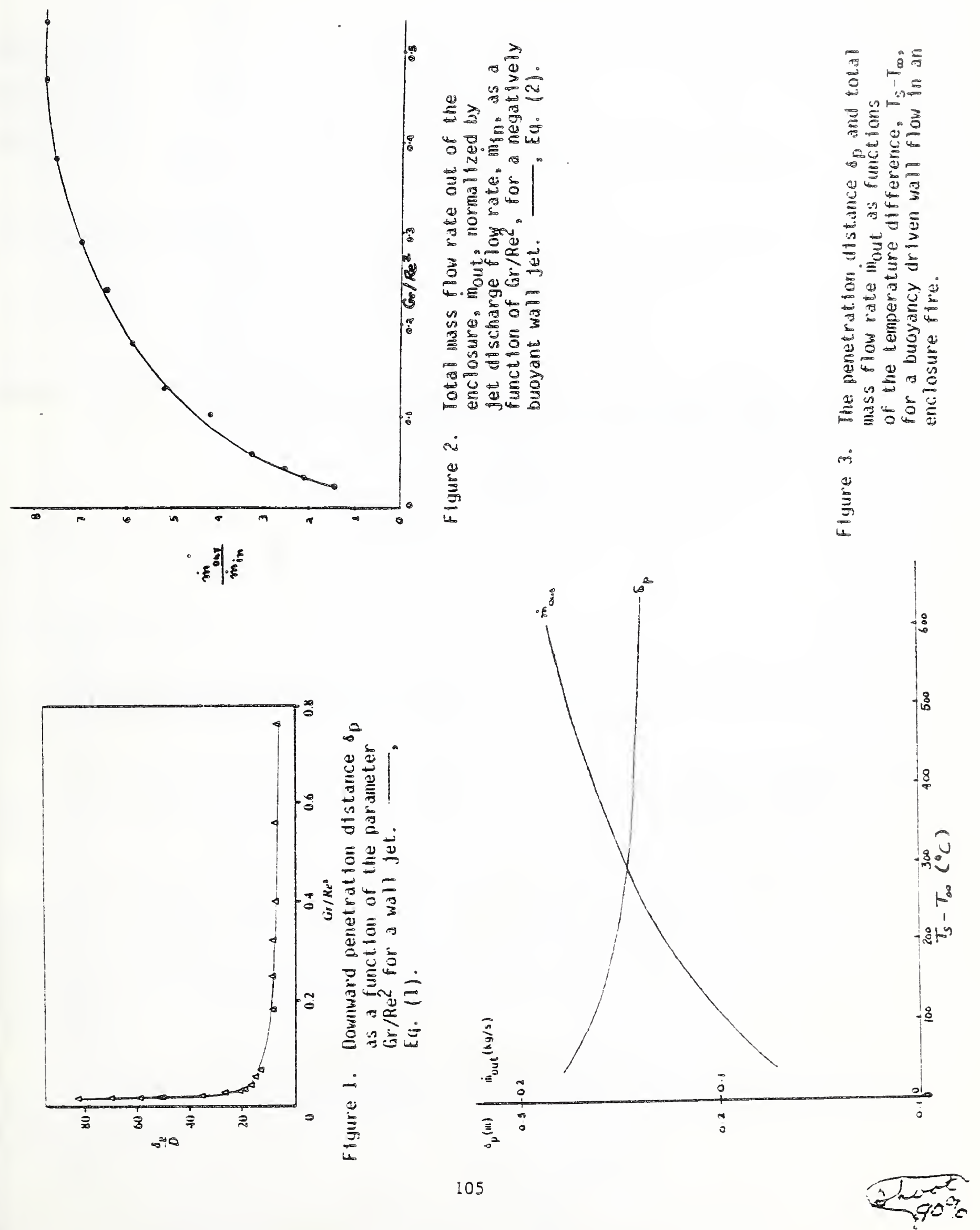

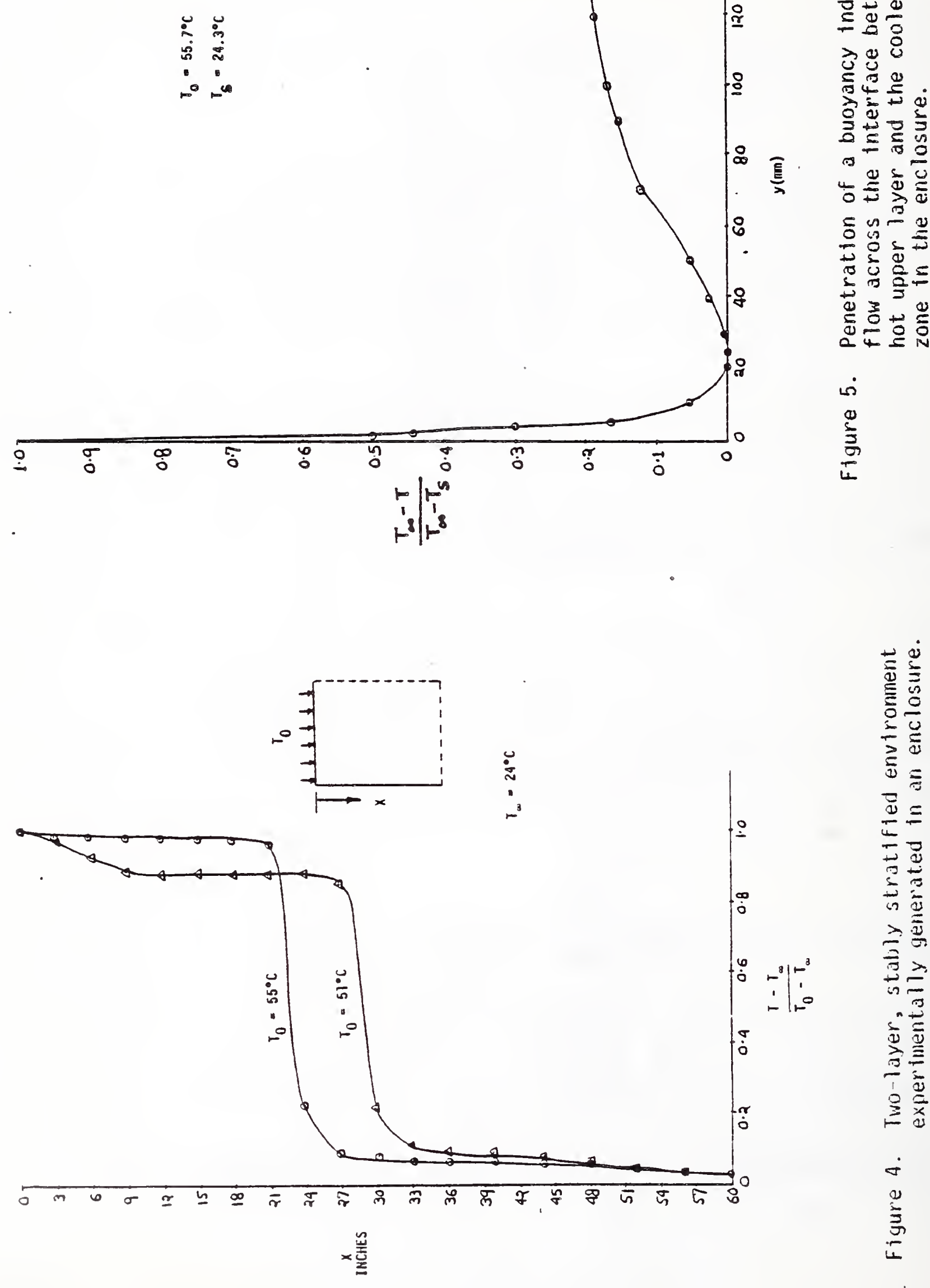
Institution:

Grant No.:

Grant Title:

Principal Investigator:

\begin{abstract}
Other Professional Personnel:
\end{abstract}
NBS Scientific Officer:

\section{Southwest Research Institute}

60NANB6D0635

Analysis of Hazards to Life Safety in Fires:

A Comprehensive Multi-Dimensional Research

Programem Second Year

Dr. Gordon E. Hartzell

Director, Department of Fire Technology

Southwest Research Institute

6220 Culebra Road

San Antonio, Texas 78238

Telephone: $\quad 512 / 522-3038$

Technical Abstract:

The overall objective of this research program is to develop methodology to assess toxicological hazards to human life from the time course of analytical data on fire gases.

Under funding from a previous grant, a Fractional Effective Dose (FED) Model was developed based on carbon monoxide and hydrogen cyanide. Additionally, the effects of an irritant (HCl) on inhalation of $\mathrm{CO}$ by rats were studied.

The FED model will now be modified as necessary to accommodate the presence of $\mathrm{HCl}$ and $\mathrm{CO}_{2}$, in addition to the asphyxiant toxicants, as may be combined in smoke. Aiter validation of the model using pure gas studies, it will be tested using real smoke from burning matepiais. Any significant discrepancies betiveen model-predicted and experimental data from animal exposures will aid in identifying the presence of other toxicants requiring investigation.

At the time of the preparation of this summary, work under this grant had not commenced.

Reports and Papers:

None. 
Institution: University of California, Berkeley

Grant No.: $\quad$ 60NANB5D0552-1

Grant Title: Fire Modeling

Principal Investigator: Professor Patrick J. Pagni

Vice-Chairman

Mechanical Engineering Department

University of California

Berkeley, CA 94720

Telephone: (415) 642-0729

Other Professional Personnel: James Ang (Ph.D. Candidate)

Valerie Lyons (Ph.D. Candidate)

Corey Dunsky (Ph.D. Candidate)

Thomas Mataga (M.S. Candidate)

NBS Scientific Officer: Dr. Howard Baum

Technical Abstract:

While the overall goal of this project is to develop chemical, physical and mathematical models of the detailed combustion phenomena which control a fire's growth, our emphasis recently has been on fire radiation, discussed first below. In addition, this grant period we have added thermal effects of fuel cracking, bouyancy, and variable properties to sooting boundary layer analyses. Perturbation techniques have been utilized wherever possible.

Fire Radiation:

In flame radiation, the most important and least known parameter is $f_{v}$, the soot volume fraction, defined as the volume occupied by soot per unit of flame volume. Previous summaries have described a multiwavelength laser extinction technique for in-situ measurement of the local flame $f_{y}$ in free and forced boundary layers as well as in pool fires. Detailed experimental comparisons are underway with alternative single-wavelength scattering/extinction measurement methods.

Limited data on small pool fire mean soot volume fractions suggest $f_{v}$ scales with optical thickness, $k L$, as

$$
\begin{aligned}
& f_{v} / f_{v_{\max }}=1.5(K L)^{1 / 3}, K L \leqslant 0.3 \\
& f_{v} / f_{v_{\max }}=1 \quad, K L \geqslant 0.3
\end{aligned}
$$


Equation (1) is shown in Fig. 1, where $f v_{\max }$ is an experimental fuel characteristic ( $=3.4 \mathrm{ppm}$ for polystyrene + ; and $=0.62 \mathrm{ppm}$ for PMMA.), $K$ is the soot absorption coefficient and $L$ is the mean beam length. If this correlation holds for all fuels, it will permit scaling of the mean $f_{V}$ in pool fires to any size from a single measured $f_{v}$. For example, a $15 \mathrm{~cm}$ diameter pool of iso-octane gave $f_{v}=0.46 \mathrm{ppm}$. Using Tien's soot optical properties gives $\mathrm{k}\left(\mathrm{m}^{-1}\right) \approx$ $1.5 \mathrm{fv}_{\mathrm{v}}(\mathrm{ppm})$. So $\mathrm{k} \approx 0.67 \mathrm{~m}^{-1}$. The mean beam length is well approximated by the pool radius, $7.5 \mathrm{~cm}$ here. Then from Eq. (1), $f_{v} / f_{v_{\max }}=0.85$, and $f_{v_{\max }}=0.83 \mathrm{ppm}$. This $f_{v_{\max }}$ will exist in all iso-octane pool fires for which $\kappa L \geqslant 0.3$, i.e., all pool diameters $\geqslant$ $0.5 \mathrm{~m}$. By the method of Ref. 6 , this volume fraction corresponds to a maximum conversion of fuel carbon to soot for iso-octane of $6.3 \%$. Additional experiments are underway to confirm this correlation.

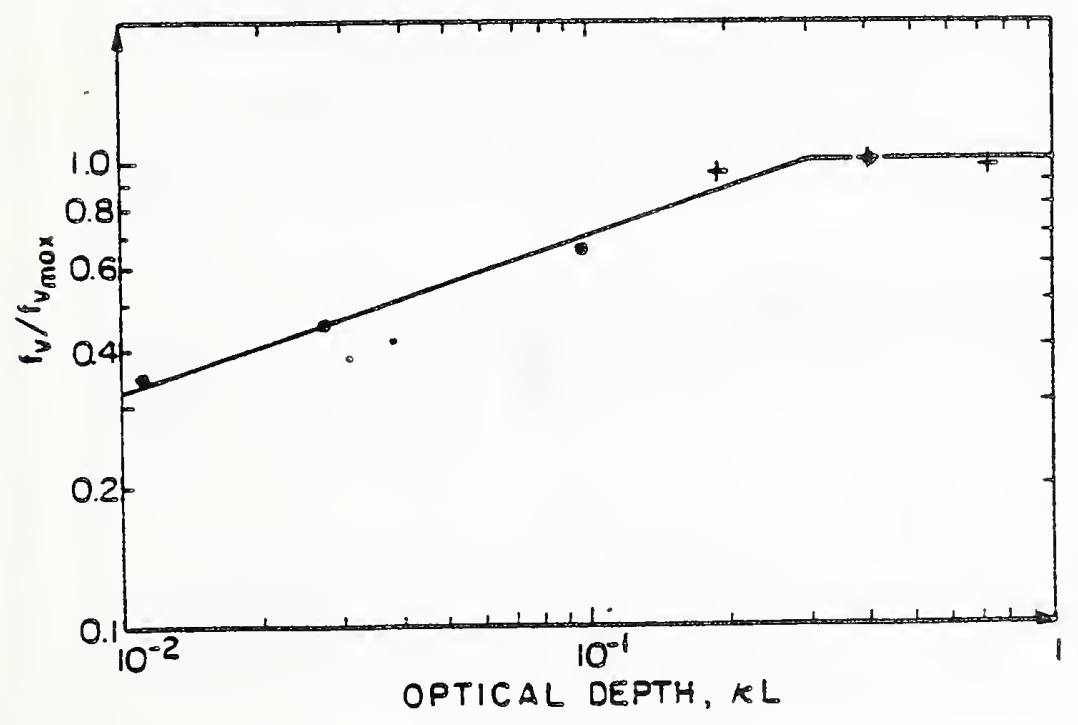

Fig. 1

Universal pool fire soot volume fraction correlation.

Combusting Boundary Layers:

In order to interpret our $f_{v}$ measurements in free and forced boundary layers, accurate temperature and velocity fields are needed (4). The classic solutions of boundary layer diffusion flames neglected phenomena such as fuel cracking, property variations, buoyancy and radiation and, therefore, produced profiles that are not adequate for soot formation modeling. This analys is adds buoyancy, soot radiation, wall radiation, and confinement pressure gradient effects as perturbations (2). To maximize the utility of previous solutions, each perturbation is broken into two parts. The first contains the effect of the perturbation in the governing equations, assuming no blowing at the wall. The second separately accounts for 
the additional blowing due to that perturbation. An advantage of this approach is that each perturbing effect can be assumed independent, with the similarity solution incorporating fuel cracking and property variations as the zeroth order. Summing the contributions provides the full solution with a clear indication of the importance of each perturbation. The effect of soot radiation is to increase the blowing at the wall and lower the temperatures in the regions where soot is present. The buoyancy perturbation causes velocity maxima in mixed flow and moves the peak temperature closer to the wall. Confinement pressure gradient effects in our system appear to be so large that they cannot be adequately treated as perturbations.

The fact that predicted temperature profiles significantly overestimate measured temperatures between the fuel surface and the flame (6) even when soot radiation is included in the analysis, implies that endothermic fuel cracking may be important (see e.g. Nakagawa, et al., 13th Combustion Symposium, p. 813, 1971). Therefore, we have included a second reaction, $Y_{F I} \rightarrow Y_{F 2}$, in our analyses. Fast kinetics are assumed so that a fuel cracking sheet exists inside the flame sheet as shown in Fig. 2. These sheets can be expanded using activation energy asymptotics. Similarity solutions are still possible provided the Shvab-Zeldovich variables are redefined to include the cracked fuel product, $Y_{F 2}$.

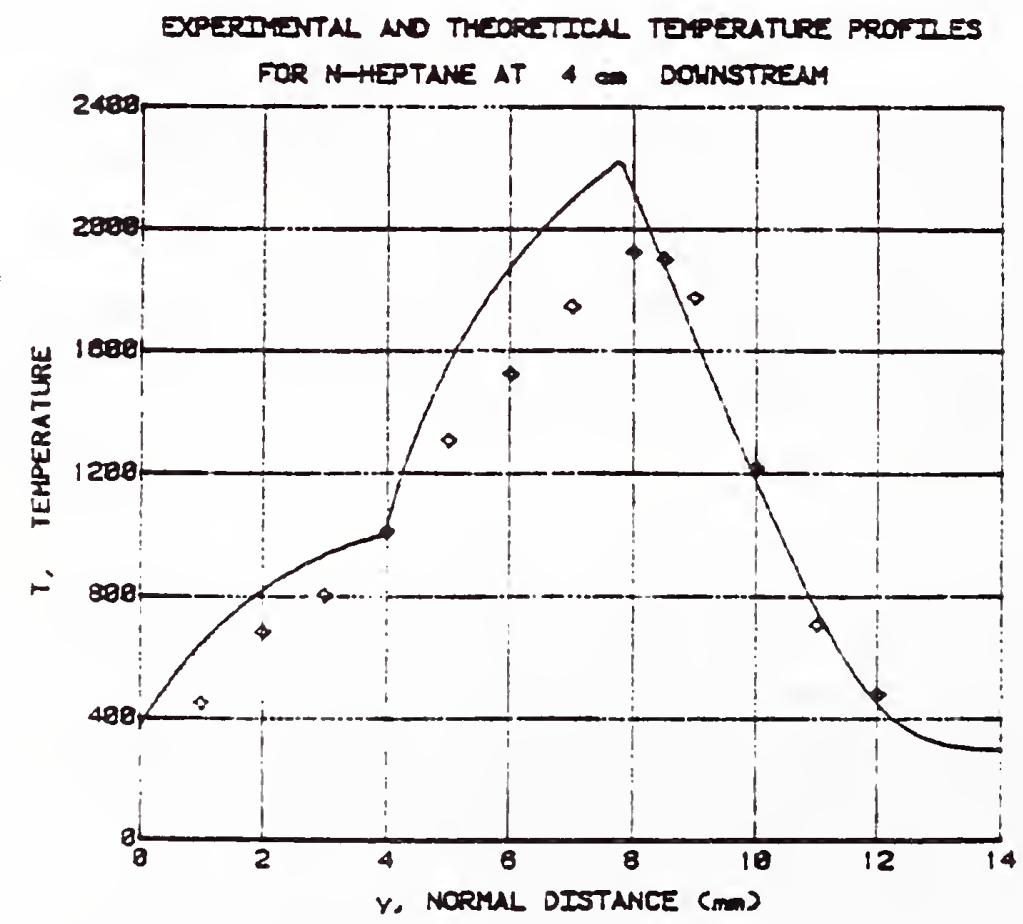

Fig. 2. Temperature $\left({ }^{\circ} \mathrm{K}\right)$ profile for a free flow boundary layer flame of $n$-heptane in air. Theory $(-)$ includes a fuel thermal cracking sheet at $1000^{\circ} \mathrm{K}$ and an endothermicity there based on acetylene as the primary product. Experiment results $(0)$ are described in Ref. 4. 
and

$$
B=Y_{F I} / \nu_{F} M_{F}+Y_{F 2} / \nu_{F} M_{F}-Y_{O} / \nu_{O} M_{O}
$$

$$
\alpha=n / \tilde{Q}+Q^{\prime} Y_{F 2} / \nu_{F} M_{F}+\left(1-Q^{\prime}\right) Y_{0} / \nu_{O} M_{0} \text {. }
$$

$Q^{\prime}$ is the cracking endothermicity, $Q=Q+Q^{\prime}$, where $Q$ is the original heat of combustion. $Y_{F Z}$ is the original fuel. A separate simple boundary value problem is solved for $Y_{F Z}$, allowing $Y_{F I}$ and $h$ to be extracted from Eq. (2) between the fuel and the fiame.

\section{Reports and Papers:}

1. C.E. Grant and P.J. Pagni, eds., Fire Safety Science - Proceedings of the First International Symoosium, Hemisphere Publishing Co., New York (1986).

2. J.A. Ang, P.J. Pagni, H.R. Baum and T.G. Mataga, "Combusting Boundary Layers Perturbed by Pyrolysis, Bouyancy and Radiation," poster presentation at the Twenty-first International Symposium on Combustion, Aug. 3-8, 1986, Muinchen, F.R.G.

3. S.S. Dosanjh, P.J. Pagni and A.C. Fernandez-Pello, "Forced Cocurrent Smoldering Combustion," poster presentation at the Twenty-first International Symposium on Combustion, Aug. 3-8, 1986, München, F.R.G.

4. J.A. Ang, P.J. Pagni, T.G. Mataga, J.M. Margle and V.J. Lyons, "Temperature and Velocity Profiles in Sooting. Free, Boundary Layer Flames," AIAA Paper No. 86-0575, 24th Aerospace Sciences Meeting, Reno, Nevada (1986).

5. K.L. Foote, P.J. Pagni and N.J. Alvares, "Temperature Correlations for Forced-Ventilated Compartment Fires," Fire Safety Science Proceedings of the First International Symposium, pp. 139-148, Hemisphere Publishing Co., New York (1986).

6. S. Bard and P.J. Pagni, "Spatial Variation of Soot Volume Fractions in Pool Fire Diffusion Flames," Fire Safety Science - Proceedings of the first International Symoosium, pD. 361-369, Hemisphere Publishing Co., New York (1986).

7. J.P. Vantelon, P.J. Pagni and C.M. Dunsky, "Cellular Flame Structures on a Cooled Porous Burner," in AIAA Progress in Astronautica and Aeronautics Series: Dynamics of Reactive Systems Part I: Flames and Configurations, pp. 131-151, AIAA, New York (1986).

8. P.J. Pagni, "Progress Report on Matarials Fire Properties and Test Methods," in Proceedings of the Eighth Joint Meeting, United StatesJapan Natural Resources Panel on Fire Research and Safety, pp. 352358, Building Research Institute, Tsukuba, Japan (1986). 
CENTER FOR FIRE RESEARCH

NATIONAL BUREAU OF STANDARDS

FY 86

Institution: University of California, Berkeley

Grant No.: NB83NADA4020

Grant Title: Fire Propagation in Concurrent Flows

Principal Investigator: Professor A.C. Fernandez-Pello

Department of Mechanical Engineering

University of California

Berkeley, CA 94720

Other Professional Personnel: H.T. Loh, Research Assistant

B. Amos, Research Assistant

NBS Scientific Officer: Dr. H.R. Baum

Technical Abstract:

A research program is being carried out to study the mechanisms controlling the spread of flames over the surface of a solid combustible in an oxidizing gas flow. Because of the varied mechanisms involved in the flame spread process, the program includes a number of studies covering different physical phenomena from the ignition of a vaporizing fuel to the extinction of a propagating flame. Research performed during the current research period includes a numerical analysis of the flow assisted spread of flames over the surface of a thermally thick fuel, an experimental study of the extinction and stabilization of a diffusion flame over a flat combustible surface, and a theoretical study of the forced ignition of a vaporizing combustible surface. A significant contribution of the flow assisted flame spread analysis is the incorporation of finite rate kinetics in the formulation of the problem. This provides a more accurate description of the regions with slow chemistry such as the upstream leading edge of the $f 1$ ame and the flame tip. The $f 1$ ame extinction experiments were performed primarily to verify the predictions of an analysis, previously developed, of the dependence of the extinction distance on the velocity and oxygen concentration of the convective flow. The study addresses the processes controlling the structure and stabilization of the upstream leading edge of the flame. The ignition study has as final objective the description of the ignition by a hot particle (firebrand), or by gas absorption of radiation, of a vaporizing surface in a convective flow. During this reporting period, a one-dimensional model of ignition has been developed. The results, al though preliminary appear to be phenomenologically correct.

Numerical Analysis of Flow Assisted Flame Spread. This work consists of a numerical analysis of the flame spread process over the surface of a thermally thick fuel, in a concurrent forced oxidizing flow. In the analysis, the gas phase governing equations for a laminar, reacting, boundary layer flow are solved numerically to obtain the heat flux at the burning and unburnt fuel surfaces. The calculated heat flux is used later as a boundary conditicn for the solid phase transient energy equation. The rate of flame spread is obtained 
from the solution of this last equation by imposing the condition that at the pyrolysis front the surface temperature of the solid is equal to its gasificam tion temperature.

A modified version of the GENMIX computer code is used for the numerical solution of the gas phase equations. The modified code includes finite pate chemical kinetics for a one step chemical reaction of the Arrhenius type, and it is applied for a laminar, non-radiating, boundary layer flow. The calculation domain is divided into two regions: 1) The upstream region where the fuel sur. face is vaporizing and the gas phase domain can be solved independently from the solid phase, and 2) The downstream region where the solid is not vaporizing and where the solid and gas phases are coupled through their interfacial boundary conditions and consequently have to be solved simultaneously. In fig. 1 the theoretical results for the rate of flame spread as a function of the flow velocity and oxygen concentration and their comparison with the experiments are presented. It can be seen that the predicted flame spread rates agree well with the experimental results. It should be noted, however, that some of the parameters involved In the problem, in particular the pre-exponential factor in the Arrhenius reaction rate, have been selected to improve the agreement between theory and experiment.

Experimental Study of the Extinction of a Diffusion Flame. The main objective of these experiments is to verify the predictions of an analysis, already completed, of the extinction characteristics of a diffusion flame on a vertical surface, which is burning steadily in a mixed convective flow. The experiments are carried out in a small scale combustion tunnel. The flow velocity and oxygen concentration of the flow in the tunnel are accurately controlled with critical nozzles. Nifficulties in performing the experiments with a solid fue? moved us to carry out the experiments with a liquid fuel (heptane). The liquid fuel is supplied by gravity fed to a porous ceramic vertical plate. The experiment consists primarily in the measurement of the distance from the upstream edge of the fuel surface to the point where the flame leading edge is stabilized (extinction distance) as a function of the velocity and oxygen concentration of the flow. The experimental results and their comparison with the theoretical predictions are presented in Fig. 2. The agreement between theory and experiments is only qualitative. This is understandable since the analysis considers only a simple one step, Arrhenius type, reaction to describe the gas phase chemical kinetic processes. The experimental results, however, verify the theoretical predictions.

Analysis of the Ignition of a Vaporizing Combustible Surface. A numerical analysis of the forced ignition, by pilot or by vapor absorption of radiztion, and subsequent flame propagation in a gaseous mixture established over a vaporizing combustible surface in a still oxidizing environment is developed. The model considers a flat combustible surface that starts to vaporize due to the heat flux from a suddenly imposed external source of radiation. Two sources of ignition are analyzed. nne is a source of heat that is suddenly introduced at a predetermined distance from the surface and that causes the ignition of the pre-established gaseous mixture. The other is the absorption of radiation by the vapor fuel, which increases the temperature of the gas and causes its ignition. In both cases the heat source is intense enough that once the ignition of the mixture occurs, the combustion reaction becomes self-sustained. Conduction of heat upstream results in the propagation of a reaction front (flame) toward the fuel surface. Conduction and convection of heat downstream results in the 
propagation of a second reaction front toward the outer boundary. The formation and characteristics of these two reaction fronts depend on the initial location and intensity of the ignition source.

In the present analysis, the transient, one dimensional, conservation equations that describe the reacting flow are solved numerically to determine the transient ignition of the gaseous fuel-oxidizer mixture and the subsequent propagation of the combustion reaction through the mixture. A modified version of the SIMPLER computer code is used in the computation. The combustion reaction is assumed to be described by a global one-step second order chemical reaction between fuel and oxidizer. The reaction rate is assumed to be of the Arrhenius type with relatively small activation energy. The value of the activation energy is selected to ease the difficulties inherent in the numerical computation of the ignition process while providing physical insight on the process. A Lewis number unity is assumed so that the Shuab-Zeldovich formulation can be applied to simplify the numerical solution. A non-uniform grid that moves with the reaction front is used to compute the velocity of propagation of the flame. The variation with time of the temperature for a characteristic case of vapor absorption ignition is presented in Fig. 3 .

\section{Reports and Papers:}

1. H.T. Loh and A.C. Fernandez-Pello, "A Study of the Controlling Mechanisms of Flow Assisted Flame Spread," Twentieth Symposium (International) on Combustion, The Combustion Institute, 1575-1982 (1985).

2. H.T. Loh and A.C. Fernandez-Pello, "Flow Assisted Flame Spread Over Thermally Thin Fuels," First International Symposium on Fire Safety Science, 65-74 (1986a).

3. R. Rangel and A.C. Fernandez-Pello, "Convective Ignition of a Flat Combustible Surface," 1985 Fall Technical Meeting, Western States Section of the Combustion Institute, University of California, Davis, October 21-22, 1985.

4. C.-P. Mao and A.C. Fernandez-Pello, "Flame Spread in a Wall-Ceiling Corner," 1985 Technical Meeting, Eastern Section of the Combustion Institute, Philadelphia, PA, November 4-6, 1985.

5. H. Kodama, K. Miyasaka and A.C. Fernandez-Pello, "Extinction and Stabilization of a Diffusion Flame on a Flat Combustible Surface," submitted to Combustion Science and Technology, 1986.

6. H.T. Loh, "Concurrent Flow Flame Spread Study," Ph.D. Thesis, Department of Mechanical Engineering, Iniversity of California, Berkeley, 1986. 
CENTER FOR FIRE RESEARCH

NATIONAL BUREAU OF STANDARDS

FY 1986

\author{
Institution: University of California - Berkeley \\ Grant No.: $\quad$ 6ONANB4D0018 \\ Grant Iitle: Flame Radiation \\ Principal Investigator: Professor Chang-Lin Tien \\ Department of Mechanical Engineering \\ University of California \\ 6179 Etcheverry Hall \\ Berkeley, California 94720 \\ Telephone: (415) 642-0877
}

Other Propessional Personnel: M.A. Brosmer, Ph.D. completed in December 1985

B.L. Drolen, Ph.D. student

A.J. Stretton, Ph.D. student

S.H. Park, Ph.D. student

NBS Scientific Officer: Dr. Takashi Kashiwagi

Technical Abstract:

Introduction. The goal of the research sponsored by this grant is to establish simple calculation schemes for radiation heat transfer in fires, while retaining the fundamental physics of the problem. The products of the research are approximate relations developed from careful experimental studies and theoretical analyses. During the past year, three topics were addressed: (1) radiative modeling of pool fires to determine burning rates and radiative fluxes; (2) radiative properties of agglomeraced soot particulate; and (3) infrared radiative properties of several hydrocarbon gases which are pyrolysis products of PMMA. In addition to this research work, a chapter reviewing the fundamentals of thermal radiation in fires for fire protection engineers was prepared for publication [1].

Radiative Modeling of Pool Fires. The relatively cool gases evolved from the pyrolysis of burning condensed fuels are important in determining the rate of burning and the ignition characteristics of the fuel. Large fires ( $L>0.7$ m) are primarily controlled by radiant feedback from the flames, which provides the energy to pyrolyze the fuel into combustible gases. A two-zone flame model which is capable of handling large-scale pool fires has been proposed recently, and has already been successfully used to predict burning rates and total radiative output of moderate to large-scale PMMA pool fires [2]. The model is very simple in concept, consisting of two discrete, homogeneous, isothermal, conically-shaped regions: a high-temperature luminouslame region representing the turbulent combustion zone, and a cool, fuel-rich layer near the fuel surface which acts to block radiation feedback from the flames (see Eig. 1). Rigorous specification of the temperature and concentration profiles of the sases within the fire is not required to obtain accurate predictions of the burning rate and various radiative fluxes. Further 
refinement and simplification will be undertaken to make the model a more convenient tool for the fire engineering community. The scaling problem between small-scale fire plumes and large-scale plumes associated with fires of disastrous proportions is also under analytical study, with special attention to the role of thermal radiation.

Radiative Properties of Soot Particulate. The scattering and absorption characteristics of agglomerated soot particulate has been modeled as a collec* tion of spherical sub-units assuming that they are Rayleigh scatterers [3]. The model accounts for all electromagnetic interactions between the primary particies via an existing analytical solution, and investigates clusters and chains of as many as 136 primary particles aligned in various directions relative to the EM wave propagation (see Fiz. 2). The analytical results are correlated using "equivalent" sphere models based on the disymmetry ratio, the scattering cross-section and the absorption cross-section. The results indicate that a cluster of spheres has EM cross-sections which are sinilar to those of an equivalent sphere of equal solid volume. The effective diameter of the agglomerated particulate can be simply expressed by $D_{e f f} / D=N^{1 / 3}$. The results are in good agreement with existing laser diagnostic data of soot in flames.

Radiative Properties of Hydrocarbon Gases. The blockage effect of the pyrolyzed zases can significantiy lower the burning rate of the fuel and greatly influences the ignition characteristics of the spreading flames. The gases under study include methyl methacrylate $\left(\mathrm{C}_{5} \mathrm{H}_{9} \mathrm{O}_{2}\right.$, the liquid monomer of PMMA), ethylane $\left(\mathrm{C}_{2} \mathrm{H}_{4}\right)$, ethane $\left(\mathrm{C}_{2} \mathrm{H}_{6}\right)$, and propane $\left(\mathrm{C}_{3} \mathrm{H}_{3}\right)$. To date, the list of hycrocarbon gases for which infrarec properties have been publisned is limited to methane $\left(\mathrm{CH}_{4}\right)$, acetylene $\left(\mathrm{C}_{2} \mathrm{H}_{2}\right)[4]$, and propylene $\left(\mathrm{C}_{3} \mathrm{H}_{5}\right)[5 j$. Typical spectral absorption data from ongoing work with methyl methacrylate is presented in Eiz. 3. The experimental data are reduced and presented in a variety of formats: 1) spectral mean properties for narrow band models; 2) average band properties for the exponential wide-banc model; and 3) total absorption properties of the gas for the super-band model, the Planck mean absorption coefficient, and total emissivity charts.

\section{Reports and Papers:}

i. C.L. Tien, K.Y. Lee, and A.J. Stretton, "Radiation Heat Transfer", in SEPE (Society for Eire Protection Engineers) Quantizative Methods Handbock (to appear).

2. M.A. Brosmer and C.L. Tien, "Radiative Energy Jlockage in Large PocL Eires," Comb. Sci. and Tech. (to appear).

3. 3.L. Drolen and C.L. Tien, "Abscrption and Scattering of Agsiomerated Soot Particulate," J. Quant. Spectrosc. and Rad. Irans. (uncer review).

4. M.A. Brosmer and C.L. Tien, "Thermal Radiation Properties of Acetylene," J. Heat Trans. 107, 943-948 (1985).

5. C.L. Tien and M.A. Brosmer, "Infrared Radiation Properties of Propylene," Comb. Sci. and Tech. 48, 103-175 (1986). 

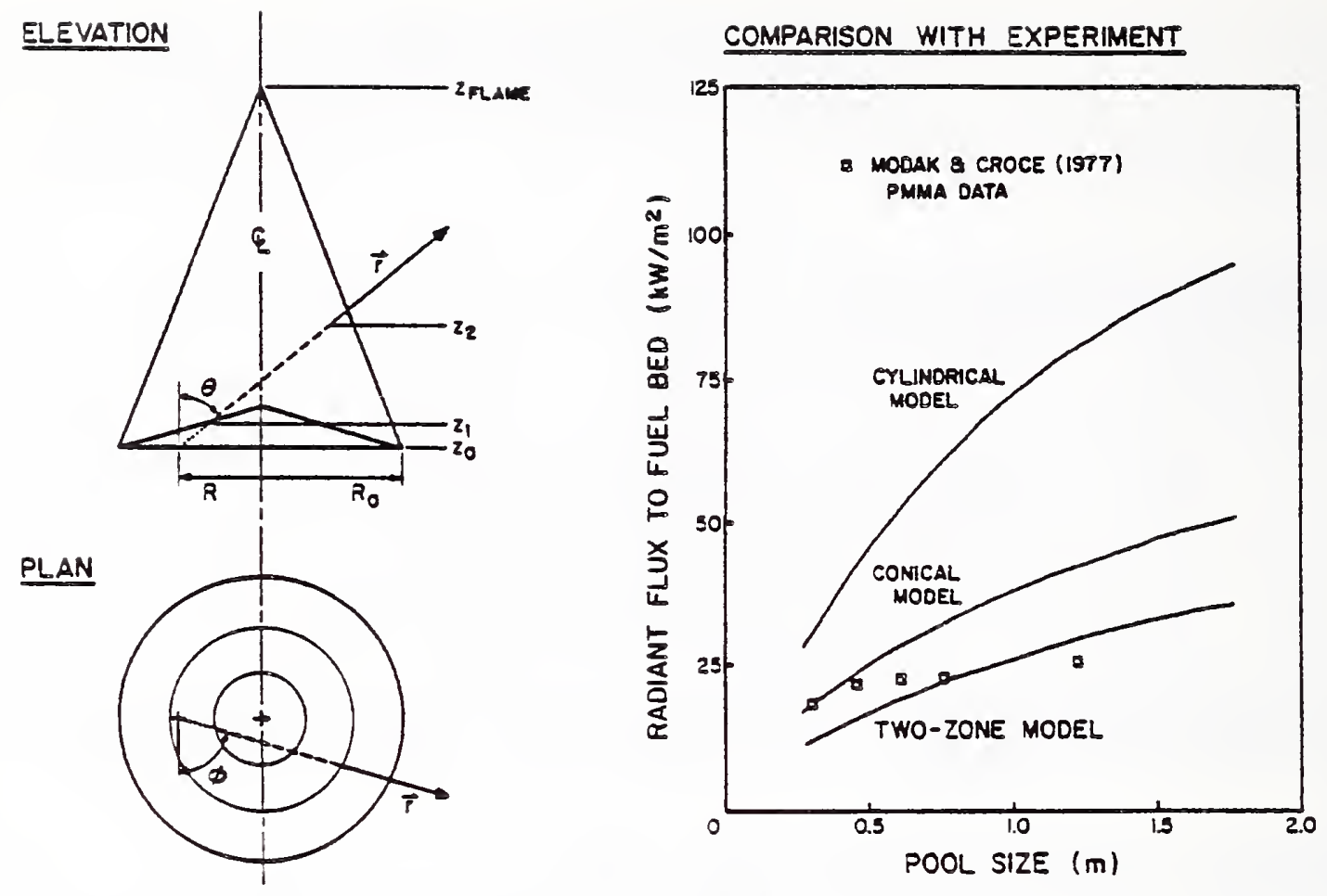

Fig. 1 Two-Zone Model for Large Pool Eires

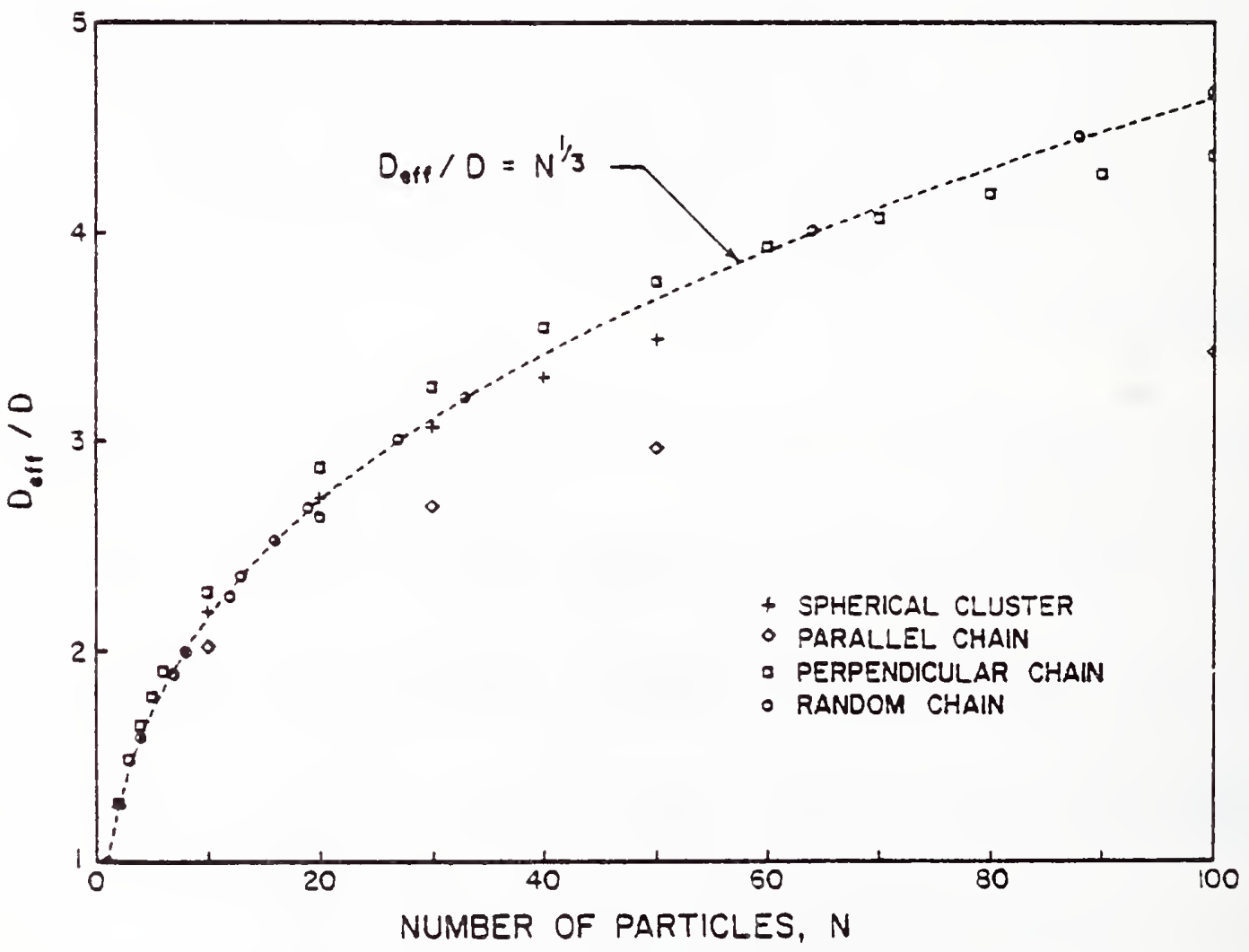

Fig. 2 Equivalent Sphere Correlation for Agglomerated Soot Particulate 


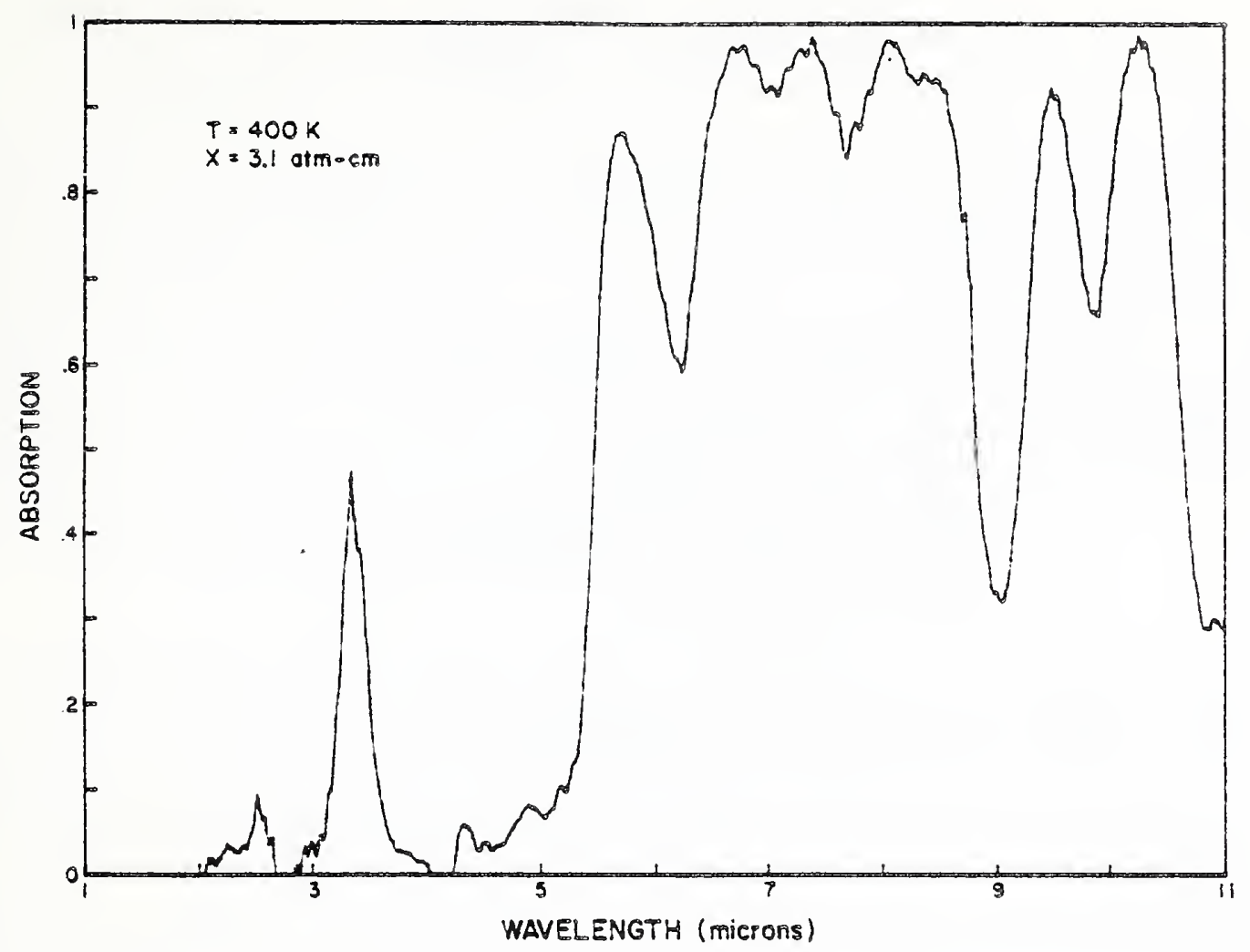

Eiz. 3 Absorption Soectrum for Methy M Methacrylate 
Institution: University of Dayton Research Institute, Dayton, Ohio Grant No.: NB83NADA4056

Grant Title: Mathematical Modeling of Furniture Fires

Principal Investigator: Mark A. Dietenberger

Research Physicist

University of Dayton Research Institute

300 College Park - JPC/201

Dayton, Oh io 45469

(513) 229-3921

Other Personnel: Joyce Smith, Research Programmer

Scott Musson, Student Ass istant

NBS Scientific Officer: Or. Vyten is Babrauskas

Technical Abstract:

The objective of this work is to develop a working computer model of a furniture fire which utilizes the bench scale measurements on furniture samples of burning rate history, flame spread rate, time to ignition, and the fraction of fuel converted to soot. The primary prediction of the model is the burning rate of a furniture fire as a function of time. The approach is to design modular submodels that are simple, accurate, and highly coupled and which can be incorporated into room fire models such as FAST and HARVARD CFC Series.

The current research has concentrated in two areas: (1) Upgrade the demonstrator furniture fire model, which was coded during the previous grant period, to take into account more real istic flame shapes, to incorporate Pagni's recent estimates of flame radiation temperature and soot volume fraction for PU foams, to fine-tune the $f l$ ame spreading algorithms, and to accomodate burning rates as a function of net radiative flux to the burning surface, and (2) Merge the resulting furniture fire model into FAST code, a current multi-room fire model developed at NBS by Walter Jones. The design of four modular sub-models corresponding to ignition/flame spreading, the surface burning rate, the flame shapes and bulk properties, and the furniture fire thermal radiation was confirmed for easy adaptability to a room fire model. The merged program is now called HEMFAST and some interesting results were obtained. 
The purpose of the improvements was to prepare the furniture fire model for incorporation to the FAST program. For example, in the thermal ignition flame spreading module a routine for calculating the temperature rise of the furniture surface and its thermal ignition was put in place. In the flame spread module a routine for calculating flame spreading taking into account the preheat surface temperatures and the surface orientations was put in place. It is notad that the user can input an ignition source location at any time in the simulation. The module also includes a feature for merging of overlapping flame spread polygons and to keep spacings between polygon points at reasonable values. The surface burning rate module now calculates the individual burning history of each surface element inside a flame spreading "polygon" in response to a net radiative heat flux and then sums them up for input to the flame structure module and to the FAST model.

In another example, the flame structure module no longer considers a cyl indrical or a conical flame shape because the VCR observations of mockup furniture fires revealed a more complicated shape when the back or the arm rests became involved in burning. To keep the problem of flame shapes simple, yet consistent with VCR observations it was assumed only pool fires exist when both the seat and the side surfaces (back or arm rests) are involved. This implied putting the ignition source on the seat. In all instances the "horizontal" flame spreading polygons define the flame base while a hydraulic diameter of the base is computed as four times the base area divided by the base circumferance. The burning rate of the "pool" fire is the sum from all burning elements, both horizontal and vertical orientations. The fiame height then is an analytic function of the total burning rate and of the flame base hydraulic diameter. The flame shape is thus defined by a horizontal flame spread polygon base and a vertical length equal to the calculated flame height. It was straight forward to calculate the flame volume and surface area as well as to deternine "squarelike" surface elements on the flame surface for inputs to the radiative heat flux module.

Improvements in the radiative heat flux module were mainly in the calculation of the soot extinction coefficient and the corresponding flame emissivity. Using the results from Bard and Pagni for radiation from soot in any size or kind of pool fires, the inputs needed were the maximum soot volume fraction, the mean beam length, and the flame temperature to calculate the soot extinction coefficient. The flame temperature of the pool fire was assumed to be at $1300^{\circ} \mathrm{K}$. The radiative heat fluxes then computed are recycled as inputs to the thermal ignition/flame spread module and to the surface burning rate module after stepping the simuiation time.

Development and Results of HEMFAST Code

HEMFAST is a computer program which simulates the furniture fire and the toxic yas growth in a room and its spread to the other rooms. This was achieved by incorporating the furniture fire model into the FAST model. The furniture fire nodel was designed to be self-controllable in simuiating a 
fire source utilizing as inputs only the bench scale data of material burning rate, flame spreading, thermal ignition, and the flame properties of the following: soot volume fraction, $\mathrm{CO}_{2}$ and $\mathrm{H}_{2} \mathrm{O}$ mass fractions of fuel weight, and gas temperatures. The Froude modeling of flame shape and of uniform flame properties was utilized following McCaffrey and Orloff and de Ris. To obtain the self-controllability in the furniture fire model, and also in HEMFAST, it has involved utilization of a practical 3-0 thermal radiation model in calculating the heat feedback from the flames to the flame front in the determination of the flame spread rates, and to the flame base in the determination of the local material burning rates. In the HEMFAST program, the thermal radiation model was extended to include the upper and lower gas layers and the room enclosure. Since the Hottel's zoning method was used in the thermal radiation model it was possible to consider surface emissivities less than unity on all surfaces, and to consider three isothermal gray gas volumes which are the high-temperature flaming plume, the sooty upper gas layer, and the lower gas layer at $50 \%$ relative humidity.

Some salient features were noted in the simulation of a sample fire growth on a furniture mockup. Immediately after the seat was ignited, the pool fire was inferred to be sustained by glowing combustion within the burning material while the flame front was spreading at its slowest rate. This was shown by the relatively high net radiative power loss calculated for the burning material. The simulated furniture fire tended to grow at a low exponential rate for a slowly increasing spread rate of the flame fronts of the octogonal flame base.

As the flame base reached the right armrest and the right side of the backrest, a new phase in the fire growth rate developed because of the additional burnrate of the side walls and its radiative feedback to the burning seat. The increased burning rate led to a higher flame radiative height and also to a higher soot volume fraction. The final phase in the fire growth rate involved the spontaneous thermal ignition of the remaining surface elements and also has been observed in VCR observations of mockup burning. with all the elements burning at this time, the fire growth rate was at its greatest. However, the peak in the furniture fire burnrate in this case was limited by the surface elements burnout as opposed to the limitation by the maximum soot volume fraction for a given flame base size.

The upper and lower gas layers eventually gaines 87 and $39^{\circ} \mathrm{C}$ respectively above the initial room temperature while the upper layer constituents for $\mathrm{CO}_{2}, \mathrm{CO}$, and $\mathrm{H}_{2} \mathrm{O}$ eventually reached 4997,217 , and $19640 \mathrm{ppm}$ respectively at peak burning rate. Throughout most of the fire growth the upper gas layer had a net radiative heat loss to the lower gas layer and wall despite the heat gain from the furniture fire.

Although the HEMFAST program currently predicts the qual itative behavior of the furniture fire growth in a room, it will need some specific revisions for the quantitative comparisons with the data, especially the data by Krasny and Babrauskas. The bench scale data available on the horizontal 
and lateral flame spreading on furniture materials is very limited. At the present some data on the $f l$ ame spread rate can only be inferred from the VCR observations of furniture mockup burnings. Also, the data on the temperature of the burning surface is nonexistent for some cases.

The resulting model can aid in resolving some fire safety issues and aid in fire engineering a room. With further small improvements it can lead to a prediction of time to flashover.

\section{Publications}

"Mathematical Modeling of Furnture Fires," NBS-GCR-86-506, Interim Report, prepared for the National Bureau of Standards, Gaithersburg, 110, February 1986. 


\section{CENTER FOR FIRE RESEARCH \\ NATIONAL BUREAU OF STANDARDS \\ FY86}

Institution:

Grant No.:

Grant Title:

Principle Investigator:
University of Maryland

70NANB5H0529

Interaction of Radiation and Conduction in Polymeric Materials

Dr. Win Aung (Adjunct Professor)

Mechanical Engineering Department

University of Maryland

College Park, MD 20742

Elizabeth Upson Finlayson (M.S. Candidate)

Dr. Takashi Kashiwagi

\section{NBS Scientific Officer:}

\section{Technical Abstract:}

The research presented has been carried out as a cooperative program between the National Bureau of Standards and the University of Maryland. To date the work considers a theoretical investigation of combined radiation and conduction heat transfer in semitransparent media. The research is stimulated by the interest to improve the general understanding of the pyrolysis and flamability characteristics of an important class of solid polymeric materials, namely, materials that are classified as semitransparent.

The heating of materials that are semitransparent to thermal radiation is strongly dependent on the interaction of heat conduction with thermal radiation. In an opaque material there is no interaction. Radiation heat transfer is treated as a surface phenomenon in a purely conductive model. In a semitransparent material the radiation is absorbed throughout the model. The volumetric absorption of radiation causes increased thermal penetration. In the early stages of radiative heating the semitransparent model is considered cold. During this phase the temperature within the model is sufficiently low so that volumetric emission within the solid can be neglected. As the model temperature increases the emission as well as subsequent absorption of internal radiation must be considered; this is the reradiating model. All three modellings of radiation heat transfer: opaque, cold and reradiating are considered in this research. The main focus of the analysis is based on a finite difference scheme but analytical solutions have been obtained for the linear cases.

The general model, common to all radiation cases considers a vertical homogeneous plane layer. The homogeneous specification is applied to allow for negligible scattering. The plane layer is in local thermodynamic equilibrium so that Kirchhoff's laws are applicable. The model is heated by a high temperature gray body source which is used to model an intermediate to large scale fire. The collimated flux of normal incidence at the irradiated surface is a known quantity. The analysis considers only the early phases of heating and does not consider the added complications of phase change or chemical reaction caused by degradation. It is assumed that the temperatures within the sample are below the glass transition temperature. 
The physical properties; thermal conductivity, specific heat, and density are considered to be constant or to vary linearly with temperature. The transient response of the model is of primary interest. The constrictions of the analysis do not allow a steady state condition to be established. Combinations of constant temperature; adiabatic; and conducting, convecting and radiating boundary conditions are considered. The optical properties of the models are considered constant with respect to wavelength resulting in a gray analysis of radiation. The optical length, $r$, a dimensionless parameter relating to the absorption coefficient and model thickness is used as a parameter to indicate relative opacity of a material. An opaque problem is one in which the optical length can be considered infinite.

The following nondimensional form of the transient form of the transient energy equation is used:

$$
\frac{\partial}{\partial \mathrm{x}}\left[k \frac{\partial \theta}{\partial \mathrm{x}}\right]-\mathrm{N}_{\mathrm{r}-\mathrm{c}} \frac{\partial \mathrm{F}}{\partial \mathrm{x}}=\rho \mathrm{c} \frac{\partial \theta}{\partial t}
$$

$\theta$ the temperature parameter normalized on the ambient temperature. $x$ is the spatial parameter normalized on the model thickness. $k, \rho$ and $c$ are the dimensionless thermal conductivity, specific heat and density normalized on the values determined at ambient temperature. $t$ is the time parameter normalized on the Fourier number. $\partial F / \partial x$ is the spatial gradient of the solution of the equation of transfer, integrated over the solid body angle, normalized on the blackbody intensity of the ambient temperature. The axisymetric form of the equation of transfer is solved subject to semitransparent boundary conditions. $N_{=-c}$ is the radiation conduction interaction parameter defined as $\sigma \mathrm{T}_{\infty}{ }^{3} \mathrm{~L} / \mathrm{K}$.

The opaque model is the simplest model. The temperature profile is obtained by solution to a form of the energy equation containing only conduction and storage terms. The extemal radiation flux appears as a source term in the boundary condition at the irradiated surface. Analytical as well as numerical solutions have been obtained for the opaque model.

The cold model requires the solution of the energy equation and the equation of radiative transfer. The energy equation includes three terms : a conductive term, a storage term, and a radiation term. The radiation term contains only that part of the solution of equation of radiative transfer that relates to the external flux. Because the cold model neglects internal emission the solution of transfer is dependent only on the external source cemperature. The gradient of the flux is a simple exponent term. The cold model has been solved using both analytical and numerical methods.

The final model considered is the reradiaring model. This model requires the simultaneous solution of the energy equation and the equation of radiative transfer. The energy equation is of the same form as that used in the cold model. The solution of the equation of radiative transier, however, is dependent on the internal temperature profile, as well as the external source temperature. The energy equation and the equation are coupled through the temperature profile to form a nonlinear integrodifferential equation. An iterative technique is needed to obtain a temperature profile that satisfies both equations. No attempt is made to find an analytical solution to this problem. The solution for the equation of transfer has been obtained analytically for a linear temperature profile and this result has been compared with numerical methods. The solution to the equation of transfer is obtained by assuming a constant temperature across each finite difference nodal volume. At the beginning of each time step the values from the previous time step are used. The integrations of the individual components of the 
solution of radiative transfer over the entire model are substituted by a summation of integrations over each node. Since the temperature, hence the flux, is constant over each node these integrations can be performed analytically. The resulting solution to the equation of transfer is then used in the energy equation to obtain a new temperature profile. The process is repeated until the new temperature profile does not deviate significantly from the original one. A Newton-Raphson scheme is used to aid in the convergence of the solution.

\section{Results:}

The following figures are a sample of the results that have been obtained so far in the course of this research. Figure 1 shows a comparison of the opaque, cold and reradiating models. The temperature profiles are recorded at the time required for the maximum temperature in the opaque model to reach a value 2.0 times that of the ambient. The irradiated boundary is subjected to a flux: $F=5 \mathrm{~W} / \mathrm{cm}^{2} . \mathrm{N}_{5-\mathrm{c}}$ is taken as 0.1 . In the opaque model the flux appears in the boundary condition as $\mathrm{q}_{5}=\mathrm{N}_{\Sigma-c}(F) / \sigma \mathrm{T}_{\infty}{ }^{4}$ to allow for comparison with the cold and reradiating models. The boundary conditions are determined using an energy balance between conduction, natural convection and surface reradiation. The reflectivities relating to external flux are determined by the Fresnel equations based on a solid index of refraction: $\mathrm{n}=1.5$. The internally generated flux is assumed to be totally reflected. A value of $r=10$ is used as the optical length in the semitransparent models. Figure 1 shows the significant difference between the predicted surface temperature of the opaque and semitransparent models. The semitransparent models show a greater penetration of heat into the model. When volumetric absorption of radiation is considered the maximum temperature occurs within the solid not at the surface as in the opaque model. In this temperature range the cold and reradiating models yield nearly identical results.

Figure 2 shows the cold and reradiating models. The temperature profiles are recorded at the time required for the reradiating model to achieve a maximum temperature equal to twice the ambient. The other parameters are the same as for Fig. 1. Figure 2 shows the increased difference between the cold and reradiating models as the model temperature increases.

Figure 3 shows temperature profiles for the opaque and reradiating models. The reradiating model is analyzed for optical lengths of $20,10,5$ and 2. Other conditions are as described for Fig. 1. These results show that as the optical length becomes large the semitransparent model approaches the opaque model.

The results obtained show that under limiting cases of very large optical length the opaque modelling can be used to describe a semitransparent modelling. A better modelling is the cold modelling which gives good results for low temperature situations and requires a linear set of equations to solve. The best modelling of a semitransparent solid is the reradiating model. This model should be used when accurate prediction of the temperature profile is required.

\section{Papers:}

E.U. Finlayson, W. Aung, and T. Kashiwagi, "Interaction of Radiation and Conduction in Polymeric Materials Exposed to External Radiation," submitted for presentation at the Second ASME-JSME Thermal Engineering Joint Conference, Honolulu, Hawaii, March 22-27, 1987. 

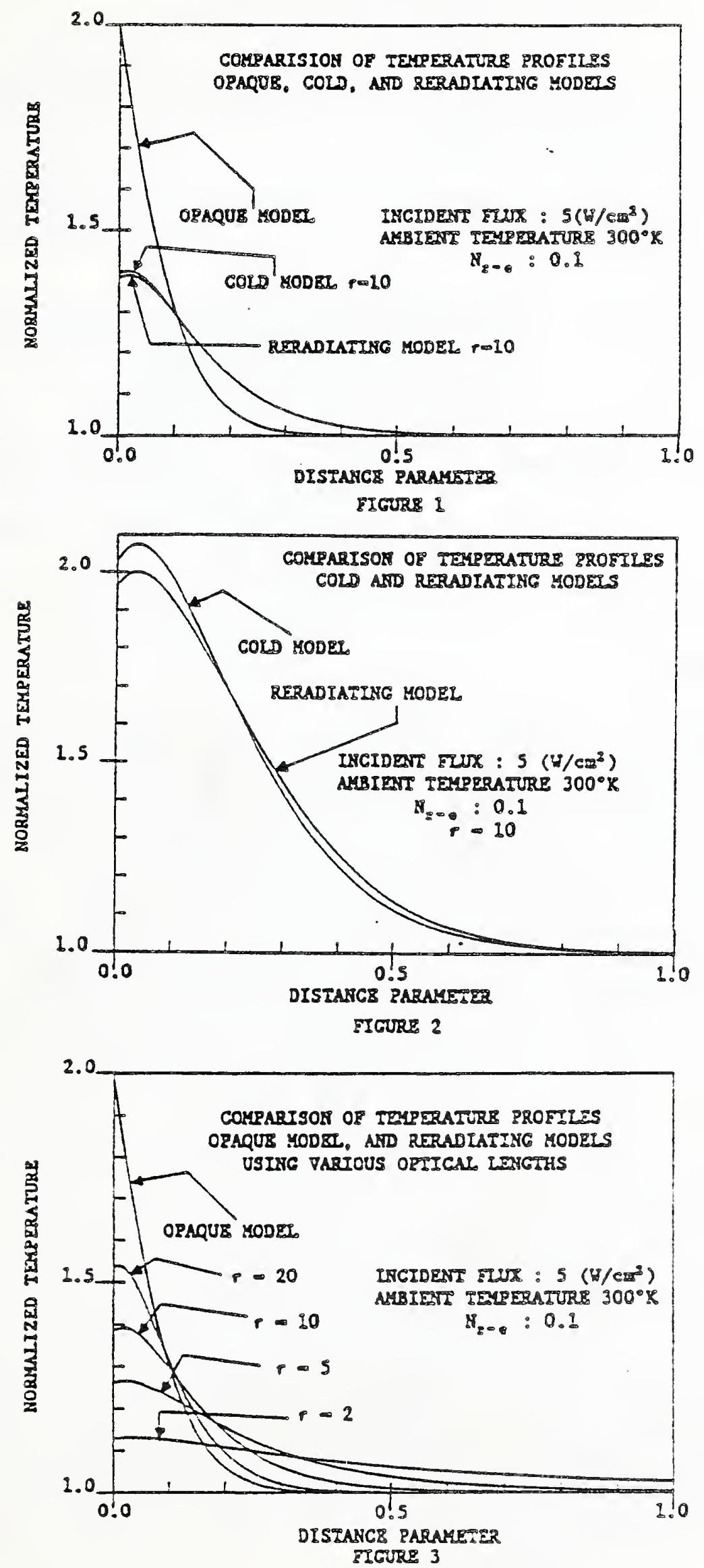
Institution: The University of Maryland at College Park

Grant No.:

Grant Title:

\section{COMM 7ONANBSHOS25}

Transient Cooling of a Hot Surface by Droplets Evaporation
Principal Investigator:

Dr. Marino di Marzo

Mechanical Engineering Department

Univeraity of Maryland

College Park, MD 20742

Telephone: (301) 454-4994
Qther Professional Personnel:

NBS Scientific Officer:
A. K. Trehan, Graduate Aseistant

W. H. Meng, Graduate Assistant

Dr. David D. Evans

Technical Abstract:

Introduction.

The research described hereafter constitutes the. Iirst phase of an extensive research program aimed at developing accurate droplet cooling models of burning solid fuel surfaces. Many studies have been performed to quantify the vaporization process of both single and multi droplet arrays impacting on hot surfaces. For the studies found in the published literature, the full apan of the droplet vaporization processes are usually reported. These would include evaporation, nucleate boiling. film boiling and Leidenfrost transition. This present research is more limited in the span of vaporization process studied, being only concerned with the evaporation of a single droplet on a hot surface. This study does report very detailed results for spacial and temporal variation of the heat flux at the exposed surface of the droplet, and for temporal variation of the droplet volume. Exclusive study of the evaporative process $1 \mathrm{mplies}$ that conditions are maintained under which nucleate boiling is fully suppressed. The cooling effect of a single droplet impinging a semi infinite solid surface ia deduced in great detail by numerical integration of the transient energy equation written for the solid. A simple relationship between the theoretically predicted evaporation time and the volume of the portion of the solid affected by the cooling induced by the droplet evaporation is found. This important result opens the way for a simplified model to describe the cooling effect of sprays on hot surfaces based on the detalled modeliting of the single droplet cooling effect. 


\section{Droplet Evaporation Phenomenology.}

upon 1 mpacting a surface spreads on

A epherical droplet configuration of the liquid varies a great deal and depends on a multitude of parameters. For the case of liquid water impinging a surface at near water saturation temperature, the shape can be regarded as a spherical segment. It is important to note that the wetted region of the gemi-infinite solid surface is constant in size throughout most of the evaporation process.

The ratio of the wetted area radius to the radius of an equivalent liquid volume spherleal droplet is identified by the parameter $B$ and 1 t is the only experimental input to the analysis. The complexity of the parameters influencing $B$ (surface tension, surface wettability, etco) is such that this semi-empirical approach was selected to formulate a reascnably simple analysis. Figure 1 illustrates the coordinate system selected and gives a representation of the droplet geometry and of the parameter $B$.

Theoretical Evaporation Time. The temperature at the solid liquid boundary under the droplet is considered uniform and constant during the evaporation in accordance ith the experimental observations and with the models of Michiyoshi [1] and Seki [2]. The temperature at the liquid-vapor interface is determined from consideration of mass transfer of the vapor in the ambient. The heat conducted from the solid-liquid interface to the droplet liquid-vapor interface is equated to the heat required to evaporate the liquid in a given time interval. Upon reassessing the liquid inventory and upon determining the new droplet configuration the heat balance calculation is performed again to yield the evaporation rate. The overall evaporation time is determined for various droplet volumes and initial solid surface temperatures. Note that both the convective and radiative heat transfer contributions are negligible with respect to the evaporative contribution. The results of the computations are compared with experimental data in Fig. 2

Cooling Effect. The volume of the solid thermaliy influenced by the droplet evaporation is determined via numerical integration of the transient energy equation written in cylindrical coordinates for the semi-infinite solid. The boundary conditions express the symmetry of the body about the vertical axis through the center of the wetted area, the prescribed value of the heat flus through the solid in the original steady state condition, the convective heat transfer taking place at the exposed surface of the solid and the adiabatic condition at large distances from the axis of symmetry in the radial disection. The volume influenced by the droplet evaporative cooling ls defined as the region where a change in the temperature of more than ten per cent of the maximum possible temperature change is observed. The 


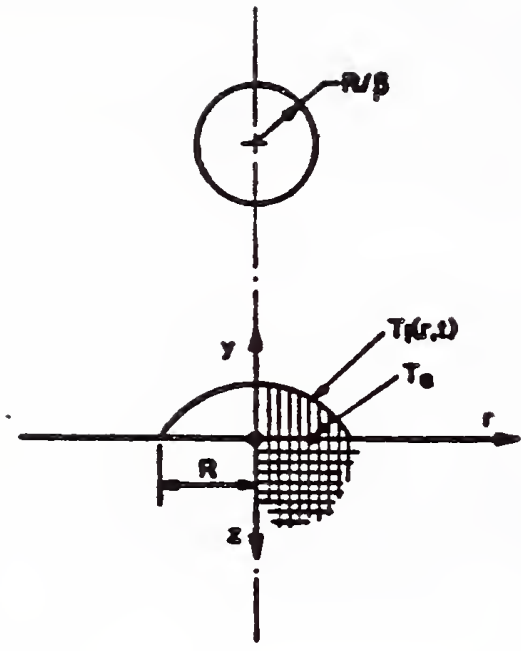

FIGLRE ONE - Nodel and Coordinate Sys tern

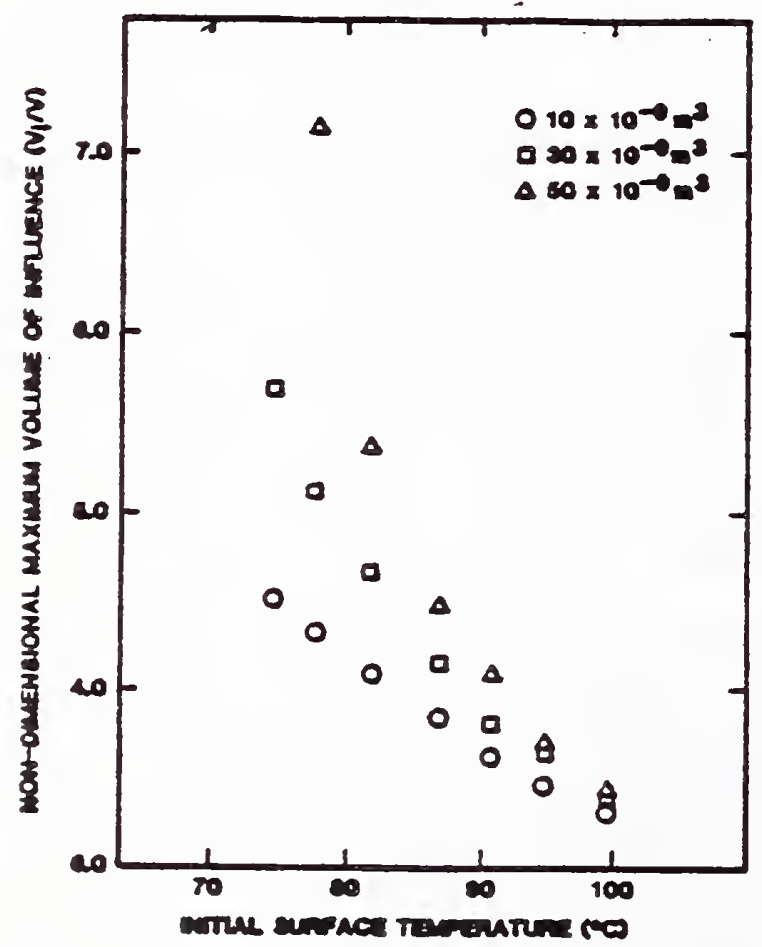

FIGURE THREE - lion-Dinesional Volume of Influence
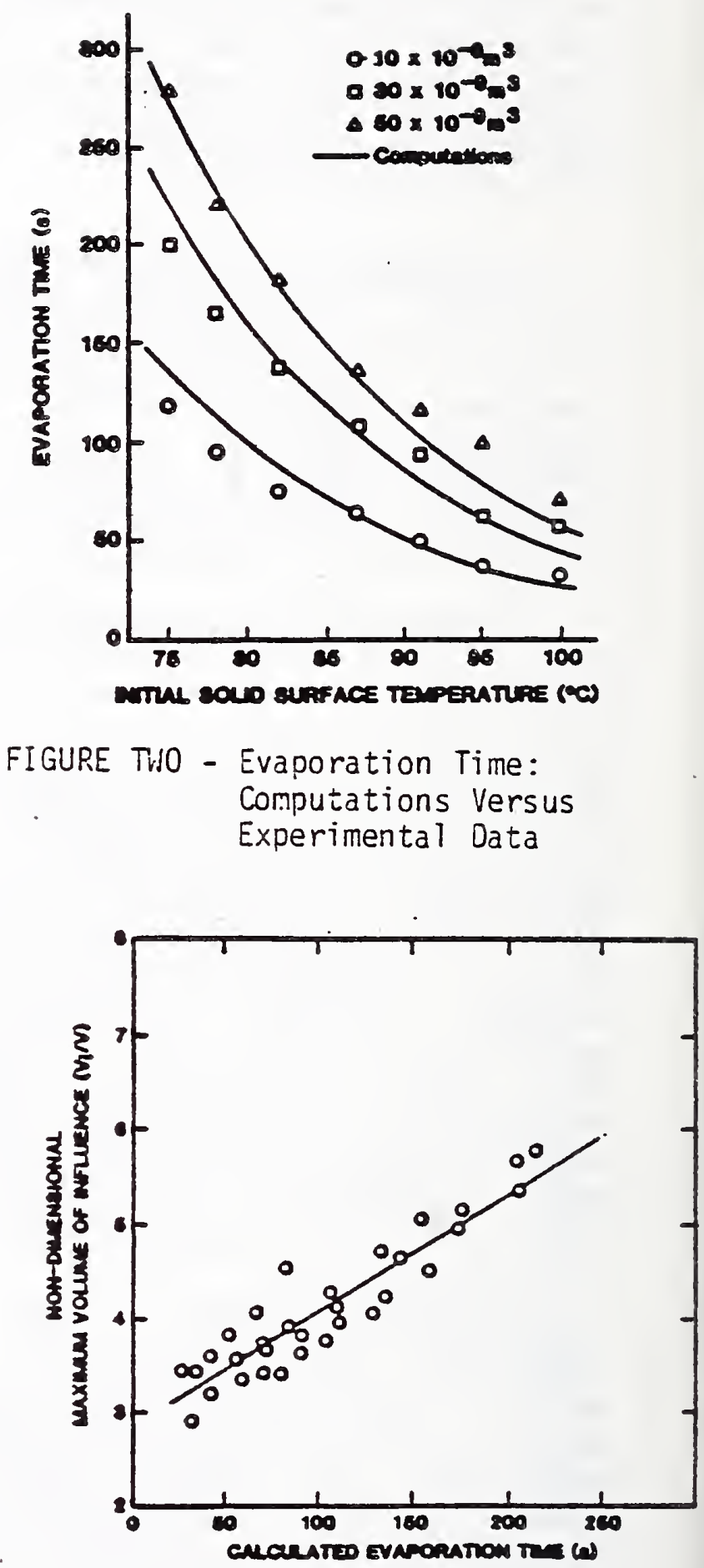

FIGURE FOUR - iton-Dimesional Volume of Influence Versus Caiculated Evaporation Time 
maximum temperature change is the difference between the original solid surface temperature and the contact temperature of the liquid and the solid as determined with Sekt's model [2].

In Fig 3, the results of the numerical integration of the energy equation are plotted in terms of the volume of the volume of influence (non-dimensionalized with respect to the droplet initial volumel for various initial solid surface temperature and droplet initial volume.

Conclusions. By considering the overall gimilarity between Fig. 1 and Fig. 2, one can deduce some interesting properties of the volume of influenee. In Fig. 4, the non-dimensional volume of influence is plotted versus the evaporation time. A linear trend of these data is detected. This finding is rather significant because it allows one to deduce a simple correlation for the volume of influence.

The implication of this simple result 111 be apparent in the modelling approach. to the multi-droplet case. However, the usual solid fuels to be considered in practical applications do not exhibit high thermal conductivity, therefore it is required to confirm these results also for those materials. Glass and MACOR are cursently investigated both experimentally and theoretically.

\section{References.}

1. I. Mtchiyoshi, K. Makino, Heat Transfer Characteristics of Evaporation of a Liquid Droplet on Heated Surfaces". Int. J. Heat Mass isansfer, 21, 605, 1978

2. M. Seki. H. Kawamura, K. Sanokawa, Transient Temperature Profile of a Hot Wall Due to an Impinging Liquid Droplet". J. Heat Transfer, 100, 176, 1978

\section{Reports and Papers}

1. A. K. Trehan, M. diMarzo, D. D. Evans, "Transient Cooling of a Hot Surface by Droplet Evaporation". Proc. Eastern Session Combustion Institute. Fall Technical Meeting, 61-1, 1985

2. M. diMarzo, A. K. Trehan, Transient Cooling of a Hot Surface by Droplet Evaporation". Mech. Eng. Dept. Report No. 86-7. Univ. of Maryland. 1986

3. M. diMarzo, D. D. Evans, Evaporation of a Water Droplet Deposited on a Hot High Thermal Conductivity Solid Surface", NBS-IR 86-3384, 1986

4. M. diMarzo, D. D. Evans, A. K. Trehan, The Cooling Effect of a Single Evaporating Droplet on a Hot SemiInfinite Metal Body", submitted to the IInd ASME-JSME Thermal Engineering Jaint Conference, Honolulu, 1987 
CENTER FOR FIRE RESEARCH

NATIONAL BUREAU OF STANDARDS

FY 86

Institution: University of Maryland

Grant No.: 70 NANB4H002O

Grant Title: Transient Heat Transfer in Ceiling Jets

Principle Investigator: Professor Colin H. Marks

Department of Mechanical Enyineering

University of Maryland

Colleye Park, MD 20742

Telephone: (301) $454-4216$

Other Professional Personnel: Vanid Motavelli, Fellow

NBS Scientific Officer: Dr. Leonard Y. Cooper

Technical Abstract:

Introduction: The objectives of this research are to determine the transient temperature and velocity profiles of ceiling jets produced by small fires (up to $2 \mathrm{Kw}$ ) and to determine the transient thermal response of ceilings to such fires. Such data is needed to support the development and verification of compartment fire models, especially models concerned with the early growth stages of fires when convection is the main mode of heat transfer.

Transient Thermal Response of Ceilings. Extensive measurements of the transient thermal response of unconfined ceilings were made by $A$. Woodhouse in the first part of this research. The data obtained were the ceiling temperature as a function of time and position from the fire plume staynation point. Three ceiling materials were used: Marinite-XL, fiberboard and coldrolled steel. The lower surfaces of the Marinite and fiberboard ceilings were painted with a stable high emissivity coatiny. Two sets of tests were run on the steel ceiling: first with a polished (low emissivity) surface, and then with the same painted hiyn emissivity surface used on the Marinite and fiberboard ceilinys. The fires were produced by burniny stoicniometric proportions of methane premixed witn air. Un each ceiling, tests were run at six nondimensional fire strenyths, $U^{*}$, between $U .0007 y$ to $0.009 y\left(U^{*}=U / \mathrm{pamb}_{\mathrm{p}} C_{p} T_{\text {amo }}\right.$ $\mathrm{g}^{1 / 2} \mathrm{n}^{5 / 2}$, where $Q=$ heat source strengtn, pamb = ambient air density, $C_{p}=$ specific heat at constant pressure, $T_{a m b}=$ ambient air density, $y=$ acceleration of gravity, $h=$ vertical distance from heat source to ceiling). A total of twenty-four tests are in the data base. A previously-developed model which predicts the transient thermal response of ceilings above room fires was revised, and a comparison was made between the experimental data and the results of the revised model.

The data base are too extensive to be reproduced here, but have been submitted for publication (Reports and Papers 1) and appear in the final report for NBS Grant No. 70NANB4HOO20 (Reports and Papers 2). Typical graphical 
results are snown in Figures 1 and 2. Figure 1, which shows the smoothed temperature-time nistory in fiberboard for $U^{*}=0.0063$ for a number of values of $r / h$ ( $r$ = radial distance from the staynation point), is typical of all such data. The temperature rises rapidly at first then becomes constant as steady state is reached. The temperature is the niyhest at the staynation point at all times and decreases with increasing $\mathrm{r} / \mathrm{h}$. Figure 2 shows the radial distribution of temperature at two different times for painted steel and for fiberboard for the same $Q^{*}$ as was used to obtain the data in Fiyure 1. In both cases, the emissivity was U.9. Note that the temperature profiles for the steel are flatter than for the fiberboard due to niyner radial tnermal conduction in the former. Thus, at late times (e.g., time $=2400 \mathrm{sec}$.) when conduction throuyn the thickness is neyliyible, the fiberboard has a hiyner temperature at the staynation point, while the opposita is true at larye $r / h$ $(r / h=1.1)$.

Ceiling Jet Temperatures and Velocities. Work is currently in proyress to obtain the transient temperature and velocity distributions in the ceiling jet for various values of $r / h$ and $Q^{*}$. The major effort to date has been to develop the instrumentation and the data aquisition and processing hardware and software.

Temperatures and velocities are measured simultaneously at eight different distances from the ceiling at a given radial position. The prode used for these measurements consists of an array of eight pairs of 0.001 -inch diameter type E thermocouples stretched betiveen vertical supports as shown in figure 3. The supports are mounted vertically with their sides parallel 60 the horizontally-flowing fluid (the ceiling jet). Each pair of thermocouples lies in a norizontal plane, and the fluid flows across eacn one. Since the second chermocouple of the pair is mounted downstream of the first, in the same norizontal plane, the turoulent eddies whicn pass the first thermocouple at time $t$ will pass the second thermocouple a time interval $t_{s}$ later, at time $t+t_{s}$, as they are carried alony by the fluid's mean motion. If $\ell$ is the distance separating the two thermocouples, the fluid's mean velocity will de $2 / t_{S}$. The turbulent edaies are detected by the thermocouples as temperature fluctuations. Fiyure 4 snows the temperature-time records for each of the therinocouples in a pair. The temperature-time recora of tne rear tnermocouple in the pair is essentially the same as that of the forward one, except that it is snifted in time by the amount $t_{s}$. The time snift $t_{s}$ can be obtained by cross correlation of the tivo temperature-time siynals and finding the value of ts for which the normalized cross correlation factor, o(ts) is the laryest. The temperature, of course, is obtained directly from the forivard tnermocouple.

in order to sample the temperatures at a fast enough rate to obtain accurate velocity meansurements and chen process tnem, the following data acquisition system has been assembled:

1. A Hewlett-Packard (HP) multiprogramer (HP 69424) with 16 data acquisition channels.

2. A 16-cnannel signal conditioning 38 series Analog Devices amplifier.

3. A series 300 Hewlett-Packard computer with lil oyte Ram and 10 M byte storage disc used as a controller ior the mu? iproyrammer and for data storaye and processing activities. 
The Hewlett-Packard multiprogrammer has an onboard analoy-to-digital converter, a scanner and a 128k byte memory for rapid data collection. It can be expanded to accommodate up to 1024 channels. The siynals from the thermocouples are delivered to the multiproyrammer after amplification by a factor of about 850 in order that they have a sufficiently nigh magnitude for the device.

The data acquisition system can collect up to 4.5 million data points at a frequency of up to $100 \mathrm{kHz}$. This capability is used to devise a procedure to monitor the ceiling jet for a period of about 30 minutes - which is about that needed for the transient period of our ceiling models - by sampling as fast as $32 \mathrm{kHz}$ for a period of about 1 second every 10 to 15 seconds. This sampling rate for 16 channels means a sampling rate of $2 \mathrm{kHz}$ per thermocouple, which produces a $5 \%$ accuracy in a velocity of $1 \mathrm{~m} / \mathrm{sec}$ as detected by thermocouples separated by a distance of one centimeter. If the thermocouple spacing is larger than $1 \mathrm{~cm}$ or if the velocity is less, a slower sampling rate will be needed (or greater accuracy can be obtained).

\section{Reports and Papers:}

1. Woodhouse, A., Marks, C.H. and Cooper, L.Y., "An Experimental Study of the Thermal Response of Unconfined Ceilings Above Fire Plumes," submitted for publication, and ASME/JSME Thermal Engineering Joint Conference, Honolulu, Hawa i , March 1987.

2. Marks, C.H. and Woodnouse, A., "A Study of the Transient Thermal Response of Unconfined Ceilings Above Small Fire Plumes," Final Report for NBS grant number 70NANB4H0020, Oct. 1985.

3. Woodhouse, A., Marks, C.H. and Cooper, L.Y., "An Experimental Study of the Transient Thermal Response of Unconfined Ceilinys Above Samll Fire Plumes," Fall Technical Meeting of the Eastern Section of the Combustion Institute, Philadelphia, Pa., Nov. 1985.

4. Cooper, L.Y. and Woodhouse, A., "The Buoyant Plume-Driven Adiabatic Ceiling Temperature Revisited" 23rd ASME/AICHE National Heat Transfer Conference, Denver, Colo., Aug. 1985. Also National Bureau of Standards Rpt. NBSIR-85-3134 of the same title, April 1985. 


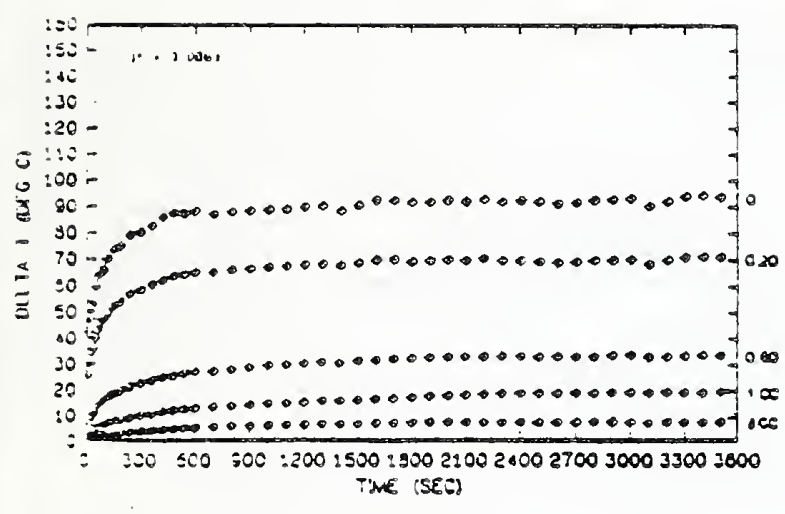

Fibertodre: 0.00 .006

$r / n=0.0 .2 .0 .0 .1 .0 .2 .0$

Fig. 1 iemperature-time record

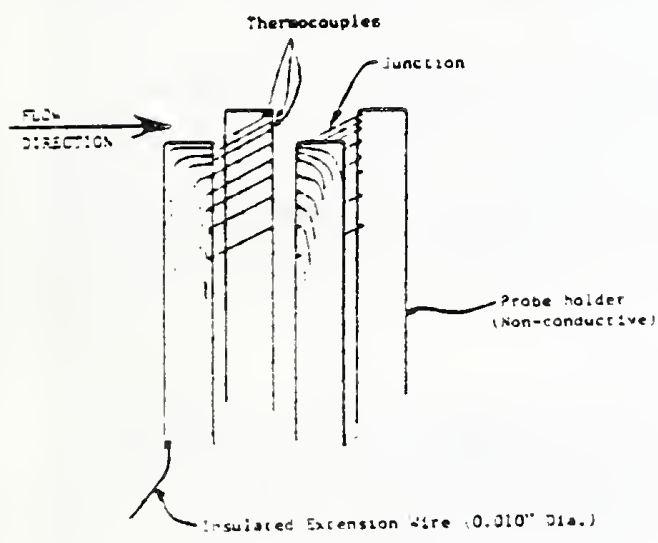

Fig. 3 Thermocouple probe

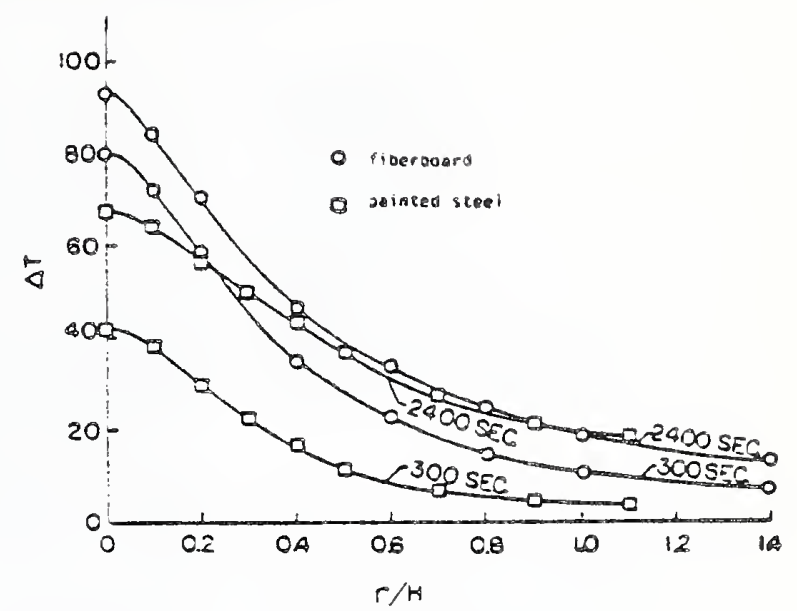

Fig. 2 Rádial temperature distribution
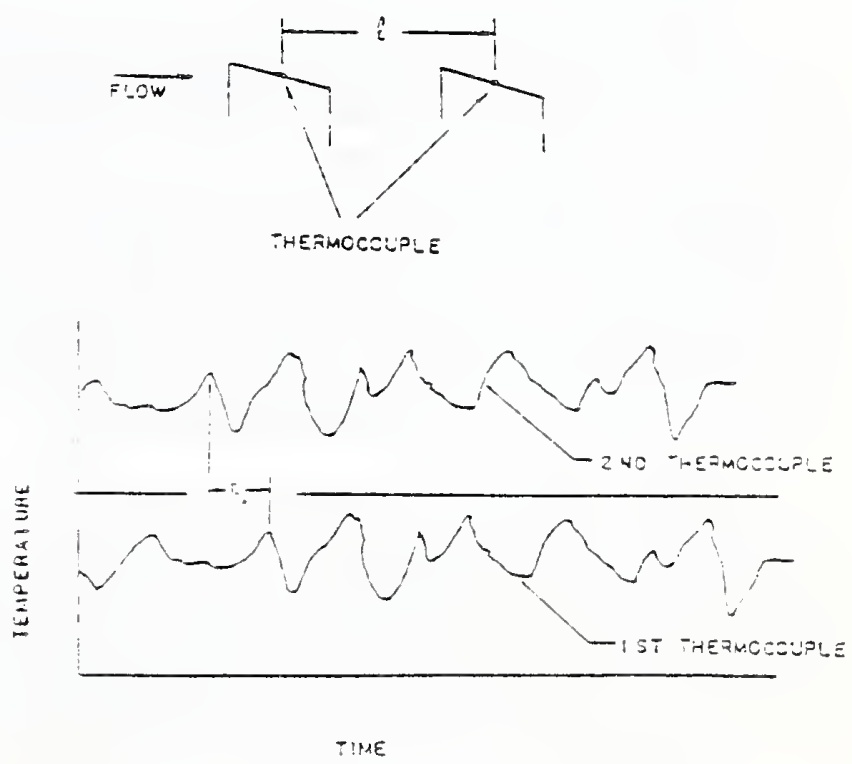

Fig. 4 Tine shift diagram 


\section{CENTER FOR FIRE RESEARCH NATIONAL BUREAU OF STANDARDS FY 86}

Institution: The University of Michigan

Grant No: $\quad$ 60NANB5D0576

Grant Title: Radiation from Turbulent Luminous Flames

Principal Investigator:

Professor Gerard M. Faeth

Department of Aerospace Engineering

The University of Michigan

217 Aerospace Engineering Building

Ann Arbor, MI 48109-2140

Other Professional Personnel: $\quad$ J.P. Gore, Pre-Doctoral Scholar

D. Hully, Undergraduate Assistant

M.-C. Lai, Postdoctoral Fellow

NBS Scientific Officer. Dr. Bemard J. McCaffrey

\section{Technical Abstract:}

Introduction. The objective of this investigation is to establish methods for predicting the structure and radiation properties of unwanted fires. The fundamental problems are to determine the scalar structure of turbulent diffusion flames and to treat effects of turbulence/radiation interactions, with emphasis on soot-containing luminous flames. These issues are being addressed using the conserved-scalar formalism of turbulent reacting flow, in conjunction with the laminar flamelet concept. This methodology seeks to circumvent difficulties in predicting complex chemical phenomena in a turbulent environment. During this report period, the research concentrated on two main topics: (1) nonluminous flames, particularly flames having high energy release rates in order to examine effects of scale; and (2) luminous flames, particularly ethylene/air and acetylene/air diffusion flames.

Nonluminous Flames. Past work demonstrated some success in predicting the structure and radiation properties of laboratory-scale (flame heights $\mathrm{ca} . \mathrm{lm}$ ) nonluminous flames using the conserved-scalar formalism for structure and a narrow-band radiation model for radiation properties. Recent tests of large-scale natural gas/air diffusion flames (flame heights ca. $10 \mathrm{~m}$ ), under the auspices of NBS, ${ }^{1}$ provided an opportunity to test these concepts for large-scale flames, more characteristic of practical applications.

Predicted and measured mean temperatures along the axis of $100 \mathrm{MW}$ flames are illustrated in Fig. 1. Initial conditions for these flames had to be estimated, and there are uncertainties in the degree of density weighting of the measurements; therefore, severail limiting predictions are shown. The comparison between predictions and measurements is reasonably good for Flame 7, which had a relatively quiescent environment, similar to the assumptions of the analysis. Flame 1 was subjected to significantly higher ambient wind disturbances and the

D. Evans and D. Pfenning, Qil and Gas J. 83(17), 80 (1985). 
performance of the analysis is worse as a result. Findings for five other flames, having energy release rates of ca. $200 \mathrm{MW}$, were similar.

Aside from effects of wind disturbances, structure predictions were reasonably good; therefore, evaluation of radiation predictions was undertaken. The measurements included the output of five radiative heat flux sensors, having various orientations with respect to the flames. Past work showed that effects of turbulence/radiation interactions and continuum radiation from soot (in spite of the yellow color of the flames) were small for nawral gas/air flames; therefore, these effects were ignored in the analysis. The resulbing comparison between predictions and measurements, for the seven flames and five sensors, was very satisfying in view of potential theoretical and experimental uncertainties, e.g.s average discrepancies between predictions and measurements were 15 percent. This suggests that present methods developed using laboratoryscale flames are promising for application to large-scale nonluminous flames.

Luminous Flames. A major hypothesis of the structure anaiysis is the laminar flamelet concept, which implies that scalar properties in diffusion flames, can be correlated solely as a function of mixture fraction (the fraction of mass at a point, irrespective of chemical compound, which originated from the fuel). These correlations, called state relationships, can be found from routine measurements in laminar flames, assuming a wrinkled laminar flame structure for turbulent flames. Past work demonstrated the viability of this concept for nonluminous flames. Present work concentrated on the luminous flames of ethylene and acetylene in air.

Measurements of state relationships in laminar flames were completed for the two luminous flames. The results showed that concentrations of major gas species were primarily a function of mixture fraction -- supporting the laminar flamelet concept. Moreover, soot volume fractions, which are a major property needed to compure continuum radiation from soot, were also crudely universal functions of mixture fraction as well. Departures from universality that were observed were felt to be due to hydrodynamic features of laminar flames that may very well be absent for turbulent flames, however, definitive evidence of this has not yet been achieved.

Typical predictions and measurements of the structure of luminous diffusion flames appear in Fig. 2. Mean and fluctuating streamwise velocities and the mean concentrations of major gas species, along the axis, are shown for an ethylene/air diffusion flame. The comparison between predicted and measured mean properties is reasonably good. Predictions of velocity fluctuations are less satisfactory, which is attributed to neglect of turbulence/buoyancy interactions in the analysis and differences between density weighted predictions and unweighted measurements.

The structure analysis was subsequently used for predictions of spectral radiation intensity and radiative heat flux distributions for the flames. Typical predicted and measured radiative heat flux distributions are illustrated in Fig. 3. These results are for ethylene/air diffusion flames having two different bumer exit Reynolds numbers. Measurements involved a radiarive heat flux sensor directed toward the flame axis and raversed in the vertical direction at a distance of $575 \mathrm{~mm}$ from the axis. The comparison between predictions and measurements is fortuitously good, to some extent. The analysis ignored turbulence/radiation interactions and effects of intermal radiative energy exchange within the flames, both of which are known to be important for these test conditions. However, the former effect increases radiative heat fluxes while the latter decreases them, tending to compensate each other. The fact that the heat flux is maximum at the flame tip, and is strongly dependent on Reynolds number for these conditions, is represented very well by the analysis.

Structure predictions for acetylene/air diffusion flames were also reasonably successful. This system provides a severe test of radiation analysis since roughiy 50 percent of the chemical 
energy release is radiated to the surroundings, primarily by continuum radiation from soot. The results suggest that reliable radiation predictions for flames having such properties will required coupled structure and radiation analysis. Work along these lines is currently in progress in this laboratory.

\section{Reports and Papers}

1. M.-C. Lai, S.-M. Jeng and G.M. Faeth, "Structure of Turbulent Adiabatic Wall Plumes," J. Heat Transe in press.

2. M.-C. Lai and G.M. Faeth, "A Combined Laser-Doppler Anemometer/Laser-Induced Fluorescence System for Turbulent Transport Measurements," L. Heat Trans. in press.

3. M.-C. Lai and G.M. Faeth, "Turbulence Properties of Adiabatic Wall Plumes," J. Heat Trans, submitted.

4. M.-C. Lai and G.M. Faeth, "The Structure of Adiabatic Wall Plumes," Final Report, NBS Grant No. 60NANB4D0032, The Pennsylvania State University, University Park, PA, November 1985.

5. J.P. Gore, S.-M. Jeng and G.M. Faeth, "Spectral and Total Radiation Properties of Turbulent Hydrogen/Air Diffusion Flames," L Heat Transe in press.

6. J.P. Gore, S.-M. Jeng and G.M. Faeth, "Spectral and Total Radiation Properties of Turbulent Carbon Monoxide/Air Diffusion Flames," AIAA Ju in press.

7. J.P. Gore and G.M. Faeth, "Spectral Emission and Absorption Properties of Turbulent Ethylene/Air Diffusion Flames," Proceedings of Eighteenth Fall Technical Meeting pp. 73.1-73.4, Eastern Section of the Combustion Institute, Pittsburgh, PA (1985).

8. G.M. Faeth, "Heat and Mass Transfer in Flames," 1986 International Heat Transfer Conference, San Francisco, CA (1986).

9. J.P. Gore and G.M. Faeth, "Structure and Spectral Radiation Properties of Turbulent Ethylene/Air Diffusion Flames," Twenty-First Symposium (International) on Combustion. The Combustion Institute, Pittsburgh, PA, in press.

10. G.M. Faeth, J.P. Gore, S.G. Chuech and S.-M. Jeng, "Radiation from Turbulent Diffusion Flames," Annual Review of Numerical Fluid Mechanics and Heat Transfer, submitted.

11. J.P. Gore, G.M. Faeth, D. Evans and D.B. Pfenning, "Structure and Radiation Properties of Large-Scale Natural Gas/Air Diffusion Flames," Fire and Materials, submitted.

12. J.P. Gore, G.M. Faeth, D. Evans and D.B. Pfenning, "Radiant Heat Fluxes from 100200 MW Natural Gas/Air Diffusion Flames," Nineteenth Fall Technical Meeting, Eastem Section of the Combustion Institute, Pittsburgh, PA, submitted.

13. J.P. Gore and G.M. Faeth, "Radiation from Turbulent Flames," Final Report, NBS Grant No. 60NANB4D0032, The Pennsylvania State University, University Park, PA (1985). 


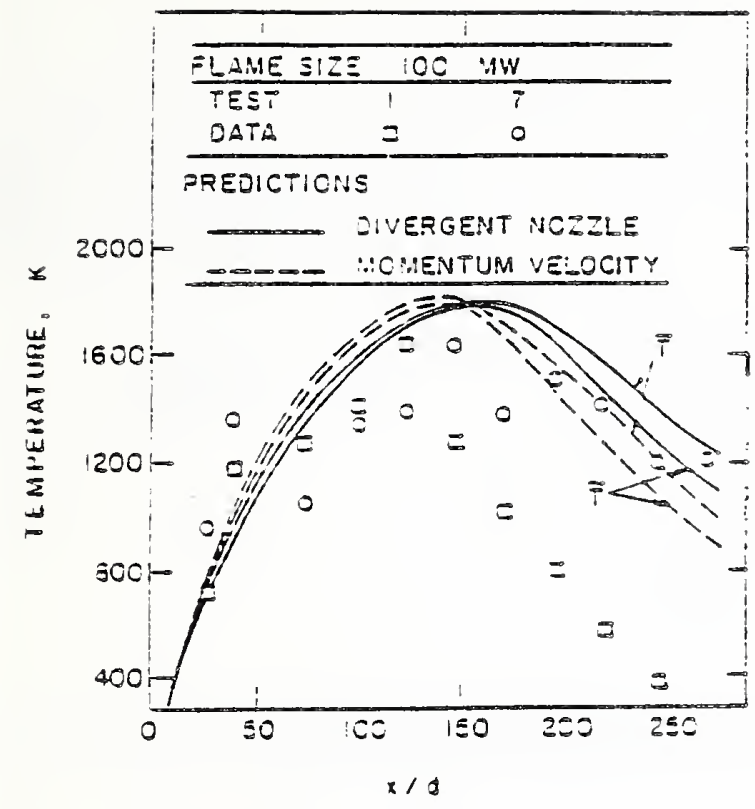

Fig. 1 Mean temperatures along the axis of natural gas/air diffusion flames.

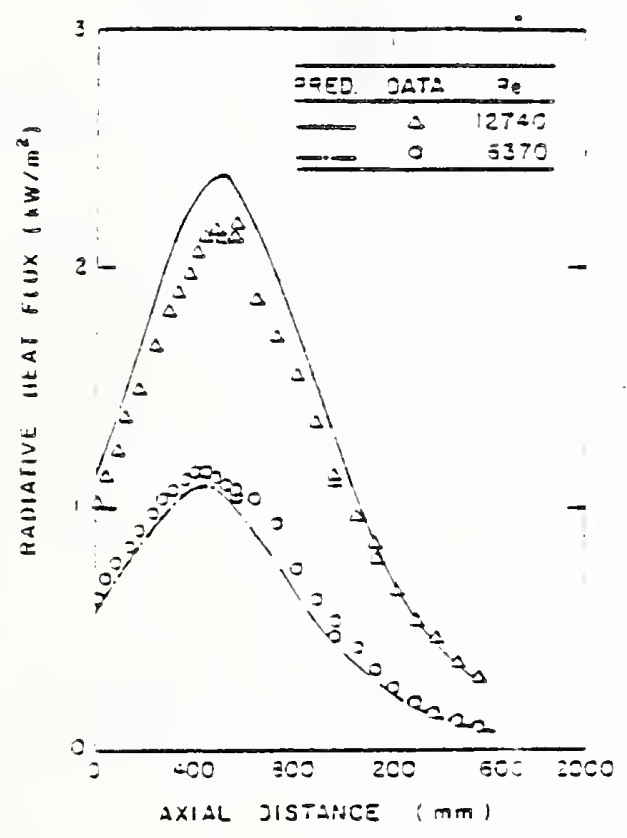

Fig. 3 Radiative heat fiux distributions for ethylene/air diffusion flames.

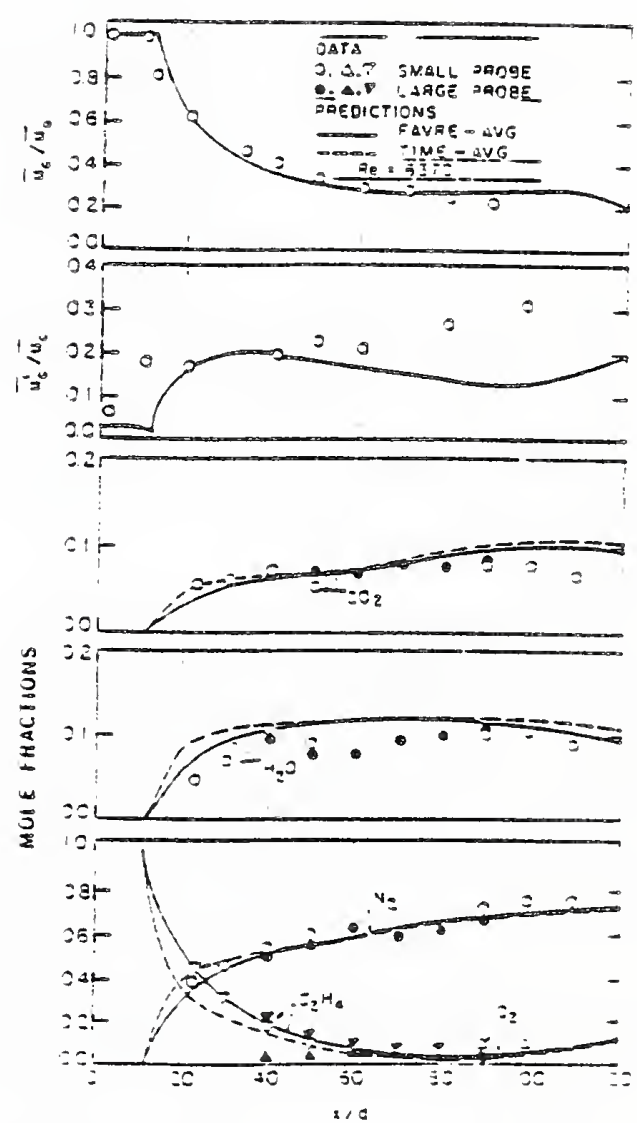

Fig. 2 Properties along the axis of an ethylene/ air diffusion flame. 
Institution: University of Montana

Grant Number: 60NANB5D0554

Grant Title: Kinetics of Oxygen Chemisorption and Desorption of Combustion Products in the Smoldering Combustion of Cellulosic Material

$\begin{aligned} \text { Principal Investigator: } & \text { Professor Geoffrey N. Richards } \\ & \text { Wood Chemistry Laboratory } \\ & \text { University of Montana } \\ & \text { Missoula, Montana } 59812 \\ & \text { (406) 243-4435 }\end{aligned}$

Other Professional Personnel: Dr. W.-P. Pan, Postdoctoral Research Associate William DeGroot, Research Specialist

NBS Scientific Officer: Dr. Thomas Ohlemiller

Technical Abstract:

Introduction. The tendency of a material to support smoldering combustion has previously been correlated with the kinetics of oxygen chemisorption at low temperatures on stable chars formed under pyrolytic conditions. This investigation commenced in January, 1986 and aims to extend the analysis of chemisorption kinetics to chars formed at lower temperatures and includes kinetic analysis of the gasification reactions which occur simultaneously with or subsequent to oxygen chemisorption. This will be accomplished by simultaneously recording changes in the weight of the sample and measuring the concentration of combustion products in the gas stream flowing past the sample using the combined techniques of thermogravimetry and Fourier transform infrared analysis. Using the same experimental design, the influence of specific (single) ion-exchanged cations on oxidative pyrolysis of wood, cellulosic insulation and of chars will also be studied with the aim of designing treatments which are fire retardant without promoting smoldering combustion.

Equipment Design and Commissioning. The Cahn TG system has been interfaced to microcomputer control and coupled to the Fourier transform infrared system. The system has been calibrated for quantitative analys is of $\mathrm{CO}_{2}, \mathrm{CO}, \mathrm{H}_{2} \mathrm{O}$, methanol, and acetic and formic acids, all of which are known to be produced in oxidative pyrolysis of cellulosics.

Quantitative Analys is of Volatile Products of Oxidative Pyrolysis of Wood. Concentrations of above six compounds have been determined against time for dynamic heating of cottonwood at $3 \%$. from room temperature to $550^{\circ} \mathrm{C}$ in nitrogen and air and also under isothermal conditions at $250^{\circ} \mathrm{C}$. The results show unequivocally that hemicelluloses and lignin begin to degrade first and that the major portion of the cellulose survives to higher temperatures. The presence and nature of trace cation components such as calcium and potassium have dramatic effects, both on low temperature $\left(250^{\circ} \mathrm{C}\right)$ oxidative pyrolys is and 
on subsequent oxidation of chars.

This work will be extended to newsprint, which is the basis of most cellulosic insulation and chemical analyses will be carried out on the heated samples at relevant times. Related chemisorption studies will be undertaken on chars from wood, newsprint and cellulose with various thermal histories and with controlled cation content. 
CENTER FOR FIRE RESEARCH

NATIONAL BUREAU OF STANDARDS

FY 1986

Institution: Graduate School of Public Health, University of Pittsburgh

Grant No.: $\quad$ 60NANB4D001

Grant Title: $\quad$ Toxicity of Plastic Combustion Products.

Principal Investigator: Yves Alarie, Ph.D.

University of Pittsburgh

Pittsburgh, PA 15261

Telephone: (412) 624-3047

Other Professional Personnel: M. Schaper, Ph.D.

D. Malek, (Ph.D. Student)

NBS Scientific Officer: $\mathrm{Dr}$. B.C. Levin

Technical Abstract:

The current objective of this project is to establish animal models of escape performance which can be used to provide a data base suitable for inclusion in hazard analysis of fire situations. A first model using mice running in a track has now been completed. A second model being developed uses guinea pigs as test subject in an attempt to better characterize the effects of not only the asphyxiants present in smoke but also the irritants. In this model, both distance traveled and running time are also available as in the model using mice. However, the investigator will have complete control of the experimental situation in the sense that distance and time can be varied at will (within reason as in fire situations). Thus, we anticipate that a wide range of situations can be investigated to provide the basic parameters of escape performance under toxic atmospheres as required by scientists developing models for fire hazard analys is.

Preliminary work has also been undertaken using the NBS cone calorimeter as the device to thermally decompose polymers. This is an attempt to replace the furnace used in the University of Pittsburgh toxicity protocol. The work done so far is limited but nevertheless indicates that this investigation should be pursued. The advantages of using this device would be numerous, particularly in the sense that the conditions of decomposition could be varied much more widely than when using a furnace and secondly the relevant parameters, irradiance and mass loss rate, would be available while only mass loss rate is available with the furnace.

Reports and Papers:

Burleigh-Flayer, H., Wong, K.L. and Alarie, Y. Evaluation of the pulmonary effects of $\mathrm{HCl}$ using $\mathrm{CO}_{2}$ challenges in guinea pigs. Fund. Appl. Toxicol. $\underline{5}$, 978-985, 1985. 
Kennah, H.E., Stock, M.F. and Alarie, $Y_{\text {. }}$ Toxicity of thermal decomposition products from composites. J. Fire Sciences., submitted.

Malak, D.E., Stock, M.F. and Alarie, Y. Performance under intoxicating atmospheres. Fund. Appl. Toxicol., submitted. 


\section{CENTER FOR FIRE RESEARCH \\ NATIONAL BUREAU OF STANDARDS \\ FY 86}

\section{Institution: Texas A\&M University}

\section{Grant No.: 70NANB6H0619}

Grant Title: Computer Verification, Validation and Use of Selected State-of-the-Art Fire Safety Model for One-Story MultiCompartment Buildings

Principal Investigator: Nadir Khoudja

Research Associate"

Texas Engineering Experiment Station

Engineering Research Center

Texas A\&M University

College Station, TX 77843

Telephone: (301) 921-3242

Co-Principal Investigator: Dr. Waymon L. Johnston

NBS Scientific officer: Mr. Harold E. Nelson

Technical Abstract:

Introduction. The objectives of this investigation are to establish generic methodologies for a sensitivity analysis and performance validation analysis of an analytical fire safety model. These analyses are part of the overall model evaluation process. The expected benefit of the former goal is to inform potential users on the sensitivity of major input parameters. The latter objective would establish levels of confidence in the model for predicting fire behavior. The target model of this investigation is an analytical fire safety model known as Fire and Smoke Transport (FAST).

Sensitivity Analysis. FAST requires a large number of input parameters; 16 of them are the focus of a sensitivity analysis. This was achieved through the use of fractional factorial to two level methodology. It required 256 different computer runs portraying respective prescribed fire scenarios.

The 16 parameters encompassed three categories of the model's input requirements. These are:

1. Geometrical data,

2. Fire Specifications, and

3. Thermophysical Properties.

Table 1 portrays the experimental input parameters used in the analysis. Two dependent variables have been selected to represent a comprehensive model's output. These are the upper layer temperature, and the depth of the upper layer of smoke in the respective compartments. 
As a result from the sensitivity analysis, sensitivity coefficients from each studied parameters are presented as a function of their respective dependent variable. Hence, a set of results, for each compartment, is illustrated for temperature and smoke, respectively. The relative sensitivity of each parameter is tracked over the simulated time. A relative ranking of parameters was achieved through the superimposition of respective sensitivity function as shown in Figure 2. From the same figure, one may observe that parameter $S$ is the most sensitive followed by $L$. Parameters $M, P$, and 0 exhibit minimal sensitivity behavior.

Performance Validation. The goal of this study is to establish criteria by which FAST predictive capabilities are measured against full-scale fire data. This criteria is supported by a systematic statistical analysis. The performance validation effort is still in progress. 
TABLE 1. EXPERIMENTAL PARAMETERS

CODE

NAME

VALUE IOW

VALUE HIGH

Geometrical Data

$\begin{array}{ll}\text { A } & \text { Compartment Width (m) } \\ \text { B } & \text { Compartment Depth (m) } \\ \text { C } & \text { Compartment Height (m) } \\ \text { D } & \text { Number of Compartment } \\ \text { E } & \text { Vent Width (m) } \\ \text { F } & \text { Vent Height (m) } \\ \text { G } & \text { Vent Sills (m) }\end{array}$

3.5

4.0

2.5

2

1.0

1.5

0.0

7.0

8.0

5.0

4

2.0

2.5

1.0

Fire Specifications

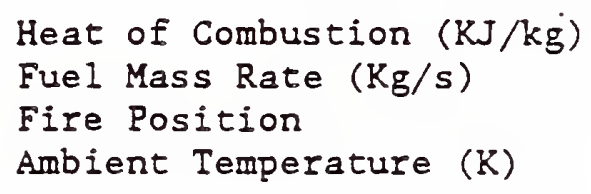

25,000

0.002

Center

273
50,000

0.004

Corner

330

Thermophysical Properties

$\begin{array}{llll}M & \text { Conductivity }(\mathrm{KW} / \mathrm{mK}) & 0.18 \times 10^{-3} & 5 \times 10^{-3} \\ N & \text { Specific Heat }(\mathrm{kJ} / \mathrm{kgK}) & 0.9 & 1.9 \\ 0 & \text { Density }\left(\mathrm{kg} / \mathrm{m}^{3}\right) & 790 & 2200 \\ \mathrm{P} & \text { Emissivity } & 0.3 & 0.9 \\ \mathrm{~S} & \text { Thermal Properties (Walls/ } & & \\ & \text { Ceilings/Floors) } & \text { Existant } & \text { Inexistant }\end{array}$




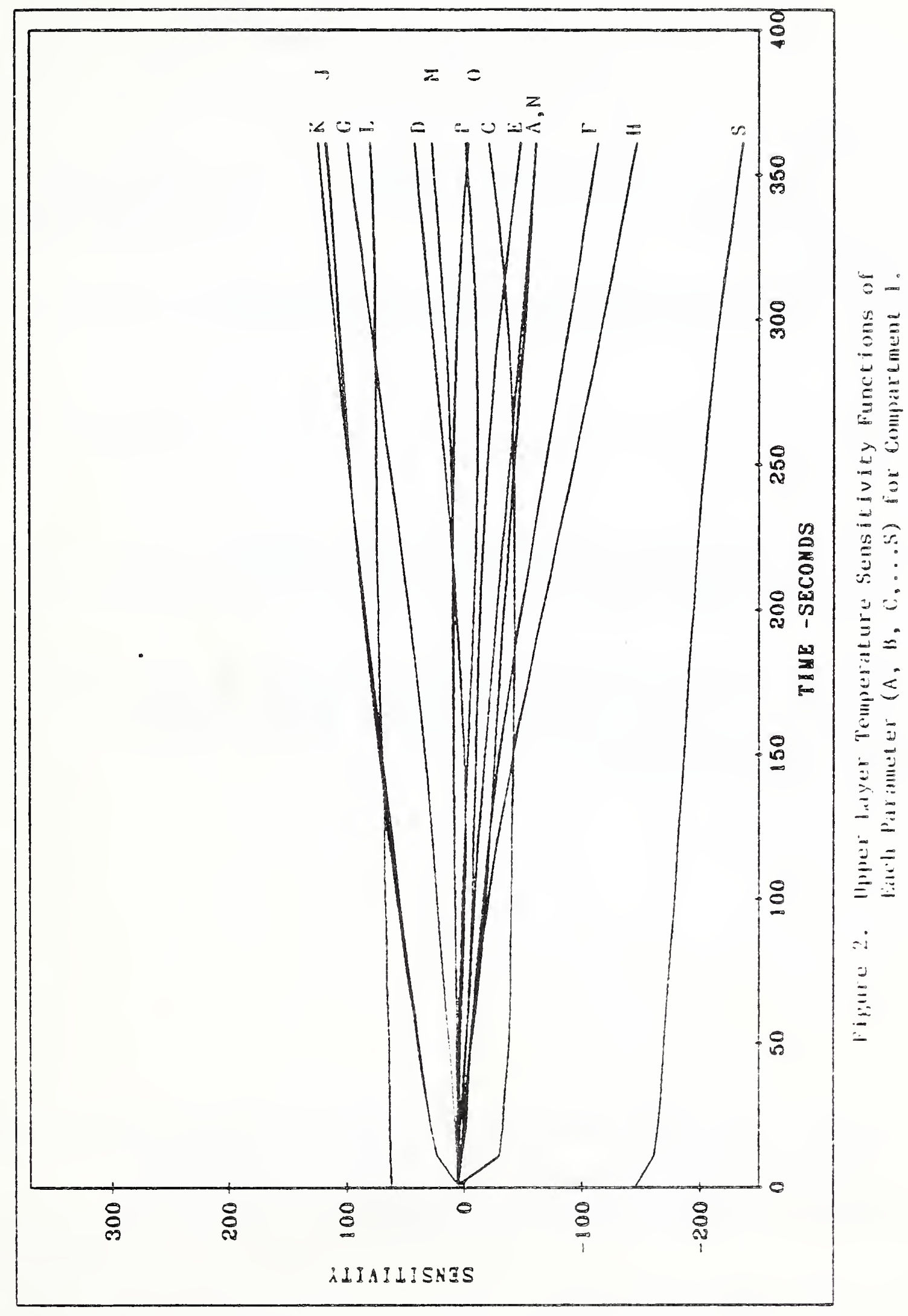


1. PUBLICATION OR REPORT NO. NESIR $-86 / 3498$
2. Performing Organ. Report Nod 3. Publication Date Decamber 1986

4. TITLE ANO SUBTITLE

Summaries of Center for Fire Research Grants and In-House Programs - 1986

\section{AUTHOR(S)}

Sonya M. Cherry

6. PERFORMING ORGANIZATION (If joint or other than NBS. see instructions)

7. Conerace/Grane No.

\section{NATIONAL BUREAU OF STAMDARDS \\ DEPARTMENT OF COMMERCE

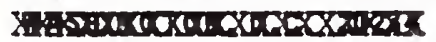

Gatthersburg, MD 20899

9. SPONSORING ORGANIZATION NAME AND COMPLETE ADDRESS (Street, City. Stote, ZIP)

10. SUPPLEMENTARY NOTES

Document describes a computer program: SF-185, FIPS Software Summary, is attached.

11. ABSTRACT (A 200-word or less factual summary of most significont information. If document includes a significont bibliogrophy or literoture survey, mention it here)

This report contains extended abstracts of grants for fire research sponsored by the Center for Fire Research, National Bureau of Standards, as well as descriptions of the internal programs of the Center for Fire Research.

12. KEY WORDS (Six to iwelve entries; alphabetical orter: capitalize only proper names; and separate key words by semicalons)

cellulose; charring; combustion; fire models; flame spread; ignition; polymers; smoke; soot; toxicity

\section{AVAILABILITY}

Xn Untimited

For Official Distribution. Do Not Release to NTIS

Order From Superintendent of Documents, U.S. Government Printing Office, Washington. D.C. 20402.

Worder From National Technical Information Service (NTIS), Springfield, VA. 22161
14. NO. OF PRINTED PAGES 153

15. Price

$\$ 16.95$ 
- 


\section{-}

